\title{
Tracing change in female genital mutilation/cutting through social networks: An intersectional analysis of the influence of gender, generation, status, and structural inequality
}

Amadou Moreau

Bettina Shell-Duncan

Follow this and additional works at: https://knowledgecommons.popcouncil.org/departments_sbsr-rh

Part of the Demography, Population, and Ecology Commons, Family, Life Course, and Society

Commons, Gender and Sexuality Commons, and the Women's Health Commons

How does access to this work benefit you? Let us know!

\section{Recommended Citation}

Moreau, Amadou and Bettina Shell-Duncan. 2020. "Tracing change in female genital mutilation/cutting through social networks: An intersectional analysis of the influence of gender, generation, status, and structural inequality," Evidence to End FGM/C: Research to Help Girls and Women Thrive. New York: Population Council. 


\section{Evidence to \\ End FGM/C}

Research to Help Girls and Women Thrive

Tracing Change in Female Genital Mutilation/Cutting through Social Networks: An Intersectional Analysis of the Influence of Gender, Generation, Status, and Structural Inequality

February 2020 


\section{Tracing Change in Female Genital Mutilation/Cutting through Social Networks: An Intersectional Analysis of the Influence of Gender, Generation, Status, and Structural Inequality}

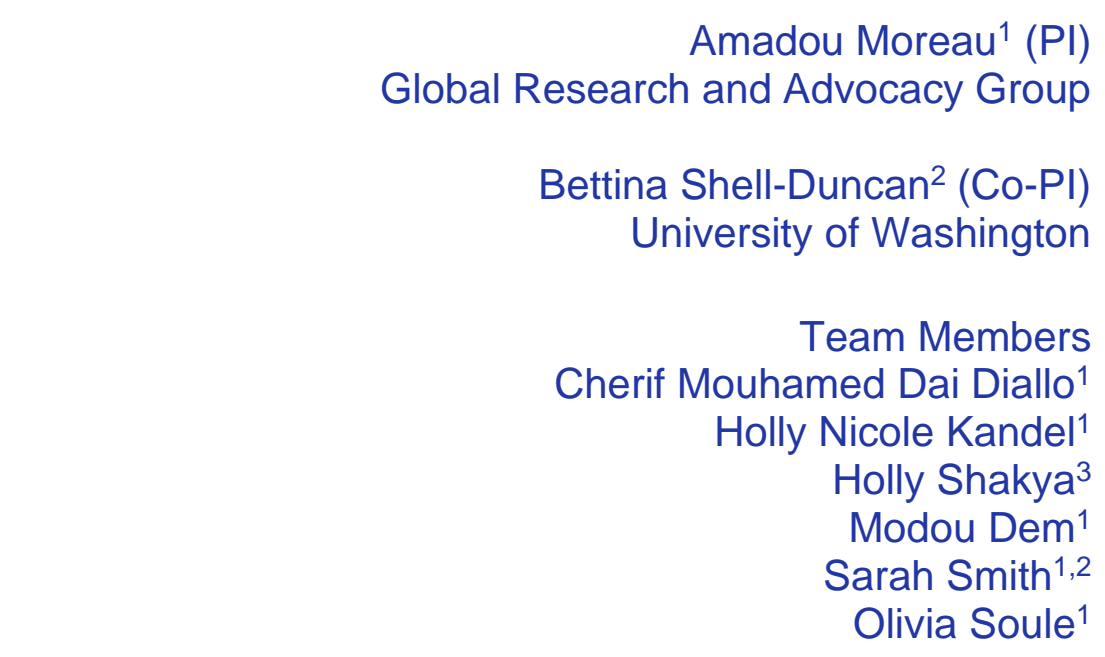

${ }^{1}$ Global Research and Advocacy Group (GRAG), Senegal ${ }^{2}$ University of Washington, Seattle ${ }^{3}$ University of California, San Diego 
Evidence to End FGM/C: Research to Help Girls and Women Thrive generates evidence to inform and influence investments, policies, and programmes for ending female genital mutilation/cutting in different contexts. Evidence to End FGM/C is led by the Population Council, Nairobi in partnership with the Africa Coordinating Centre for the Abandonment of Female Genital Mutilation/Cutting (ACCAF), Kenya; the Global Research and Advocacy Group (GRAG), Senegal; Population Council, Nigeria; Population Council, Egypt; Population Council, Ethiopia; MannionDaniels, Ltd. (MD); Population Reference Bureau (PRB); University of California, San Diego (Dr. Gerry Mackie); and University of Washington, Seattle (Prof. Bettina Shell-Duncan).

POPULATION COUNCIL

Ideas. Evidence. Impact.

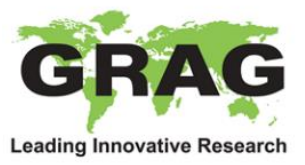

The Population Council confronts critical health and development issuesfrom stopping the spread of HIV to improving reproductive health and ensuring that young people lead full and productive lives. Through biomedical, social science, and public health research in 50 countries, we work with our partners to deliver solutions that lead to more effective policies, programmes, and technologies that improve lives around the world. Established in 1952 and headquartered in New York, the Council is a nongovernmental, nonprofit organisation governed by an international board of trustees. www.popcouncil.org

Global Research and Advocacy Group (GRAG) strives to discover possibilities for every woman, child, and vulnerable population as a whole, through high standard research and training. Our vision is to harness the power of research innovation, and become a leading organisation dedicated to advancing the evidence base for behaviour change that can be used to inform programmes or policies throughout Sub-Saharan Africa.

www.globalresearchandadvocacygroup.org

The University of Washington is one of the world's preeminent public universities. Our impact on individuals, our region, and the world is profound -whether we are launching young people into a boundless future or confronting the grand challenges of our time through undaunted research and scholarship. We turn ideas into impact and transform lives and our world. www.washington.edu

Suggested Citation: Moreau A. and Shell-Duncan B. 2020. "Tracing Change in Female Genital Mutilation/Cutting through Social Networks: An Intersectional Analysis of the Influence of Gender, Generation, Status, and Structural Inequality." Evidence to End FGM/C: Research to Help Girls and Women Thrive. New York: Population Council.

This report represents the opinions of the authors and is the product of professional research. The report has been peer reviewed. For more information, contact the lead authors [amoreau@globalresearchandadvocacygroup.org] and [bsd@uw.edu].

Please address any inquiries about the Evidence to End FGM/C programme consortium to: Dr Jacinta Muteshi, Project Director, jmuteshi@popcouncil.org

Funded by:

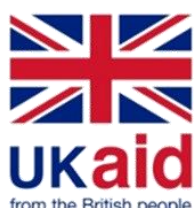

This document is an output from a programme funded by UK Aid from the UK government for the benefit of developing countries. However, the views expressed and information contained in it are not necessarily those of, or endorsed by the UK government, which can accept no responsibility for such views or information or for any reliance placed on them. 


\section{Table of Contents}

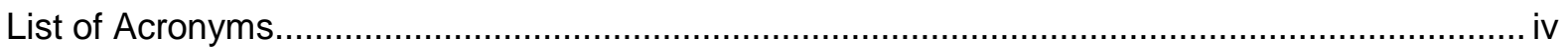

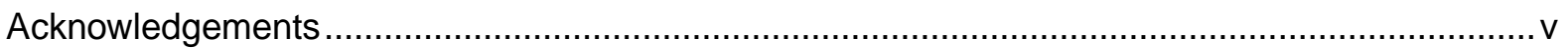

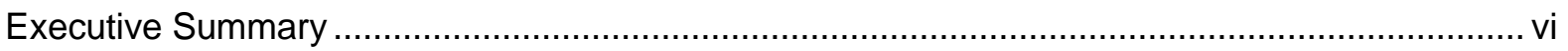

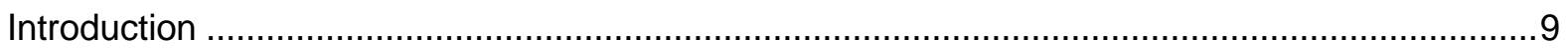

Gender Norms, Feminisms, and Shifting Meanings of "Patriarchy" .......................................

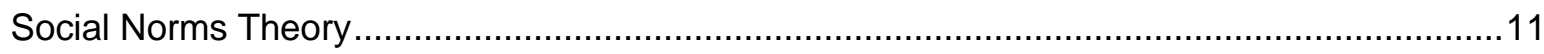

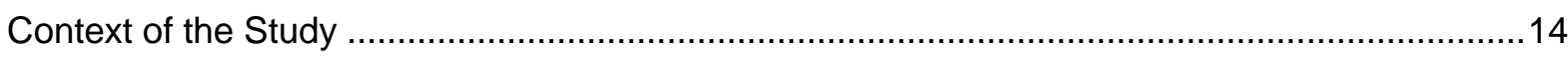

Study Population

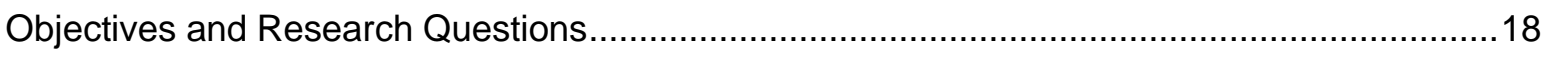

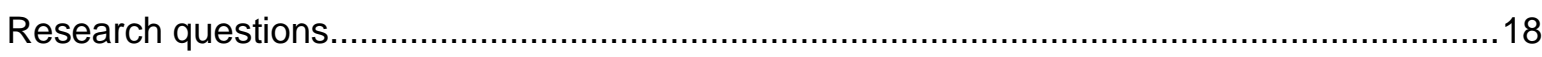

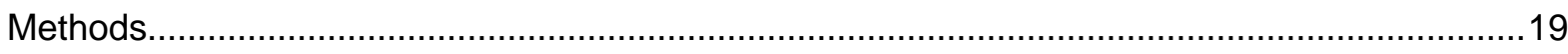

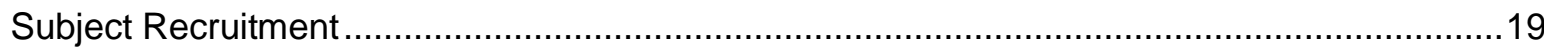

Data Collection Instruments, Field Team Training and Pre-Testing.......................................19

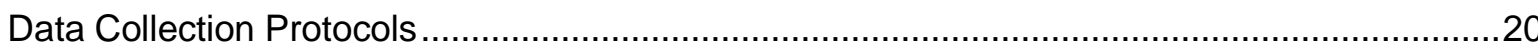

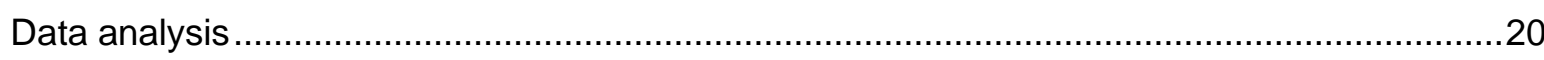

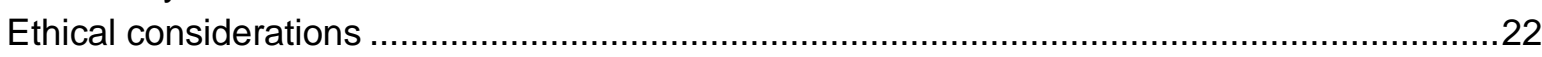

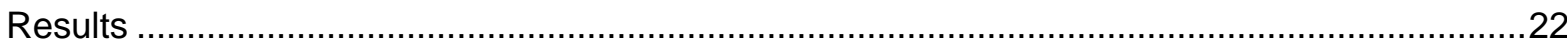

FGM/C as a Practice in Flux: "New Era, New Behaviour, New Way of Life" ...........................22

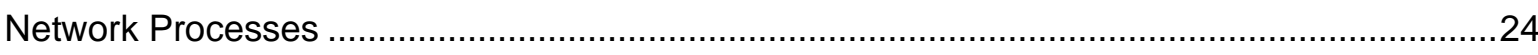

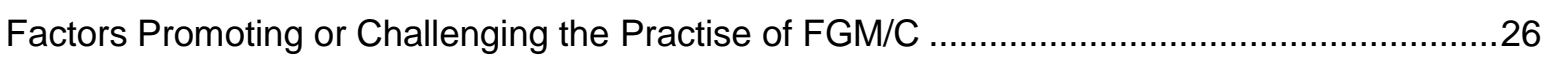

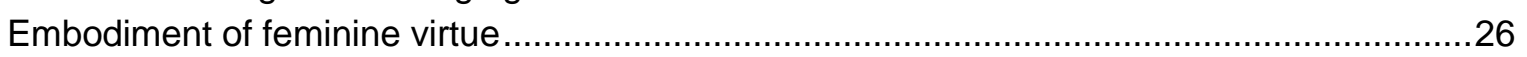

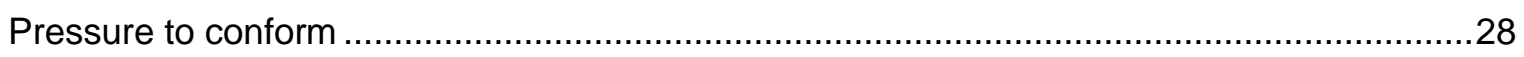

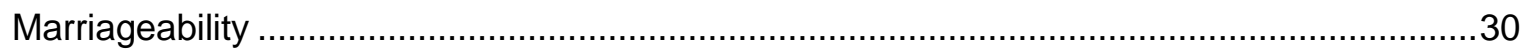

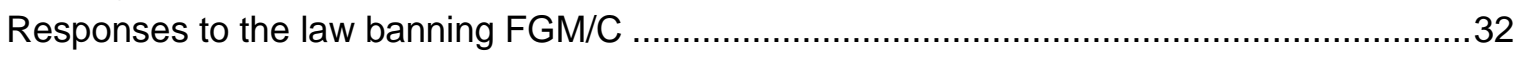

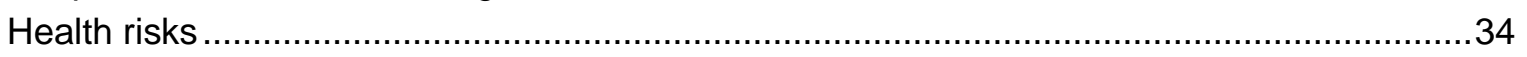

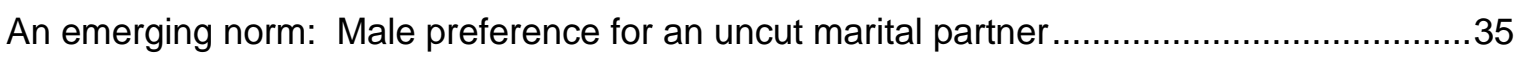

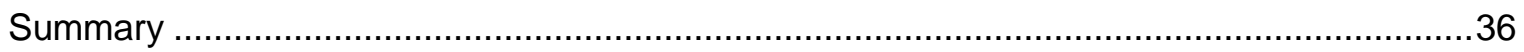

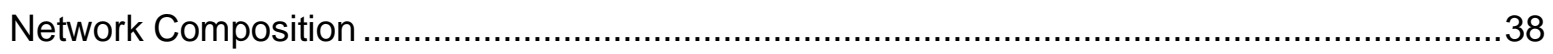

Patterns of Influence and Differential Power over Decision making on FGM/C .......................45

Generation: The power of older women over younger women..............................................48

The role of gender in structuring hierarchies of power and authority ......................................53

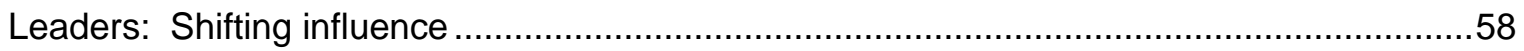

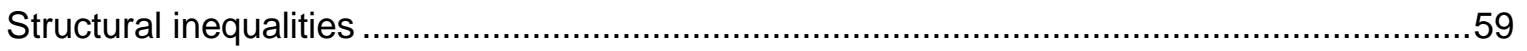

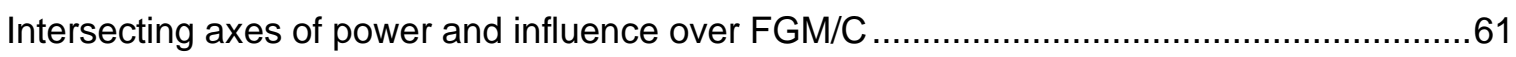

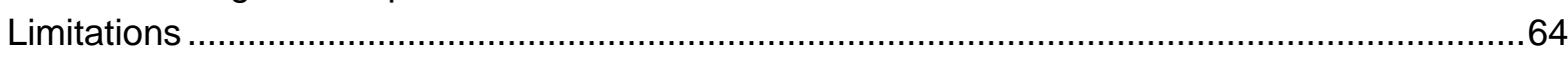

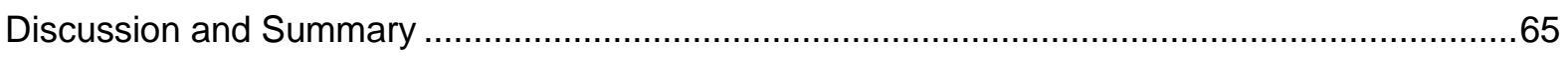

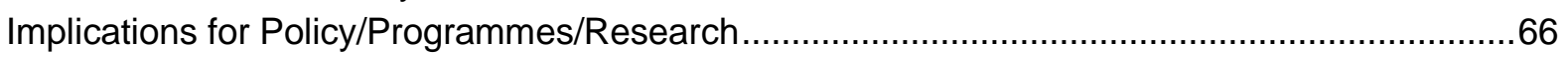

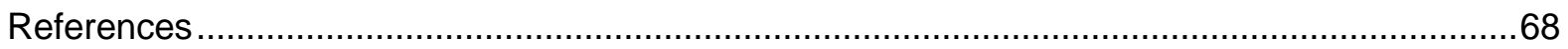

Appendix A: Interview Guidelines for Key Informant Interviews and Focus Group Discussions .73 


\section{List of Acronyms}

$\begin{array}{ll}\text { ASBEF } & \text { Association Sénégalaise pour le Bien-Etre Familial } \\ \text { CNERS } & \text { Comité National d'Ethique pour la Recherche en Santé } \\ \text { COFESEPRAT } & \begin{array}{l}\text { National Committee for the Abandonment of Harmful Practices Affecting } \\ \text { Women and Children }\end{array} \\ \text { DHS } & \text { Demographic Health Survey } \\ \text { DM } & \text { Decisionmakers } \\ \text { ENDA-ACAS } & \text { Environmental Development Action-Action in Casamance } \\ \text { FGD } & \text { Focus Group Discussion } \\ \text { FGM/C } & \text { Female Genital Mutilation/Cutting } \\ \text { GRAG } & \text { Global Research and Advocacy Group } \\ \text { HIV } & \text { Human Immunodeficiency Virus } \\ \text { IAC } & \text { Interafrican Committee on Traditional Practices Affecting Women and } \\ \text { NGO } & \text { Children } \\ \text { SDG } & \text { Nongovernmental Organisation } \\ \text { UN } & \text { Sustainable Development Goals } \\ \text { UNDP } & \text { United Nations } \\ \text { UNFPA } & \text { United Nations Development Programme } \\ \text { UNICEF } & \text { United Nations Fund for Population Agency } \\ \text { UNIFEM } & \text { United Nation's Childrens Fund } \\ \text { WHO } & \text { United Nations Development Fund for Women } \\ & \text { World Health Organization }\end{array}$




\section{Acknowledgements}

Funding for this work was provided by UK Aid and the UK government through the Department for International Development (DFID)-funded project, "Evidence to End FGM/C: Research to Help Girls and Women Thrive," coordinated by the Population Council.

Computing support and grant administration through the Center for the Study of Demography and Ecology at the University of Washington was supported by the Eunice Kennedy Shriver National Institute of Health and Human Development award number 5R24HDO42828.

We would like to thank people who have inspired our team to adapt and experiment with the use of social network methods/analysis to study harmful social norms, in particular female genital mutilation/cutting (FGM/C) in the context of Senegal. This has been a tremendous learning experience, and for their commitment and determination to contribute to the overall process in selected communities in Central and South Senegal, we would also like to thank our field team members at GRAG including: Alhagy Bah, Alpha Diallo, Amadou Tidiane Ly, Awa Coulibaly, Helene Benga, Moustapha Diagne, Papa Momar Guèye, and Sokhna Aminata Dia.

Special thanks also go to all the stakeholders that the study team has visited/met with for their time and contributions. We are grateful for the involvement of the Ministry of Health, the Directorate of Family Affairs, and members of the National/Senegal Ethics Committee (CNERS) - Doulo Der, Lamine Mané, and Samba Cor Sarr-for their effort to join our field team and validate their work being in the study sites.

We would also like to thank all the community members who participated in the study, particularly the key informants that the team interacted with, for their time and sharing of information.

We acknowledge the significant support that we received from the research assistants through their hard work, which contributed to the review/validation of completed tools, their translation, and the design of the social network maps/sociograms, among other relevant materials.

Finally, we would like to give a special thanks to Dr. Benjamino Cislaghi, Dr. Katherine Wander, and Dr. Jacinta Muteshi for providing detailed reviewer comments on earlier versions of this report. We also appreciate the editorial support of Christina Tse and the publishing team of the Population Council. 


\section{Executive Summary}

\section{Background}

Policies and programmes designed to eliminate the practice of female genital mutilation/cutting $(F G M / C)$ in Senegal have been implemented out over the span of several decades, but the practice has been surprisingly tenacious. Strategies for accelerating abandonment have been informed by theories of change, and social norms theory, in particular, has become a prominent framework for understanding the dynamics of behaviour change. It draws attention to the fact that FGM/C is held in place by interdependent normative expectations: what one family chooses to do is linked to expectations of others and reinforced through social sanctions. Hence, a key strategy for promoting behaviour change rests on coordinating change in norms and behaviour among people who interact with one another. While progress has been made in the development of methods for identifying social norms linked to $\mathrm{FGM} / \mathrm{C}$, much less is known about how to identify the relevant "people who interact." Often referred to as the reference group, this includes salient people within a person's social network, such as close friends and family, neighbours, co-workers, or other people within or beyond the community.

The purpose of this study is to identify the social norms surrounding the practice of FGM/C in two regions in Senegal, and to investigate the social networks in which these norms are embedded. Our interests lie in identifying the salient social network members influencing FGM/C, as well as the patterns of power and influence within these groups. The aim of this research is to produce evidence to inform the design of targeted network interventions that can optimise behaviour change and accelerate abandonment of FGM/C.

A network approach to the study of FGM/C makes it possible to examine patterns of power and axes of influence that underlie the practice. FGM/C has long been posited to be linked to gender inequality, being a manifestation of patriarchal oppression of women. Scholars increasingly advanced the concept of "intersectionality," emphasising that there may be multiple, co-existing axes of power, with gender inequality intertwined with inequalities along other lines, such as race and class. Network data allow us to examine the intersecting axes of power and influence surrounding the practice of FGM/C in rural Senegal. We argue that along with focusing on "risk," it is important to also invoke the concept of vulnerability, the differential ability to cope with social stressors or challenges. While "risk factors" are most often understood to be traits of an individual (e.g., ethnicity, age), family (e.g., economic status), or community (e.g., harmful social norms), vulnerability can be exacerbated by structural factors, such as poverty and political marginalisation, that shape systems of power and limit access to resources.

The key questions addressed in this study are:

1) What social interactions produce, uphold, and potentially alter FGM/C-related social norms, and what are the patterns of variation in which norms are being challenged?

2) What are the intersecting lines of authority and patterns of influence that exist among members of social networks, and what role, if any, do men play in these networks?

\section{Methods}

Ethics approval was obtained by the Population Council Institutional Review Board and the Comité National d'Ethique pour la Recherche en Santé (CNERS) (National Ethics Committee) in Dakar. The study took place in two regions in Senegal: 1) a low-FGM/C prevalence, ethnically mixed region in Central Senegal, and 2) a high-FGM/C prevalence, ethnically homogeneous region in South Senegal. The study employed a parallel mixed design for social network analysis that involved first conducting in-depth qualitative network interviews guided by the co-production of 
network maps, and then quantifying data elicited in these interviews. A total of 40 mothers, referred to as primary respondents, were selected to participate in the in-depth network interviews using two inclusion criteria: 1) having a daughter between the ages of 3 months and 5 years, and 2) coming from a family that once practiced FGM/C. Network partners identified by the mothers as highly influential were then interviewed as secondary respondents, producing a total of 90 network interviews that paint a rich picture of social interactions, roles and responsibilities, and patterns of influence. The analysis was triangulated by 24 key informant interviews and 13 focus group discussions (FGD). Focus groups were organised using a factorial design, divided by region, gender, and age. This design allowed for the identification of social norms linked to $F G M / C$, and patterns of strength and contestation across and within subgroups.

\section{Results}

Excision was commonly described as a practice that formerly took place in the context of a celebratory coming-of-age ritual for girls. However, knowing that this practice has been subject to ongoing public censure, FGM/C has been transformed into a highly private family affair in both Central and South Senegal. Moreover, the criminalisation of FGM/C has amplified the need for secrecy when carrying out the practice; as a result, the age at cutting has declined, with most cutting now taking place in infancy.

Our findings reveal regional discrepancies concerning factors promoting or challenging the practice of FGM/C. In South Senegal, many respondents were aware of recent convictions of those who had violated the ban on FGM/C. Fear of prosecution was an incentive to either abandon FGM/C or drive the practice underground. In both South and Central Senegal, it was commonly understood that health care professionals have a duty to report violators of the ban on FGM/C, and people have not sought treatment for FGM/C-related health complications. The reduced access to health care was a prominent concern of those who continued $\mathrm{FGM} / \mathrm{C}$, as well as a strong reason to abandon the practice. However, limited access to healthcare and fear of prosecution were actively weighted against the benefits of social norms upholding FGM/C. In both South and Central Senegal, gender norms associated with the embodiment of feminine virtue were incentives to continue the practice. In South Senegal, norms linking FGM/C to marriageability and social acceptance, inclusion, and access to social support were strongly upheld. By contrast, in Central Senegal, which is ethnically heterogeneous and has a low prevalence of $F G M / C$, norms linked to marriageability have drastically eroded, and the stigma once cast on uncut girls and women has declined precipitously. Thus, in Central Senegal, the norms that encourage the practice of FGM/C have mostly eroded but have not entirely disappeared. Many informants in both South and Central Senegal were actively weighing the advantages and disadvantages of $F G M / C$ in light of shifting social circumstances, making it difficult to answer the seemingly simple question: Do you support or oppose the continuation of FGM/C?

Analysis of social network data shows that men, particularly fathers and their brothers, feature prominently in networks of care, comprising $50 \%$ of core network members. Excision networks are more constrained, often excluding formal leaders and healthcare providers who are perceived to have a duty to report violators of the ban on FGM/C. Furthermore, in South Senegal, men are often excluded from excision networks to heighten secrecy and potentially to protect men from prosecution. However, the opinions of male network members were known by decision-makers and influenced FGM/C outcomes. While excision networks in South Senegal were ethnically homogeneous (Pulaar), networks in Central Senegal were ethnically mixed, and included both cut and uncut women.

The data revealed several important intersecting lines of power and influence over decision-making regarding $\mathrm{FGM} / \mathrm{C}$, divided along the axes of gender, generation, ethnicity, and structural 
inequalities. Our data show that FGM/C is "women's business" to the extent that it is arranged and carried out by older women on younger women. As previous research in Senegambia has demonstrated, there is a generational component, wherein $\mathrm{FGM} / \mathrm{C}$ confers access to the resources and support of older women for younger, newly married women who have moved to their husband's home. At the same time, older women often assess whether or how excision practices should be altered or ended in light of shifting social circumstances. Men are far from uninvolved with FGM/C, and when fathers, in particular, are directly involved in excision decision-making, they often advocate for abandonment. Importantly, men have the ability to negotiate with older women, who also have great influence over FGM/C decision-making. And finally, network interviews show that major structural factors are widening gendered disparities in health and well-being. These include responses to the law, gendered vulnerability to prosecution, reduced community cohesion and social support, and deterrence from seeking healthcare services. Notably, residents of our study communities are predominantly poor, rural, ethnic minorities with limited education. Many view rural livelihoods as precarious due to economic instability, climatic instability, and political powerlessness. In turn, residents rely on their social networks for support-possibly now more than ever. Excision, a practice that once assured social inclusion and support, is now criminalised, and women are acutely aware that they are under surveillance and at risk for being reported as suspected violators of the ban. Additionally, the very population who has the greatest need for specialised reproductive health care-girls and women living with FGM/C - have increasingly limited access to professional medical treatment. Thus, current strategies aimed at curbing FGM/C may serve to erode social cohesion and exacerbate health disparities among rural girls and women. We therefore suggest that future measures begin with an understanding that $\mathrm{FGM} / \mathrm{C}$ is often a common-sense means of coping with precarity and focus on strategies that strengthen the ability of individuals, families, and communities to devise alternative solutions to the challenges they face.

\section{Discussion}

There are two main limitations of this study. First, in contrast to full network studies that provide information on entire study populations, our methodology does not provide the information on the architecture of social networks and identification of individuals in key positions of influence. Second, study participants were often reluctant to disclose their personal opinion on FGM/C or the perception of their network partners. To this end, paired first- and second-degree network interviews were crucial for gaining complete insights, as was triangulation with key informant interviews and focus group discussion. Our parallel mixed-methods approach generated rich data on the salient social referents and patterns of power and influence on excision and offers numerous insights for adopting targeted network interventions.

\section{Implications for policy/programmes/research}

Our findings point to the importance of engaging older women and men, particularly fathers of young girls and their brothers, as well as addressing structural barriers to abandonment of FGM/C. We propose that next steps involve consulting with experts in development to explore ways in which the findings from this study may inform novel programme strategies aimed at accelerating the abandonment of FGM/C. 


\section{Introduction}

In 2015 the United Nations General Assembly released a new set of development goals, the Sustainable Development Goals (SDGs) that aim to eliminate female genital mutilation/cutting $(\mathrm{FGM} / \mathrm{C})$ by the year 2030. This reinforces a decades-long international commitment to ending a practice recognised as a form of gender-based violence and a violation of the human rights of girls and women. Progress towards this goal has been uneven. Global statistics indicate that at least 200 million girls and women in 30 countries have undergone FGM/C (UNICEF, 2016), and approximately 70 million girls aged 0-14 years have already been cut or are at risk of being cut (Shell-Duncan, Naik, and Feldman-Jacobs 2016). Analyses of data from 29 countries (27 African countries plus Yemen and Iraq) reveal that while 14 countries have experienced a decline in the prevalence of FGM/C, the other 15 countries-Senegal included-show no clear evidence of change (Shell-Duncan, Naik, and Feldman-Jacobs 2016). This finding is perplexing, as Senegalese activists have long been at the forefront of both local and global campaigns to end $\mathrm{FGM} / \mathrm{C}$.

As efforts to eliminate $\mathrm{FGM} / \mathrm{C}$ have intensified, social norms theory has become a prominent framework for understanding the dynamics of behaviour change, and in recent years has been influential in the design of interventions aimed at accelerating abandonment. From the lens of social norms theory FGM/C is seen as held in place by interdependent normative expectations: what one family chooses to do is linked to the expectations of important others and reinforced through social sanctions. Hence, a key strategy for promoting behaviour change rests on coordinating change in norms and behaviour among people who interact with one another. Progress has been made in the development of methods for identifying the constellation of social norms linked to FGM/C (Mackie et al, 2015; Shell-Duncan et al. 2019). Much less, however, is known about how to identify the relevant "people who interact." Often referred to as the reference group, this includes salient people within a person's social network, such as close friends and family, neighbours, co-workers, or other community members.

The purpose of this study is to identify the social norms surrounding the practice of FGM/C in two regions in Senegal, and to investigate the social networks in which these norms are embedded. Our interests lie in identifying the salient social network members influencing $F G M / C$, as well as the patterns of power and influence within these groups. It is our hope that insights on social norms along with insights on the social interactions most influential on the practice of FGM/C will make it possible to design targeted network interventions that can optimise behaviour change and accelerate abandonment of the practice.

Notably, a focus on social power and influence is not new in the study of FGM/C. Beginning in the 1970s, feminist scholarship drew connections between FGM/C and gender inequality. In this study we draw on more recent scholarship on intersectionality which recognises that different axes of social power relations are interrelated (lyer, Sen, and Osterlin 2008). These may include not only gender, but also ethnicity, class, and generation. Increasingly, health researchers and policy makers recognise that intersecting axes of power undergird complex processes that produce health inequalities (Hankivsky 2012). A possible benefit of de-centering gender in an intersectional study of $\mathrm{FGM} / \mathrm{C}$ may be to illuminate novel empirical insights that can inform the design of network interventions.

\section{Gender norms, Feminisms, and Shifting Meanings of "Patriarchy"}

In the vast literature on female genital cutting, there exist two dominant but conflicting views on the role of men in the perpetuation of the practice. One paints men as culprits, with FGM/C viewed as 
a manifestation of patriarchal oppression of women. By making females sexually passive, FGM/C ensures women are chaste prior to marriage, and faithful to their husbands after marriage. By serving to signal fidelity, it is argued that FGM/C increases paternity certainty, and thus improves marriage prospects. In settings where women's future security and well-being are linked to their role as a wife and mother, being circumcised becomes a prerequisite to marriage.

An alternative perspective portrays men as relatively uninvolved in a practice described as "women's business" (Hernlund 2003; Yoder, Camara, and Soumaoro 1999). Noting that the practice is often organised and performed by women on women, anthropologists in various African contexts have emphasised women's agency, and the importance of community initiation in the formation of a ritual that creates bonds between women (Ahmadu 2000; Kratz 1994; Thomas 2000).

These two divergent perspectives on the role of men in the perpetuation of $\mathrm{FGM} / \mathrm{C}$ lead to conflicting predictions. If $\mathrm{FGM} / \mathrm{C}$ is an underpinning of patriarchal structures, men should be expected to be ardent supporters of the practice, as its elimination may pose a threat to their superior status in the social hierarchy. Alternatively, if FGM/C is indeed "women's business," men should have limited interest in whether or not the practice is maintained and have little influence in the decision-making process. The questions raised are:

- What role, if any, do men play in the perpetuation or abandonment of FGM/C?

- By whom are the decisions made, and are men ever among those who negotiate a decision?

- Even if they play a peripheral role in decision-making regarding $\mathrm{FGM} / \mathrm{C}$, does their opinion carry any weight?

- Who holds greatest power and influence over FGM/C decision-making?

While opposition to FGM/C can be traced back to the early 1900s, in the late 1970s the issue gained renewed attention and international prominence through the efforts of second-wave Western feminists, for whom FGM/C became the symbol par excellence of patriarchal oppression of women (Gosselin 2000). As the concept of women's liberation became intertwined with the idea of sexual liberation, FGM/C came to signify "gender oppression to end all gender oppression" (Dawit and Mekuria 1993; see also Abusharaf 2000; Gosselin 2000; Wade 2011). In this context, the notion of patriarchy became cast as a system of social structures which allow men to exploit women. According to Harrell and Santos (2017), this represented a departure from the historical use of the term patriarchy that prevailed in anthropology from the time of Morgan (1877) and Engels (1884) until the 1970s; patriarchy was defined as a "form of social organisation in which the father or oldest male is head of the family, and descent and relationships are reckoned through the male line" (Harrell and Santos 2017: 7). The most salient characteristics highlighted by this classic use of the concept are patrilineal descent and inheritance, patrilocal residence, strong patrilineal authority, and power of the senior generation, especially men, within the domestic sphere. Yet in the 1970 s a second definition was shaped by feminist scholarship, employing the term "patriarchy" as masculine domination, sexually and otherwise. Lerner's widely cited definition of patriarchy describes it as "the manifestation and institutionalisation of male dominance over women in society in general" (Lerner 1986: 239). Hence, the concept of domination was not just circumscribed to the realm of the family but linked to broader societal institutions that reinforce structures of gender inequality.

Debates and theoretical developments in third-wave feminist scholarship critique traditional second-wave feminist concepts of patriarchy as simplistic accounts of gender oppression that often invoke the image of a homogenised global sisterhood (Harrell and Santos 2017; Patil 2013), and were seen as patronising, arrogant, and failing to recognise the varied plights of women around the world. Some Western feminist discourses came under considerable critique for their 
ethnocentricism and reductionism, particularly for letting sexuality become "assumed as an a priori issue around which 'all women' should organise" (Abusharaf 1996: 5-6). Gilliam (1991: 218) charged that because FGM/C was portrayed as a "savage custom" from "barbaric African and Arab cultures," the way that Western women championed the cause revealed "latent racism," "antiIslamic fervor," and "intellectual neo-colonialism." Walley (1997: 419) further pointed to the "tendency to characterise African women as thoroughly oppressed victims of patriarchy, ignorant or both." Such characterisations contributed to critical divisions between various feminist groups throughout Africa and the West who were engaged in what Abusharaf termed (2000: 156) a "war of visions."

Some African feminists instead characterised FGM/C as "a symptom rather than a cause of women's subordination," and urged that the injustices experienced by women be considered within the broader socioeconomic and political contexts (Abusharaf 2000: 156). Scholars increasingly advanced the concept of "intersectionality," emphasising multiple axes of power and posit that gender inequalities may be intertwined with broader systems of social inequalities, including those of class, ethnicity, and education (Patil 2013). Intersectionality is an analytic tool that holds that people's lives and organisation of power in society are shaped not by a single axis of social division, such as gender, but instead by many axes that work together and influence each other (lyer, Sen, and Osterlin 2008; Hankivsky 2012; Collins and Bilge 2016). The term "intersectionality" was popularised in a landmark 1991 paper by Kimberlé Crenshaw entitled "Mapping the margins: Intersectionality, identity politics and violence against women of color." She argued that solutions to violence could not be found by imagining women as one homogeneous mass, or by painting men as perpetrators (Crenshaw 1991); instead, fuller understandings of violence among black women are garnered by looking at interlocking and mutually reinforcing domains of race and gender. As intersectional analyses have been dispersed across disciplines in academia, it has become apparent that rather than elevating one category of analysis, such as gender, subordination can be reinforced through more than one axis of social division, such as race, class, and gender. In addition to focusing on multiple elements of individual identity, intersectionality also embraces a focus on social context and the multiple domains that may shape and constrain power. Collins and Bilge (2016: 47) argue that "power relations are to be analyzed both via their intersections, for example racism and sexism, as well as across domains of power, namely structural, disciplinary, culture and interpersonal" (emphasis in original).

\section{Social Norms Theory}

We adopt an intersectional analysis to examine social interactions, domains of power, and the social and gender norms that are produced and contested regarding FGM/C. We draw on social norms theory, which has been a prominent framework for understanding FGM/C. Social norms are unwritten expectations regarding appropriate behaviours within particular social groups (Cislaghi and Heise, 2018a). Social norms theory posits that people follow social rules that are shared among people in their reference group. Norms theorists use the term reference group to refer to people with whom an individual or group commonly interacts and who influence a certain domain of behaviours, often a subset of the entire social network. It is among these people that there exist expectations for social norms to be upheld. In a model first developed by political scientist Gerald Mackie, it was posited that FGM/C is a social norm that spread and became locked in place by interdependent expectations regarding marriageability (Mackie 1996). Mackie posited that in the competition for marrying into higher social strata, FGM/C provided an advantage by signaling fidelity, and became a universal prerequisite for marriage. Once locked in place, FGM/C as a prerequisite to marriage operates as a social coordination norm. Individuals opting out pay the high price of losing marriageability and legitimate childbearing. 
In the original application of social norms theory to FGM/C, Mackie also identified a second possible mechanism: peer pressure (Mackie 1996; 2000). In prior research, Shell-Duncan and colleagues found support for this second mechanism (Shell-Duncan et al. 2011). FGM/C was most often only indirectly related to marriageability via concerns over preserving virginity. Instead they found strong evidence for what they called an intergenerational peer convention. They proposed that being circumcised serves as a signal to other circumcised women that a girl or woman has been trained to respect the authority of her circumcised elders and is worthy of inclusion in their social network. In this manner, FGM/C facilitates the accumulation of social capital by younger women and of power and prestige by elder women.

With the subsequent empirical investigations, as well as a growth in scientific literature on social norms, views on norms related to $\mathrm{FGM} / \mathrm{C}$ have expanded to emphasise something that anthropologists have long understood: $\mathrm{FGM} / \mathrm{C}$ may be held in place not only by norms related to marriageability, but also by a wide range of norms and associated meanings that may centre on concerns including ethnic identity, adolescent rites of passage, religion, honour, modesty and sexual restraint, aesthetics, and hygiene (Mackie and LeJeune 2009). It is useful to tease apart the constellation of norms that reinforce $\mathrm{FGM} / \mathrm{C}$ in order to gain insights on the diversity of ways that the practice is enforced or upheld. But as Ellen Gruenbaum has emphasised, it is important to recognise that these multiple factors do not operate in isolation, but rather are intricately intertwined in complex sociocultural systems analogous to cogs in a machine, threads in a tapestry, or organs in a body (Gruenbaum 2005).

Norms scholars have also noted that in addition to individual factors and social norms, there are additional nonsocial factors that can influence behaviours. Mackie and colleagues (Mackie et al. 2015) refer to these as extra-social influences, and include any other factor that could be economic, legal, political, religious, or related to access to social services, technology change, and others. Numerous social-ecological models have been developed to jointly outline these multi-level influences on behaviour (see, for example, Figure 1).

Ecological models, popular since the 1980s, emphasise that determinants of health involve not only individual-level risk factors, but multiple levels of influence. These models are often depicted by the visual metaphor of nested or concentric circles, representing domains of influence.

\section{Figure 1: Social ecological model of health behaviour}

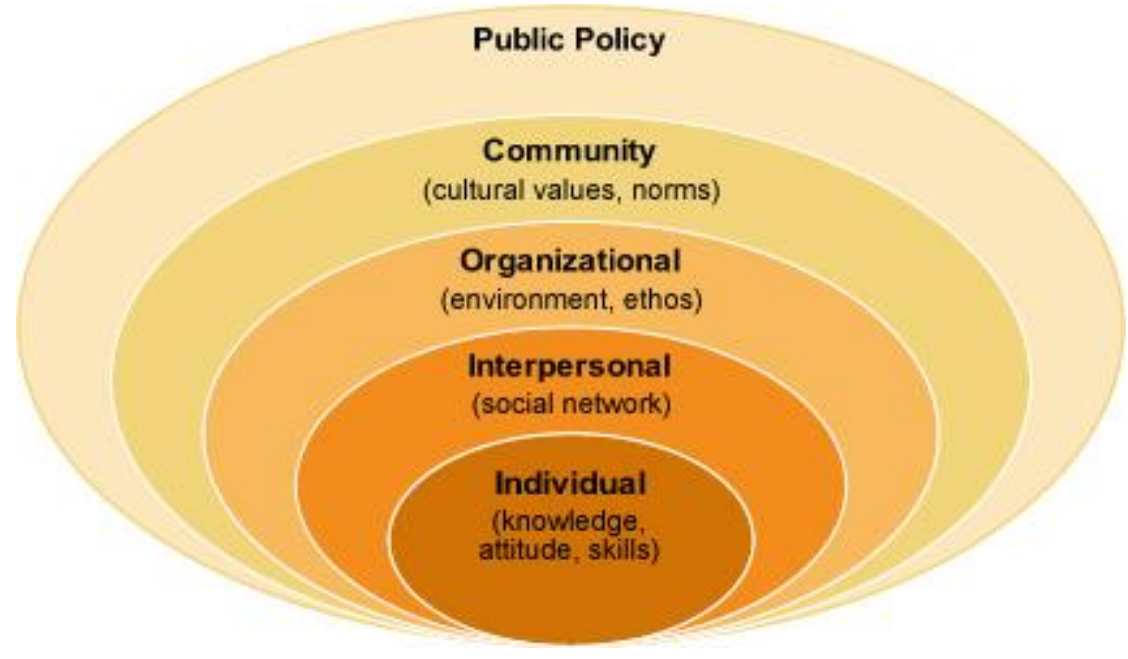

Noting that although social norms exist at several levels of social ecological models, Ben Cislaghi and Lori Heise have suggested reconfiguring this framework to emphasise the potential 
intersections between factors at various levels, a model known as the Flower Framework (Figure 2) (Cislaghi and Heise 2018b).

Figure 2 Flower framework (Cislaghi \& Heise, 2018b)

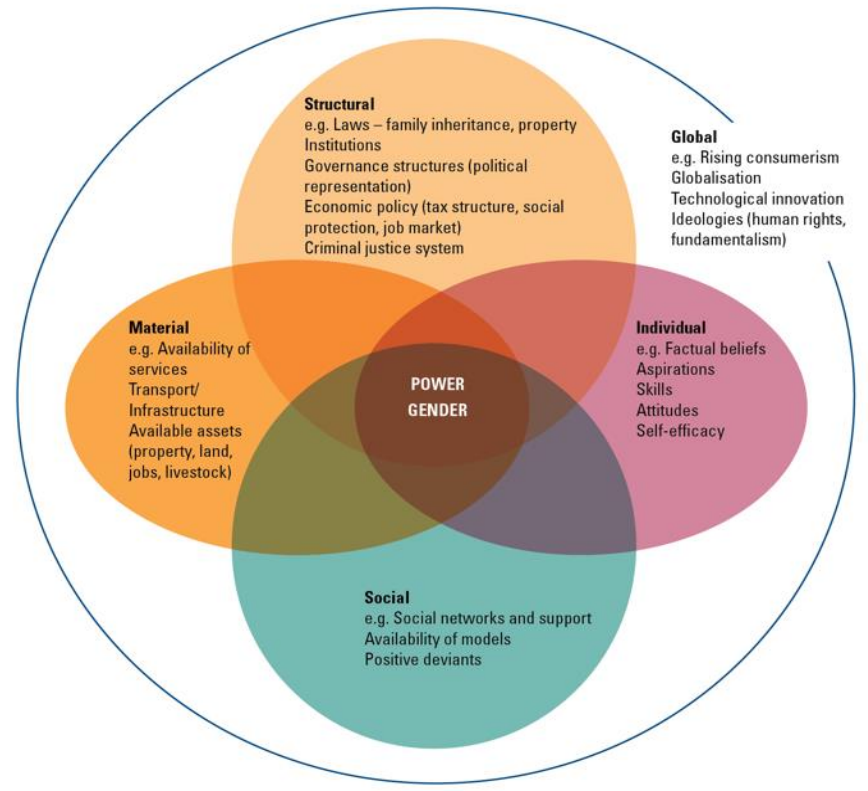

They also draw attention to the role of gender norms. Gender norms are cultural schemas that define what is appropriate behaviour for upholding ideals linked to masculinity or femininity in different social arenas-at home, in the community, in school or the workplace, and in interpersonal relationships. Behaviours that are driven by gender norms differ in their expression for those who are biologically male and female. Discriminatory gender norms limit girls' and women's access to power within their families and communities, reduce their educational and economic opportunities, and alter their own aspiration and ambitions for their lives (Heise et al. 2019).

What these advances draw attention to are not only the possible intersections across individual, social, material, and structural domains, but also the fact that social norms are produced and upheld through social interactions that involve unequal lines of authority and power differentials within these relationships (Heise et al. 2019). A great deal of the scholarship on social norms has emphasised identifying the constellation of social norms that hold a practice in place, with little attention to the role of power relations in sustaining a set of norms. Cislaghi and Heise (2019) suggest that integrating power analysis with the study of social norms may be useful for health promotion interventions, as it can provide information on who benefits and to what end. Hence, we ask whether patterns of subordination are generated within intersections of factors such as gender, generation, locality, ethnicity, and structural inequalities.

By focusing on multiple domains that may influence the perpetuation or change in $\mathrm{FGM} / \mathrm{C}$ norms and practices, we draw on the concept of vulnerability, defined as "exposure to contingencies and stress, and difficulty coping with them" (Chambers 1989). Vulnerability theory, rooted in the literature on the differential ability to cope with natural disasters, has now been applied to the study of health, including the ability to cope with cancer (Constant,2016), HIV (DeSantis 2008) and malaria (Ribera and Hausmann-Muela 2011). While "risk factors" are most often understood to be traits of an individual (e.g., ethnicity, age) or family (e.g., economic status), vulnerability is not simply an attribute of the individual or the community, but the systems of power and access to resources in which they are situated. This conception of vulnerability has two sides: 1) the 
challenges that an individual, family, or community are exposed to; and 2) factors that influence their ability to cope with these challenges (Chambers 1989).

Extending earlier multi-level models of behaviour change, the Flower Framework posits four domains of influence-institutional, material, social, and individual-that overlap, generating intersecting axes of influence.

With this focus in mind, our interests are twofold:

1) How can we study the interactions that produce, uphold, and potentially alter FGM/C-related social norms, and identify patterns of variation in which norms are being challenged?

2) How can we better understand the intersecting lines of authority and patterns of influence that exist among members of social networks, and what role, if any, do men play in these networks?

\section{Context of the Study}

The Republic of Senegal, with a 2018 population of about 15 million, is home to more than 20 ethnic groups, each with their own language, culture, and history. The largest ethnic group is Wolof (37.1\%), followed by Pulaar (also known as Fula) (26.2\%), Sereer (17\%), Mandinka (5.6\%), Diola (4.4\%), Soninké (1.4\%), and others (8.9\%) (CIA 2019). The former capital of French West Africa, Senegal is a semi-arid country located at the western-most point of the African continent. Although Senegal serves as the regional business center for West Africa, it is one of the world's poorest countries, with dramatic disparities in wealth. Predominantly rural, and with limited natural resources, about $75 \%$ of Senegalese are engaged in agricultural production (Kingston et al. 2011; CIA 2019). Despite recent efforts to diversify crop production, the rural agricultural sector has been vulnerable to recurrent drought and fluctuations in world commodity prices, and performance has steadily worsened. After its economy contracted in 1993, and at the behest of international donors, Senegal adopted radical economic reforms through structural adjustment policies (Kingston et al. 2011). This began with a $50 \%$ devaluation of the Senegalese currency that produced severe social consequences. Overnight the price of goods such as milk, fertiliser, and machinery doubled. Further reforms included the removal of government price controls and subsidies on food staples, and price fluctuations hit the lowest-income Senegalese hardest as basic staples such as cooking oil, rice and sugar became unaffordable. Currently, the UN Human Development Index (a summary measure of a long and healthy life, being knowledgeable, and having a decent standard of living, scaled from $0-1$ ) is classified as low (.505, ranked 164 out of 189) (UNDP 2018). Austerity measures tied to structural adjustment gutted government programmes such as education and health care, widening disparities that persist today (Kingston et al., 2011). Currently, primary education is compulsory and free, but with rapid population growth it has been difficult to keep up with demand; hence primary school enrolment is low, and particularly for women, illiteracy is high. The Gender Inequality Index, which measures loss of achievement due to gender inequality in the domains of reproductive health, empowerment, and labour market participation, is high (.515 on a scale of 0-1) (UNDP 2018).

$\mathrm{FGM} / \mathrm{C}$, also called excision in French, is practiced by a minority of the Senegalese population (22.7\% of women ages $15-49$ years, according to the 2016 DHS). National figures mask enormous regional variation in the prevalence of the practice. As shown in Figure 3, the prevalence of FGM/C ranges from $6 \%$ in Central Senegal to $77.8 \%$ in South.

\section{Figure 3. Prevalence of FGM/C by greater geographic area in Senegal, DHS 2016.}

The prevalence of FGM/C varies widely across geographic areas of Senegal. Our research was conducted in two contrasting areas: South Senegal, where the prevalence of FGM/C is very high, and Central Senegal, where the prevalence is low and declining. 
Figure 3: Prevalence of FGM, by region

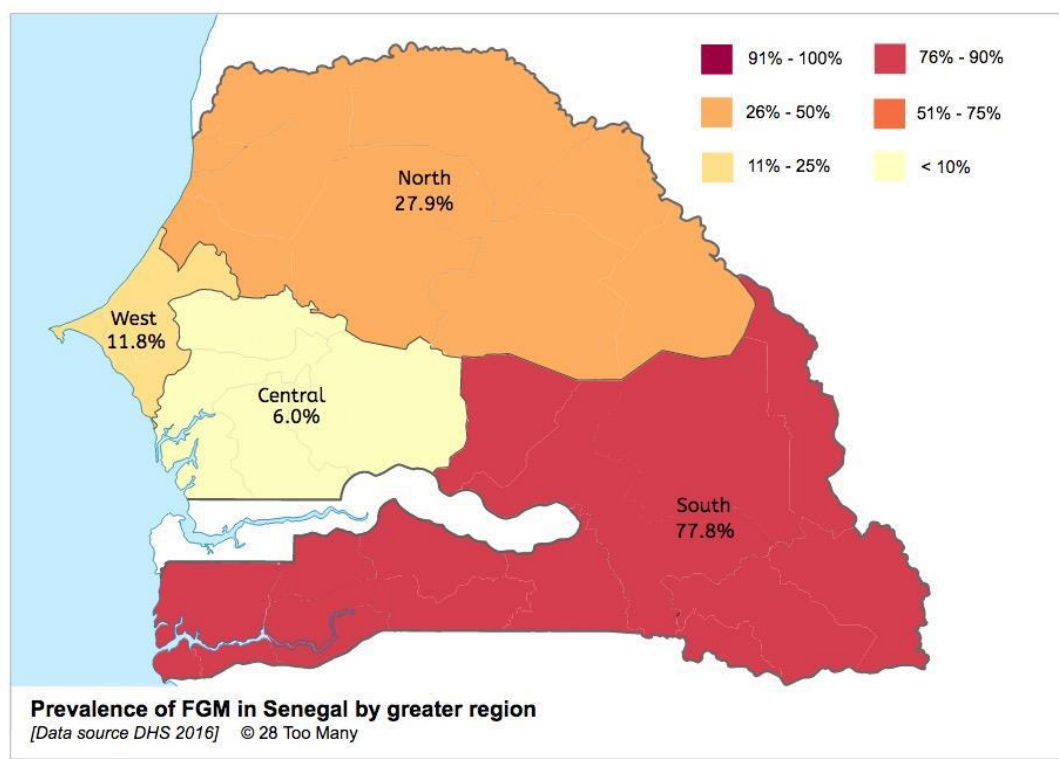

In Senegal FGM/C is often understood to be tied to ethnicity; it is said to be "not practiced" by the Wolof and Sereer (Sylla 1990), and thought to be near universal among the Pulaar and Mandinka ethnic groups. In reality, there is substantial variability in FGM/C prevalence within ethnic groups living in different areas of Senegal. Figure 4 highlights that regional variability in the prevalence of FGM/C in the two largest ethnic groups, Wolof and Pulaar. The overall prevalence among Wolof women ranges from zero in Diourbel to as high as 35\% in Matam. Among Pulaar women, the prevalence of $\mathrm{FGM} / \mathrm{C}$ ranges from $95 \%$ in Kedougou and Sedhiou to $2 \%$ in Diourbel. Prevalence is generally understood to run along lines of lineages.

For Wolof women, the prevalence is from zero in Diourbel to 35\% in Matam. For Pulaar women, the prevalence ranges from $95 \%$ in Kedougou and Sekhiou to $2 \%$ in Diourbel.

Figure 4 FGM/C affects Wolof and Pulaar woman differently depending on the region (Data source: 2010-11 Senegal DHS).

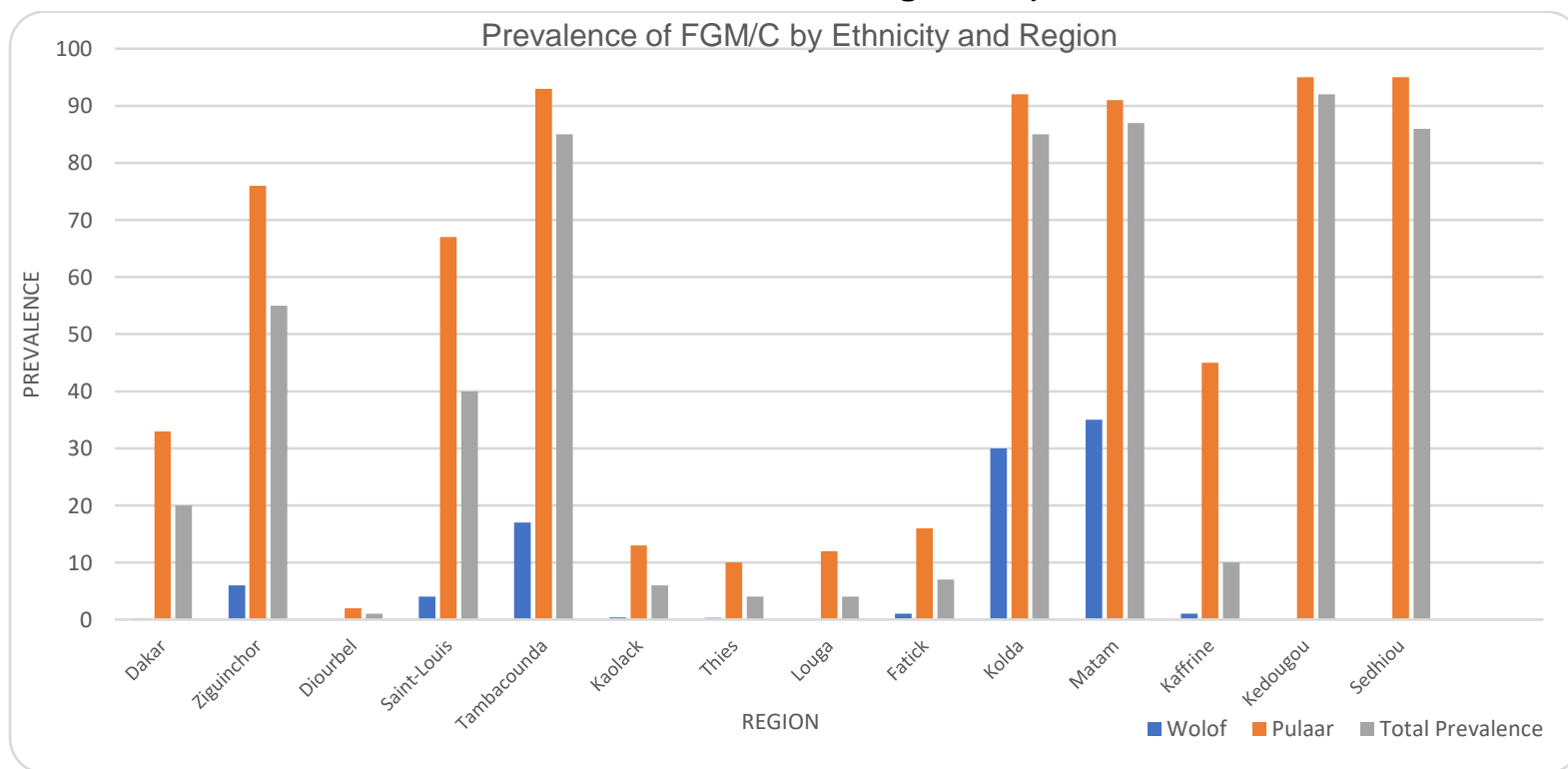

Across different communities, the cultural meanings of $\mathrm{FGM} / \mathrm{C}$ are multiple, fluid, and increasingly contested and negotiated by diverse groups of people who draw on local social and political 
movements, as well as national and international campaigns aimed at ending the practise. For decades, Senegalese activists have been at the forefront of both local and global strategies to end FGM/C. In February 1984, Senegal hosted a UN-sponsored conference that re-appraised antiFGM/C policies. With delegates from 20 African nations in attendance, a pivotal outcome of this conference was the formation of the Inter African Committee on Traditional Practices Affecting the Health of Women and Children (IAC). One of the primary mandates of the IAC was to call for governments to use existing national legislation to criminalise $F G M / C$, and to implement legislation specifically banning the practice.

In 1999, Senegal adopted a criminal law (Article 299A of Senegal's penal code) that prohibits the violation of "the integrity of the genital organs of a female person by total or partial ablation of one or several of the organ's parts, by desensitisation or any means." It applies to anyone who carries out $\mathrm{FGM} / \mathrm{C}$ or gives instructions for it to be carried out. The penalty for performing or attempting to perform, or procuring, aiding, or abetting $\mathrm{FGM} / \mathrm{C}$, includes imprisonment for six months to five years, or where cutting results in death, hard labour for life (Middlelburg, 2016). Additionally, Article 49 of the Penal Code states that the failure to report a crime against the bodily integrity of a person is punishable for six months to five years in prison and a fine between 25,000 and 1 million Francs (approximately USD $\$ 45-\$ 1,800)$ (28TooMany 2018). In the first year following the passage of the law, there were two arrests, but following an emotional public outcry, the charges were dropped and no convictions resulted. In an effort to promote public acceptance of the law, there have been programmes concentrated on awareness-raising and educational outreach that disseminated information about the existence and content of the new legislation. Additionally, in 2015 the Ministry of Women, Family, Social Development and Women's Entrepreneurship organised workshops around the country to encourage enforcement of the law. Administrative authorities, local elected officials, and representatives of community-based organisations attended these workshops (US Department of State 2015). To date there have been at least seven cases that have each led to multiple convictions; half of these have taken place in South Senegal (Middelburg 2016; Ndiaye 2010), and because women are the ones who typically arrange and carry out FGM/C, they have been the primary targets of legal action.

The Senegalese government has taken a stance in opposition to the practice of FGM/C. The country has ratified all international instruments which call on governments to work toward the abandonment of the practice. Additionally, the government adopted a National Action Plan for 2001-05 that articulated a clear goal of working towards total abandonment by 2015 . The main objectives were to improve networking and coordination among actors involved in efforts to eliminate the practice, to explain the legal framework to them, and to integrate the issue into formal and nonformal education. A second National Action Plan for 2010-15, adopted in February 2010, reiterated the government's commitment to working towards total abandonment of FGM/C by 2015, and called for further community-led, human-rights-based approaches for accelerating change (UNICEF 2010). The United Nations Population Fund (UNFPA) announced in 2016 an intent to create a common plan of action for Senegal and The Gambia (Agence de Presse Sénégalaise 2016), but it has not been released as of the end of 2018. A commitment to address the needs of survivors of FGM/C, and to strictly apply the criminal ban is articulated in the 2015 National Plan for the Fight against Gender-Based Violence and for the Promotion of Human Rights in Senegal (Plan d'Action de National Lutte Contre VBG). A national child protection plan that includes the abandonment of FGM/C was adopted for 2016-18, and a strategy on gender equity and a children's code are currently being developed (28TooMany, 2018).

Senegal has been the site of a number of media campaigns and NGO-sponsored initiatives aimed at ending the practice of $\mathrm{FGM} / \mathrm{C}$. Several organisations, associations, and networks work alongside the government to attempt to reach these goals. Among these are l'Association Sénégalaise pour le Bien-Etre Familial (ASBE-Senegalese Association for Family Well-Being), 
Comité Sénégalais sur les Pratiques Traditionnelles Ayant Effet sur la Santé de la Mère at de I'Enfant (COFESEPRAT_National Committee for the Abandonment of Harmful Practices Affecting Women and Children, Senegal); ENDA - ACAS (Environment and Development Action -Action in Casamance); the Siggel Jigeen network (Network for the Empowerment of Women); Femmes et Société (Women and Society); le Collectif des Femmes Parlementaires (Women Parliamentarians Collective); Réseau des Parlementaires en Population et Développment (Network of Parliamentarians on Population and Development); Réseau des Journalistes en Population et Développement (Network of Journalists on Population and Development); Réseau des Communicateurs Traditionnels (Network of Traditional Communicators); Projet Développement Holistique des Filles (Girls' Holistic Development Project); and Tostan. A great deal of attention has focused on the Community Empowerment Programme developed by the NGO Tostan, noting its correspondence with key aspects of social norms theory (UNICEF 2007; UNICEF 2010). Tostan began to work with Senegalese communities in 1991, and in 1997 their nonformal education programme led to the first public declaration to end FGM/C (Gillespie and Melching 2010). To date, more than 4,000 Senegalese communities have participated in declarations to abandon FGM/C. The Développement Holistique des Filles project also uses nonformal education to facilitate change in social norms (albeit on a smaller scale), and actively engages grandmothers to guide discussions designed to foster critical reflection on cultural practices that influence the well-being of girls, including FGM/C (Musoko, Scoppa, and Manoncourt 2012). To varying degrees, these diverse initiatives technical and financial support from partners in the international community (UNICEF, WHO, UNFPA, UNIFEM, GTZ, and other foundations) for the implementation of their programmes.

The prevalence and distribution of $\mathrm{FGM} / \mathrm{C}$ has been measured in a series of Demographic and Health Surveys (DHS); the first survey with a module on FGM/C was implemented in 2005, repeated in 2010-11, and since 2014 has been measured using a continuous survey system. Over this period, the national prevalence of $\mathrm{FGM} / \mathrm{C}$ has declined moderately: from $28 \%$ in 2005 to $26 \%$ in 2010-11, and 24\% in 2015 and 2017 (Matanda et al. 2019). A geospatial analysis of the 2005 and 2010-11 DHS data revealed that several high prevalence regions remained "hot spots," bearing a consistently high FGM/C risk (Kandala and Shell-Duncan,2019); these include the entire

South Senegal Region. At the same time, the prevalence of FGM/C decreased between 2005 and 2010-11 in Central Senegal, becoming a very low FGM/C risk region in 2010-11. The results of these geospatial analyses were used to guide the selection of study communities in this current study, with the goal of comparing social interaction and their influence on FGM/C norms and practices.

\section{Study Population}

The research reported here is a qualitative investigation of the social interaction and social influence regarding $\mathrm{FGM} / \mathrm{C}$ in four communities: two from a low-prevalence region in Central Senegal, and two from a high-prevalence region in the South. These sites were selected to provide a rich mixture of perspectives and practices related to the care of young girls, including the practice of excision, and to uncover various ways that social interactions may serve to form, uphold, challenge, and potentially transform socially embedded norms and practices. Schema theory asserts that social change happens through processes that create disequilibrium in which information or experience is at odds with existing schema (Strauss and Quinn 1997). Such disequilibrium is posited to motivate realignment of old schema, changing associated norms and practices. It is these processes that we seek to investigate in this research.

The practice of $F G M / C$ is found in both study sites, but in distinctly different contexts. In Central Senegal, the prevalence of FGM/C is low (6\%), and declining (Kandala and Shell-Duncan 2019). Rural communities are economically based in subsistence and commercial agricultural production. 
Being proximate to main peanut trading and processing centers, this region was once bolstered by commercial peanut production. However, setbacks have been experienced due to drought, poor land quality, and a marked reduction in the peanut trade following privatisation of the agricultural sector (Simpson 2002; Kingston et al. 2011). Communities are ethnically mixed, including Mandinka, Sereer, Serahulé, Diola, Wolof, and other ethnic groups. Ethnic identification and FGM/C practices are said to follow patrilineal descent, but in some cases ethnic identity is fluid and situational, and FGM/C practices are contested and negotiated.

The South Senegal study sites are much more homogeneous in terms of ethnicity and FGM/C practices: nearly all residents are Pulaar (known in English as Fula or Fulani) and come from families that have long practiced $\mathrm{FGM} / \mathrm{C}$. In the Pulaar language, they are referred to as "Haalpulaar," meaning "people who speak Pulaar." In Senegal, the Haalpulaar are understood to be two groups, the "Toucouleur," who are residents of Fouta Toro in North Senegal, and the "Peul": current or former semi-nomadic pastoralists. However, as O'Neill notes, "the Haalpulaar'en themselves do not refer to themselves in such a way in Pulaar and the origin of this distinction is thought to be rooted in the French colonial administration" (2013: 27). The Pulaar in South Senegal identify as semi-nomadic pastoralists, although they have resided in permanent settlements since the 1930s in response to a combination of drought, privatisation of land, and government policies discouraging nomadism. Similar to the Central Senegal research sites, these communities are small agricultural communities connected by dirt roads to main roads that lead to larger towns and market centres. Nearly every family has a variable portion of land that is owned and inherited by men. Immediately surrounding the town are plots of land that are used year-round for subsistence gardening. Beyond that are larger tracts of land used to grow cash crops such as peanuts and millet. Grazing fields for cattle are located at an even greater distance from the town.

In both study regions, families live patrilocally in multigenerational households in structures known as compounds. Co-residing family members often include parents, paternal grandparents, aunts, uncles, and co-wives. Men are typically in charge of herding, large scale farming using horsedrawn plows, and other income-generating activities and skilled trades. Women are most often responsible for subsistence gardening, and in some instances, market trade. These roles are considered complementary, and men and women share responsibility for contributing to the wellbeing of the family. The concept of well-being draws on a holistic understanding of health (Botte 1999), and consequently child-care practices reflect a concern for their combined physical, mental, moral, and spiritual development.

In this study we seek to investigate the norms and meanings associated with FGM/C, the possible ways that these norms and practices have become challenged or altered, and the social interactions that shape FGM/C norms, preferences, and behaviour.

\section{Objectives and Research Questions}

The broad objective is to gain an improved understanding of the individual attributes, social network characteristics, and possible intersecting axes of power that influence FGM/C decisionmaking, and can shape or alter the dynamics of change. The results will contribute to an improved understanding of the empirical decision-making process, and will allow us to assess and revise theoretical models of behaviour change that guide the design of intervention efforts.

\section{Research questions}

In this research, we investigate the following questions:

- Who are the decision-makers regarding whether or not to perform FGM/C on young girls?

- Who are their network partners? That is, from whom do they seek advice or support?

- What are the patterns of power and influence among network members? 
- What cultural meanings and social norms are associated with the practice of FGM/C?

- When and where are these norms being contested?

- What factors are encouraging or discouraging the practice of $\mathrm{FGM} / \mathrm{C}$ ?

- What structural factors are influencing FGM/C decision-making?

\section{Methods}

This study used a mixed-methods design to illuminate social norms and the social interactions that influence the continuation, change or abandonment of the practice of FGM/C. The study employed a parallel mixed design for social network analysis that involved first conducting in-depth qualitative network interviews, and then quantifying data elicited in these interviews. These data were complemented by key informant interviews and focus group data to identify social norms associated with $\mathrm{FGM} / \mathrm{C}$ and factors influencing changes in the practice.

\section{Subject Recruitment}

Initial contact with study communities was made by contacting the local leaders (both women and men), and describing the purpose and design of the study. Upon receiving permission from the leaders to proceed with the study, a list was compiled of all community residents meeting the eligibility criteria for each arm of the study (ethnographic network interviews, key informant interviews, and focus group discussions).

Key informant interviews were conducted with three categories of people: 1) community leaders, 2) healthcare professionals, and 3) educators. The purpose of these interviews was to solicit respondents' views on $\mathrm{FGM} / \mathrm{C}$, and to understand their professional experiences related to this issue. They were asked to explain their interactions with anti-FGM/C programmes and campaigns, their roles in community education and advocacy, and their views about the varied efforts aimed at ending $\mathrm{FGM} / \mathrm{C}$ in their communities.

Ethnographic network interviews began with randomly selecting mothers of children between the ages of 3 months and 5 years from the list of eligible community residents. A total of 40 mothers were selected as primary respondents to participate in these ethnographic network interviews. Using a snowball methodology, those identified by mothers as influential in decision-making concerning their daughters were invited to become secondary respondents and asked to participate in an ethnographic network interview. In total, 93 interviews (primary and secondary respondents) were completed.

A factorial focus group design was employed, allowing comparison across different subgroups (Shell-Duncan et al. 2018; Shell-Duncan et al. 2019a). This involved holding focus group discussions with separate groups, each homogeneous in terms of control characteristics (residing in the study community for at least one year, being from a family that once practiced FGM/C), and break characteristics that differentiate each group. Six focus groups were held in each region (South and Central Senegal) composed along break characteristics of age and gender: younger women (18-29 years), middle aged women (30-49 years), older women (ages 50+), younger men (18-29 years), middle aged men (30-49 years), and older men (age 50+). Each focus group had 5-6 participants. Inclusion criteria were being member of the study community, while exclusion criteria were having provided a key informant or social network interview.

\section{Data Collection Instruments, Field Team Training, and Pre-Testing}

In June 2016, a one-week training session was held to introduce the data collection team to basic concepts in network analysis, overall study objectives and design, interview and consent protocols, and techniques for data collection and storage. A mixed-gender and linguistically diverse team was 
assembled to assure that interviews could be conducted by a same-sex interviewer and in the respondents' language of choice. Guidelines for key informant interviews and focus group discussions were translated into local languages, back-translated by another translator, and differences were reconciled. A reference guide was developed to explain the protocol for the design and implementation of factorial focus groups; this guide has been published by Population Council and is available online (Shell-Duncan et al. 2019a). A reference guide for conducting qualitative network interviews that involved the co-creation of a social network map (sociogram) was also developed (Shell-Duncan et al. 2019b). Following training at the GRAG office in Dakar, an initial pre-test was conducted in Mbour (60 miles outside of Dakar). This was followed by a debriefing feedback session and revision of data collection instruments. A second round of pretesting took place in South Senegal. The guidelines and data collection instruments for social network interviews are available in the reference guide, as are details of the lessons learned during pre-testing (Shell-Duncan et al. 2019b). The guidelines for key informant interviews and focus group discussions are found in Appendix A.

\section{Data Collection Protocols}

The interviews were digitally audio recorded, transcribed, and translated the GRAG office in Dakar. The transcripts were shared with the data analysis team and reviewed for clarity and completeness. Once all queries were resolved, the transcripts were anonymised, and digital files were deleted.

At the outset of the study, 24 key informant interviews were conducted one-on-one with leaders, educators and health care professionals in each study region. Focus group discussions were conducted by two trained fieldworkers, one who moderated the discussion and the another who digitally recorded the session and took notes to guide the transcription of recordings. They were trained to address problems that are known to arise in focus group discussion: there is a risk that one or two participants may dominate a discussion, or that critical comments may silence members with dissenting views. The fieldworkers were trained to encourage open participation in a supportive environment that invited exploration of a range of opinions. At the end of each FGD, the fieldworkers made notes about body language and tone, explained jokes or statements with double-meaning, and any other relevant observations that came from "closeness" to the data that would aid in interpretation and analysis.

The study also employed in-depth social network interviews to illuminate not only how people are personally connected, but also the degree to which these specific connections impact decisions concerning childcare. Using a parallel mixed-method design, we also quantified the results of our social network interviews. A database has been created that provides information on name generators that elicited each named network partner, demographic characteristics of each network partner, patterns and types of social support, levels of influence on decisions regarding the wellbeing of young girls, and perceived views on support for excision. In all, the data produced include: 1) a transcript of the interview, 2) a network map (sociogram) created in conjunction with the respondent, and 3) a database that includes information on the name generators used to identify each network partner, demographic characteristics of interviewees (ego) and their network partners (alters), patterns of social support, and information on level of influence (see Shell-Duncan et al. $2019 \mathrm{~b}$ for further details).

\section{Data analysis}

A grounded theory approach was used to analyse transcripts from the key informant interviews. Grounded theory is an iterative process that involves successively engaging in more focused rounds of coding text to identify themes or categories, writing memos to explore each theme, and 
identifying relations among themes or categories (Bernard 2011; Creswell 2007). A team approach was used, involving double-coding transcripts, and making comparisons to achieve consistency between coders. An initial set of topical codes was created, and expanded codes and sub-codes were added in the initial set of interviews. The first round of coding involved labeling key topics; this was followed by a round of analytical coding that identified themes. Analytical memos were then created.

Focus group transcripts were similarly coded in the first step of conducting a factorial analysis using methods described in detail by Shell-Duncan and colleagues (2019a). Briefly, initial coding was followed by the creation of summary documents of the themes raised in each FGD. Notes were made on the emphasis placed on each theme (ranging from a passing remark to a prolonged topic of conversation), and the degree of consensus or disagreement on each topic. This was used to identify norms, and the strength of the norms - what Cislaghi and colleagues (2019) call a normative spectrum that can range from strong to weak or absent. This approach was used to identify the degree to which norms surrounding FGM/C were shared, contested, or rejected by the members of the group. Following methods developed by Knodel (1993) and extended by ShellDuncan and colleagues (2018), we created an overview grid to make comparisons across different FGDs, organised along the line of break characteristics: gender, generation, and region (South or Central Senegal). This grid was then used to create a summary matrix for overarching themes and sub-themes, allowing for identification of patterns in which norms are being upheld or challenged.

The qualitative social network interviews were used to generate three forms of data: 1) a qualitative narrative that centered on naming network partners and identifying those who are involved in decision-making or influential on matters of child well-being, and respondents' views and decisionmaking regarding $\mathrm{FGM} / \mathrm{C}$; 2) an interactively produced network map that depicts decision-makers and core influencers, level of influence, and types of social support; and 3) a list of names produced by each name-generator question, a survey on demographic data on each network partner appearing in the map, and a network density grid showing the relationships between these network partners. The interviews were conducted in the local language preferred by the respondent (in most cases Pulaar or Wolof), and digitally recorded. The recordings were translated into English or French and transcribed. Survey information was entered into a database and validated by relistening to each digitally-recorded interview and reviewing the transcribed interview. The network maps were photographed at the completion of the interview and used to create a digitised network map. The maps were validated by cross-checking against the written transcript and the database.

A comparative case-analysis approach was used to analyse the network maps in network interviews. This process involved simultaneously reviewing the network map and transcript for matched ego-alter pairs. The review was used to annotate the map, and then to produce a written case summary with illustrative quotes for each ego-alter combination. This process was done in teams, who then met to discuss key findings. The written case summary was finalised, and then the summary and annotated map were coded in duplicate, and a list of emerging themes was produced together by both coders. Key characteristics related to themes were recorded in a case comparison matrix.

Quantitative data analysis was conducted on all network interviews. Each respondent provided quantifiable demographic information, such as their age, marital status, and ethnicity. They were then asked to identify the people who comprise their social network (we refer to network members in this report as alters). The network data were collected by asking respondents a series of namegenerator questions that are designed to elicit the names of important alters in the individual's life. Name-generator questions can capture relationships that reflect many different dimensions of social interaction, such as affective relationships, resource-exchange relationships, and informational-exchange relationships. In this study, respondents were asked an extensive array of 
33 name-generator questions, which included questions on topics specific to childrearing such as "Who are the people who are most influential in your caregiving of your children?" to more general questions on relational aspects such as with whom the individual spends free time, or from whom they would borrow money (to see the full survey, see Shell-Duncan et al. 2019b). For each alter named, the respondent answered a series of additional quantifiable questions such as the relationship of the alter to themselves, the alter's marital status, and whether they believe the alter supports $\mathrm{FGM} / \mathrm{C}$. Respondents were also asked if the alter is a decision-maker regarding decisions specific to childrearing; in other words, a person who has direct power over matters such as whether or not to perform FGM/C. For alters that were not named as decision-makers, respondents were asked how influential the respondent considers that alter to be in their decisions regarding the care of their daughter.

With these interviews, we were able to create a quantitative dataset of the network data, by entering respondent information and alter information into Excel and matching them together. Using this process, we were able to make a dataset that included the information on all first- and second-degree respondents, including the number of alters that they named, and their own demographics. We also created a dyadic dataset, where we created one observation for each respondent-alter pair. Respondents provided an extensive array of answers for the relationships of the alters to themselves, which we broke down into a smaller number of categories. Seconddegree respondents were those individuals who were nominated by the first-degree respondents and then interviewed. Second-degree respondents were, therefore, included in the dataset both as survey respondents and as alters of those who originally nominated them. Using this data, we could then conduct descriptive analyses on the data, splitting them by region, and in some cases, by gender. Analyses included the gender breakdown of alters, the levels of influence broken down by alter's relationship to the respondent, the demographic differences between key influencers and decision-makers, and the ethnic makeup of respondents' core networks.

\section{Ethical considerations}

Ethics approval was provided by the Population Council in New York and the Comite National d'Ethique pour la Recherche en Santé (CNERS) (National Ethics Committee) in Senegal. In addition to reviewing the research protocol, informed consent documents, and procedures, CNERS also made a field site visit to South Senegal in October of 2016. They observed data collection to assess compliance with ethical considerations, and reviewed consent documents, data collection, and storage techniques to assure the protection of confidentiality.

\section{Results}

\section{FGM/C as a Practice in Flux: "New era, New Behaviour, New Way of Life"}

Previous research in Senegal more than a decade ago found that FGM/C was linked first and foremost to the concept of tradition, described through the often-repeated phrase, "we found it from our grandmothers" (Hernlund 2000; Shell-Duncan et al. 2010). The notions of tradition and respect for elders were closely intertwined, and a central way of venerating ancestors was by upholding their traditions. In our current research, the theme of upholding tradition was much more nuanced and complex, and varied substantially across our study sites in Central and South Senegal. Some viewed questioning excision practices to be an affront to elders by challenging their traditions. This view was most commonly expressed by young unmarried men and women who lack the authority to question the decisions made by older men and women. Among fathers and older women, the way in which excision is to be carried out, if at all, was subject to considerable debate. Although excision is described as a custom passed down from one generation to the next, whether and how the practice is carried out is constantly being assessed and revised in light of changing social 
circumstances. As O'Neill emphasised (2013: 126), the concept of tradition "does not mean that a practice never changes, but that it is reinvented and accorded value by each generation who take it up." The ubiquitous exposure to decades-long media campaigns and anti-FGM/C interventions have produced a new generation of young men and women raised in a climate of intense scrutiny of excision practices. These campaigns and interventions have produced increasingly polarised local debates about whether or how excision should continue. Numerous informants emphasised that modifications to traditional customs are inevitable, described by one Mandinka woman as "new era, new behaviour, and new way of life."

In both of our study sites, $\mathrm{FGM} / \mathrm{C}$ was described as a practice that formerly took place in the context of a coming-of-age ritual for girls. Often this unfolded in three stages. First, prepubescent girls were gathered in a group and taken to "the bush." There, girls participated in a series of adolescent initiation rites and excision was performed. Afterwards, girls remained secluded during their convalescence, and this period also served as a time in which they were trained by elder women on etiquette, morality, and sexuality. Finally, at the conclusion of the seclusion period, there was often a coming out ceremony in which girls danced back to the village and participated in a community-wide celebration that included feasting, music, dance, and masquerades. The ceremony celebrated the fact that initiates had been transformed into women, mature and trained to behave in a fashion deemed morally refined and civilised, and prepared to uphold social harmony and solidarity in their future role of wife and mother.

In the wake of long-term exposure to anti-FGM/C campaigns, residents in our study communities in both South and Central Senegal are acutely aware that this custom has been targeted for elimination. As a result, excision has, in many instances, shifted from a publicly celebrated rite of passage to a private, domestic affair carried out discretely. In Senegalese culture, sharing of intimate "secrets" creates vulnerability to ill-will or "bad eyes," heightening threats to the honour and reputation of a person, as well as their family or community. Protection from this vulnerability is offered through "sutureu," the act of using discretion while discussing delicate or private matters, and applies to a wide range of sensitive issues, including lending money; questioning the decisions of elders; and discussing matters such as sexuality, fertility, and pregnancy. When asked who she talks to about worrisome issues, one respondent replied, "I do not wish to go and expose my worries outside....You know, no one ever prays for her worries to be exposed outside her family" (55 year-old Sereer woman, Central Senegal). Another woman added:

"Today there is no one to trust. When you trust a person, you reveal your secrets. It is they who are going to tell them outside. Even your husband, sometimes you can't trust him because you tell him something, and that day he discloses it when everyone is sitting down."

-25-year-old Serahulé woman, Central Senegal

Heightened prudence, many believe, will prevent other people or unforeseen forces from exploiting one's weaknesses and compromising one's future goals. As it became a matter of public censure, excision was widely discussed in public as a concept, but carried out in "sutureu" - a highly private family affair-both in South and Central Senegal. For this reason, it has become increasingly common for girls to be cut in small groups or individually at home and if celebration occurs at all, it is only among the immediate family. Additionally, there has been a tendency to perform FGM/C at younger and younger ages to conceal the practice, as well as facilitate quicker healing. The age at cutting has now commonly dropped to infancy, well before girls can resist, be noticeably absent, or tell their friends what has happened.

"Those who do it hide it and do it at an early age, just after birth. Most of the time the circumcisers come and go into a house and the girl is brought and excised in the house." 
In fact, most of the young women interviewed who reported having been excised had no recollection of the event, having experienced it at such an early age. The training that once occurred during seclusion in the bush is now said to take place throughout childhood, with special training on sexuality taking place "in the bride's room" just before the wedding. For some people, however, the uncoupling of excision from ritual training has allowed the social importance to erode. Excision, we were told, is a custom that one must "simply do," like naming a newborn baby. This illustrates one of the many ways in which changing circumstances surrounding performing excision have led to active reassessment of its social meanings and value, along with re-appraisal of reasons to abandon the practice.

\section{Network Processes}

We identify four processes that capture important dynamics of social networks:

\section{Social Learning}

The process of social learning involves the sharing of information, not only on the social normative values surrounding the practice of excision, but also on the risks that must be averted or minimised among those who continue the practice. Among those who have altered or abandoned FGM/C, rationales for doing so are often shared. Throughout childhood, values associated with feminine and masculine ideals are inculcated through a process of gender socialisation. In the process of developing culturally shaped sensibilities and witnessing the performance of and reactions to culturally normalised gender roles, children internalise the cultural logic of gender-differentiated elements of everyday life. Through the process of genital cutting, children are oriented to what Boddy (2016: 50) calls "incompletely shared worlds" in which gender differences are made visibly distinct, socially recognised, and internalised. Thus, social interactions are formative in the inculcation of social norms, including gender norms, and moral norms that influence internalisation of values and attitudes consistent with cultural expectations of femininity and masculinity. For both females and males, circumcision practises are believed to play a crucial role in gender formation.

At the same time, every-day life includes ongoing exposure to anti-FGM/C messaging. Campaign messages are broadcast on radios; educational seminars are held at clinics, schools, and village meetings; a variety of NGOs arrive with community development programmes that include discouraging FGM/C as one of their objectives; and health professionals, community leaders, and teachers are trained and expected to deliver messages to "sensitise" the community regarding the adverse health outcomes of FGM/C, as well as its criminalisation. As a result, the fact that excision practises are subject to censure and targeted for criminal punishment is impossible to escape. Hence, the social learning process involves not only transmission of the social norms and values associated with upholding the practice of $\mathrm{FGM} / \mathrm{C}$, but also possible ways to respond to actors and institutions within and outside of the community who are opposed to the practice and are committed to bringing it to an end.

While the positive values associated with $\mathrm{FGM} / \mathrm{C}$ may provide a compelling rationale for conforming to the practice, it is important to note, as well, that these meanings are not static and are not prescriptive of the views or actions of a person or their family. Instead, as it becomes understood that current customs and values are in some instances questioned, new practises and cultural logics are introduced as possible options. As varied strategies to encourage abandonment of $\mathrm{FGM} / \mathrm{C}$ are implemented, people engage in a dynamic process of reassessing the advantages and disadvantages of maintaining, altering, or discarding previously widespread practises. To implement particular options, people must garner support and approval from those who have power and influence, as we explain below. Thus, internalised cultural logic for supporting, 
opposing, or questioning excision, as well as possible strategies for influencing a particular course of action, are learned through these social interactions.

\section{Social Pressure}

Though processes of social interaction, people develop beliefs about whether others within their networks support and uphold the practice of FGM/C as well as beliefs about the positive rewards that are bestowed on those who comply with normative expectations and the negative sanctions that are imposed on those who fail to comply. Rewards may include garnering respect, social inclusion, and social support; and negative sanctions may include derision and social exclusion. Importantly, interactions with network members create spaces in which these social sanctions may be realised, but also questioned. Easing sanctions through means such as reducing discrimination against uncut women or weakening the link between FGM/C and marriageability can open the possibility of abandonment of $\mathrm{FGM} / \mathrm{C}$. In addition to sanctions associated with social norms, people are actively assessing the costs of performing FGM/C in terms of health risks and risk of criminal punishment. Legal norms can come into play when at least some community members are aware of the legal restriction and place a value upon legal obedience. This gives rise to the real possibility that those who fail to comply with the law will be detected and reported, and thus are vulnerable to criminal punishment. This means that in a community where some members do not support the continuation of $\mathrm{FGM} / \mathrm{C}$, have become aware of the legal restriction, have a professional responsibility to report those who violate the law, and/or view the force of law as insurmountable, the pressure of legal norms must be weighed against social norms in support of FGM/C. Our data show that varied levels of social pressures to conform with FGM/C can co-exist alongside pressures aimed at discouraging the practice. As a result, for some, complexity has arisen around a seemingly simple question: "Do you support the continuation of FGM/C?"

\section{Network Members with Divergent Views}

In addition to the possibility that any single individual may be internally conflicted about his or her preferences regarding FGM/C, members of a person's social network may hold divergent views. As is true in many studies on $\mathrm{FGM} / \mathrm{C}$, we find that decision-making is rarely made in isolation by a girl's mother. Instead, decisions are often made by multiple decision-makers, and each decisionmaker may, in turn, be influenced by members of their own personal social networks. We find that it is not necessarily the case that differences of opinion are negotiated until a consensus is reached. Thus, through our social network interviews, we explore how these differences of opinion are understood, expressed, possibly negotiated, and whether and how decisions regarding excision are reached. Our data show that it is not uncommon for social networks to be comprised of people with varied views on whether or how FGM/C should be carried out. Prior research on the influence of social networks on health behaviours has shown that the perceived preferences of network partners can be an even stronger predictor of decision-making outcomes than individual preferences. As we will show in our comparative case analysis below, we find this to be true at times, depending on the power and persuasion held by that person. Thus, a crucial element of understanding network dynamics involves revealing intersecting of lines of authority and hierarchies of power.

\section{Intersecting Lines of Authority and Hierarchies of Power and Influence}

Network studies also provide a useful tool for examining differences in levels of influence and power of persuasion when multiple people are involved in FGM/C decision-making. A common finding in studies of decision-making regarding $\mathrm{FGM} / \mathrm{C}$ is that young mothers often report having low self-efficacy, defined as confidence in their ability to influence the outcome. Their inability to independently shape decisions is rooted in their subordinate positions within hierarchies of power. 
These hierarchies may have multiple axes that intersect along lines that include, but are not limited to, gender. Our analyses of patterns of influence within social networks explore multiple dimensions that simultaneously influence patterns of power and influence over FGM/C, including generation, gender, social status, ethnicity, locality, and broader structural inequalities in Senegalese society.

The network dynamics listed above are illuminated in our analyses of key informant interviews, focus group discussions, and case comparisons of ethnographic network interviews. We use these data to achieve two aims:

AIM 1: Shed light on understanding factors that encourage $F G M / C$, including the benefits accrued from complying with social norms, and factors that discourage the continuation of the practice;

AIM 2: Examine the social interactions that are salient in forming and shaping these norms and examine interesting axes of power and decision-making among social network members.

\section{Factors Promoting or Challenging the Practice of FGM/C}

To understand how norms and meanings associated with $\mathrm{FGM} / \mathrm{C}$ have evolved over time, this study conducted focus group discussions with community members in Central and South Senegal. The discussions explored the degree to which norms potentially vary, not just across study sites, but also along the lines of gender and generation. The themes that emerged fall into two general domains: those centred on the social benefits that provide an incentive to perform $\mathrm{FGM} / \mathrm{C}$, and those that actively discourage the practice (Table 1).

Table 1: Factors encouraging and discouraging the practice of FGM/C

\begin{tabular}{|c|c|c|c|}
\hline Domain & & Overarching Theme & Sub-themes \\
\hline \multirow{8}{*}{$\begin{array}{l}\text { Factors } \\
\text { encouraging } \\
\text { FGM/C } \\
\text { social benefits } \\
\text { (norms) }\end{array}$} & \multirow{3}{*}{1.} & \multirow{3}{*}{ Embodiment of feminine virtue } & Creating gendered bodies \\
\hline & & & Moral transformation \\
\hline & & & Sexual restraint \\
\hline & \multirow{2}{*}{2.} & \multirow{2}{*}{ Pressure to conform } & Inclusion and social support \\
\hline & & & Social difference and discrimination \\
\hline & \multirow{3}{*}{3.} & \multirow{3}{*}{ Marriageability } & Matrimonial strategy \\
\hline & & & Men's preferences \\
\hline & & & Domestic harmony \\
\hline & & & \\
\hline \multirow{8}{*}{$\begin{array}{l}\text { Factors } \\
\text { discouraging } \\
\text { FGM/C }\end{array}$} & \multirow{3}{*}{4.} & \multirow{3}{*}{ Legal ban on excision } & Knowledge of the law \\
\hline & & & Fear of detection and prosecution \\
\hline & & & Restricted access to health care \\
\hline & \multirow{3}{*}{5.} & \multirow{3}{*}{ Health risks } & Awareness of health risks \\
\hline & & & Acceptance of the health risk message \\
\hline & & & Deter/deny access to health care \\
\hline & \multirow{2}{*}{6.} & \multirow{2}{*}{$\begin{array}{l}\text { Male preferences for an uncut } \\
\text { marital partner }\end{array}$} & Sexual pleasure \\
\hline & & & Economic concerns \\
\hline
\end{tabular}

\section{Embodiment of feminine virtue}

Throughout our study communities, male circumcision and female circumcision were once viewed as complementary practises in the construction of moral personhood, religious identity, and gendered bodies. While the requirement for males to be circumcised is clearly laid out in the Quran, the religious mandate for female circumcision is open to interpretation. As one informant noted: 
"Everyone needs to become circumcised to become mature. Like boys, girls should be circumcised.... In the Holy Quran I have seen nowhere that says girls should not be circumcised. We have to follow God's command."

-32-year-old Pulaar man, South Senegal

Women in both of our study sites recounted that excision was once widely regarded as essential for becoming "a real woman," meaning that regardless of age, an uncut woman would hold the social status of a girl ("they will not grow up"). Our findings fit with studies across East and West African societies that view gender as created, rather than as an attribute of "natural" bodies (e.g., Boddy 1982, Ahmadu 2005). Participants emphasised that circumcision is integral to the transition from an androgynous state of infancy or childhood to a gendered, and fully sex-differentiated state of adulthood. Men and women are rendered physically distinct and socially complete by their respective genital operations. A girl's body is feminised by the removal of boyish outer flesh, producing a body that is clean and pure, and conforms with aesthetic and moral expectations of a female who will become a socially recognised adult woman, and capable of realising her reproductive potential:

"I have heard that an uncircumcised woman cannot have a child....So personally, I will have my daughters excised"

-19-year-old Pulaar woman, Central Senegal

Hence, sexually differentiated bodies are produced in a context of gender socialisation which hones culturally shaped feminine or masculine ideals that establish differences in sensibilities and adult perspectives. At very young ages, children are cared for in the family compound by their mothers and other female family members. They are trained early on to greet elders in a respectful manner and to obey their requests; showing deference and respect to elders is expected of both young boys and girls. As they become older, gender segregation and division of roles becomes an important element of socialisation, orienting children to their gender-differentiated worlds. Young boys begin to eat meals with men, separate from women and girls, and are given increasing freedom to move throughout the community, such as running errands. Girls, by contrast, are expected to stay at home, except when attending school, and are given increased responsibility in domestic duties, including household chores and care of younger children. By the time girls approach an age of marriageability, they have often been taken out of school to avoid "corrupting" social influences, and to assure that they have demonstrated their proficiency at running a household. Girls who are considered well raised are commonly those who have been taught to behave in a respectful and restrained fashion in their natal home. These girls are therefore likely to show deference to their future husband and his family, primarily their future mothers-in-law, and uphold the hierarchies of power and authority that guide domestic harmony and social cohesion. In this context, excision is seen by many to be a constitutive element in the construction of identity and personhood upholding meaning beyond simply that of body modification; the physical act of cutting can have a morally transformative value, as virtue and honour become inscribed upon the body.

According to proponents of excision, women who have been cut are described as "clean" and "pure," as well as civilised and morally superior to uncut women. Strong value is placed on protecting virginity until marriage, and girls who have been excised are believed to be more capable of exercising sexual restraint, thereby reducing the risk of engaging in wanton behaviour. Hence, gender differences are made visibly distinct, socially recognised, and internalised in excised women who embody feminine virtues.

In the past, the seclusion and training that accompanied excision was viewed as an occasion when values on feminine virtue were imparted: 
"In the past, the practice of excision was done in the bush and everyone convened to help in the preparation of the ceremony before sending the girls to the bush. After the ceremony, the girls left for the bush with the exciser, and stayed there for a period of 15 days for learning.... They excised girls at 12 or 13 years of age, and they were taught to distinguish good from bad and retain the teachings given in the bush."

$$
\text { -30-year-old Pulaar woman, South Senegal }
$$

'We were inculcated with traditional education about elders' wisdom. This was relevant because it taught one how to behave, how to talk to people, how to respect elders, my uncles, my father and mother...It was important because it improved a girl's standing."

$$
\text { -42-year-old Sereer woman, Central Senegal }
$$

Today, with excision being performed at very young ages, such training takes part outside of the ritual context, but lays the groundwork for moral education that is said to extend throughout childhood. However, with the uncoupling of excision and training, many Central Senegalese no longer regard excision as a requisite element for educating a girl on displaying respect and feminine virtues. Increasingly people contend that "girls can be educated in homes even if they are not circumcised" (29-year-old Pulaar woman, Central Senegal). Additionally, the importance of physical and social transformation to womanhood once conferred by the practice of excision has now diminished. As one Mandinka woman explained, "the elders have always said that thanks to excision, we become real women," but added that nowadays when people regard cut and uncut women, "we agree there is no difference" (30-year-old Mandinka woman, Central Senegal).

Training on feminine virtue has also become uncoupled from the act of physical cutting in South Senegal, as the age of cutting had dropped from peri-adolescence to infancy. However, conservative views about $\mathrm{FGM} / \mathrm{C}$ as a requisite element of training on gender relations, and their importance in maintaining social order and cohesion, remain largely unchallenged. Both men and women regard uncut women as morally inferior, and the unrestrained sexual desire of uncut women is viewed as morally perilous.

\section{Pressure to conform}

Whereas women who have been excised are often praised for being clean and pure, uncut women are at times described in terms of condemnation and repulsion: they "smell," and are "impure" and are contemptuously insulted as "solima"-a powerful invective meaning not only "uncut," but also dirty, ignorant, wanton, and rude. Particularly in South Senegal, the negative sanctions that would befall an uncut woman were widely acknowledged: people might refuse to eat food prepared by an uncut woman, she might not be allowed to attend family events and ceremonies such as weddings, and she would be excluded from serious discussions among mature women, as well as household decision-making. Both women and men alike recognised that cut status affords women inclusion, acceptance and social support from women in the community; for men this presented a powerful disincentive to marrying an uncut woman. A 39-year-old Pulaar man in South Senegal explained:

"They [my extended family] would scorn the uncirumcised girl. They would refer to her as "solima", being in a state of impurity, you cannot say she is giving off some stench but people would say she has some "bad smell." If you are sharing a room she will fill it with that smell. That is why some people try to denigrate the uncircumcised woman. And she would feel very uncomfortable."

Most agree that the main source of strife would stem from interactions among women, particularly co-wives, and not with men: 
"For this situation, it is women who are attached to it. They call uncircumcised women 'solimas' and it hurts them. A woman who has not been circumcised did not dare stay with a group; she would rather be around her mother because she feels embarrassed. This creates discrimination. However, for men this discrimination does not exist"

-50-year-old Pulaar man (with 4 wives), South Senegal

Use of the insult "solima" reveals the way that public discourses about excision serve to produce stigma. The classic work of sociologist Erving Goffman (1963) describes stigma as the phenomenon in which there is a gap between a person's actual social identity (attributes a person genuinely possesses) and their virtual social identity, which involves assumptions about a person based on normative expectations linked to a particular attribute that can lead to social rejection for failure to conform. In this case, being cut is intimately linked to public perceptions of moral virtue and social acceptance, and demarcating boundaries of social difference and status. An uncut woman, by contrast, is considered morally untethered, and therefore discredited and disqualified from full social acceptance. This fits with broader literature in which scholars focusing on the intersectionality of race, class, and gender find that social differences are often partially constituted within the realm of sexuality (Wilkins 2008). It can be argued that this insult captures the way in which stigma is linked to women's sexual desire and amplifies perceived social differences to define insider/outsider status, serving as an act of what has been called "defensive othering" (Schwalbe et al. 2000): women, as subordinates to men, fear further marginalisation and collaborate in gender-based stigmatisation in an effort to distance themselves from a more oppressed category.

However, focusing on women's involvement in excision as a means of colluding with patriarchal systems and deflecting stigma to uncut women ignores the social benefits of the practice for women themselves; it overlooks the way in which excision regulates access of young women to the social capital of older women, and elaborate hierarchies of power between women, namely the power of elder women over younger women (Shell-Duncan et al. 2011). These social benefits operate as positive sanctions (inclusion, access to resources, power) upholding the practice of excision. Additionally, it is important to understand how insults and exclusion serve as negative sanctions for failure to comply with dominant gender norms. This fits with a body of scholarship that interrogates the ways in which practices and customs constitute a means of "doing gender"the way that gender norms are played out in public spaces and conform to prevailing notions of feminine ideals (West and Zimmerman 1987). Emphasis is placed upon how gender norms are embedded in everyday interactions, how gender is performed, how virtue is perceived, and how women are sanctioned for failing to conform to gender norms (Armstrong et al. 2014).

In Central Senegal, a profound shift has taken place: while discrimination against women who were not excised was once commonly witnessed, this is now diminishing significantly, although certainly not entirely. While normative expectations that result in stigmatising discourses are often assumed difficult to alter, they have, in fact receded in Central Senegal. In this low-prevalence region, people who come from families that traditionally practised FGM/C live alongside families who have never practised cutting, and they frequently interact with one another. Over time, the "othering" of uncut women has lessened, allowing for a slow and subtle reworking of dominant cultural norms, and now favouring greater tolerance toward uncut women. Uncut women are no longer simply or clearly relegated to outsider status by those who practise cutting. The public scathing, mockery, and discrimination that was once frequently directed at uncut women is considered inappropriate. One uncut Serahule woman explained that in the past, elders would tell an uncut girl "that she knew nothing....But now everyone is equal and people do not perceive any difference at this level." Her friend, a leader from the women's association concurred: "Now doing or without doing the practice people will not call you 'solima'" (42-year-old Serahulé woman, Central Senegal). Hence, a 
profound sea change is underway in the ethnically mixed regions of Central Senegal, emphasising new norms around tolerance of cultural diversity, including not practising FGM/C. This begs the question: how can programmes aimed at ending FGM/C support the reduction of stigmatising discourses and, hence, the discrimination experienced by uncut women?

\section{Marriageability}

While FGM/C has been described as a matrimonial strategy in many regions of Africa, in our study communities, we find widely divergent views on the link between excision and marriageability. In the original application of social norms theory to FGM/C, marriageability was identified as the main engine driving the origins and persistence of the practice (Mackie 1996; 2000). According to this theory, FGM/C emerged under highly stratified socioeconomic conditions as a means of securing better marriage opportunities for daughters. Conditions of extreme resource inequality and polygyny were posited to underlie intense competition for marriage to powerful elite men. Mackie hypothesised that FGM/C served to signal marital fidelity, and thus created a competitive advantage in the marriage market. As the practice spread, it became a prerequisite to marriage, and was locked in place by interdependent expectations: parents believed all their daughters' peers would be cut, and prospective husbands believed that potential wives would be cut. Those who deviated from these shared norms and expectations would risk losing marriage opportunities and legitimate reproduction. Because no individual family can stop FGM/C without incurring such costs, social norms theory predicts that change in FGM/C will result from coordinated change in intermarrying groups to abandon the practice and create a marriage market for uncut girls.

Despite being central in the marriageability hypothesis, marital fidelity was not a strong concern in either of our Senegalese study sites. Other norms linked to marriageability were expressed but were quite different across our two study regions. In Central Senegal, FGM/C was only weakly associated with marriageability via concerns about maintaining virginity prior to marriage. Both older men and women in Central Senegal expressed that it has become increasingly difficult to control the sexual behaviour of unmarried adolescent girls, giving rise to concerns that their granddaughters may be "ruined," or worse yet, become pregnant out of wedlock. By harming the reputation of the girl (and her family), and threatening the marriage prospects for a girl, this perceived growing problem was viewed as a sign that the social order has become threatened. They disagreed, however, about whether this trend was caused by no longer excising girls. In this region, "love" marriages have begun to replace arranged marriages, and interethnic marriage and FGM/C discordant marriages have become increasingly common. Hence, there was strong consensus that FGM/C no longer directly influences marriage prospects:

"It used to happen before, people saying 'I will not marry a Wolof, a Mandinka, Sereer, or Diola.' And this is not happening nowadays."

\section{-43-year-old Mandinka man, Central Senegal}

"I do not know any benefit as per men. I know that it's a tradition but do not know. I have travelled to Pulaar, Bambara and Sereer communities, but to say that it is important to men or it benefits women this way to get husbands, no."

$$
\text { -44-year-old Mandinka man, Central Senegal }
$$

By sharp contrast, respondents in South Senegal strongly viewed FGM/C as a prerequisite to marriage. Our data suggest that the issue of marriageability is salient both directly and indirectly: 1) directly in terms of influencing chances of securing a good marriage; and 2) indirectly through concerns regarding harmony in the marital home, and beliefs about the link between $F G M / C$, sexual pleasure, and men's virility.

In South Senegal, marriages are most often arranged by the families of the bride and groom, with a preference for endogamous cross-cousin marriage. Endogamy, it is argued, affords stability for 
the couple and promotes social unity, solidarity, and social order. As the practice of FGM/C has been near universal among Pulaar families in this region, the excision status of a potential bride was assumed. However, now that abandonment efforts have been underway for many years, the prospect that a potential bride could be uncut has become a possibility. Some Pulaar men, but not women, speculated than an uncut woman would have serious challenges in obtaining a husband, and offered this as an important reason to uphold the practice:

"An uncircumcised woman has no value and she will not obtain a husband." -24-year-old Pulaar man, South Senegal

"Personally, I will not marry a wife who has not been circumcised. Marrying an uncut woman is an ugly fact. It is not normal."

$$
\text { -32-year-old Pulaar man, South Senegal }
$$

Men commonly expressed repulsion to the image of uncut genitals, describing a clitoris that can grow into a penis-like appendage that can become an obstacle not only for childbirth, but also for intercourse.

"If you are with an uncircumcised woman, you feel something rubbing, and it is the clitoris. The circumcised woman makes it easier during sexual intercourse. For this reason, men prefer circumcised women."

-43-year-old Pulaar man, South Senegal

Moreover, men's aversion to the image of uncut female genitals is intimately intertwined with concerns about potential sexual insatiability of uncut women.

"An uncircumcised woman is not easily satisfied sexually; men have difficulties with their sexual satisfaction. Personally, I experienced uncircumcised women and circumcised, but the most pleasing was with circumcised. For others, there is more tiredness than pleasure, especially if the man is not powerful and strong. The circumcised girl gives exceptional pleasure."

-45-year-old Pulaar man, South Senegal

Uncut women's violations of gender norms were described as a threat to men's virility:

"I heard that a man is impotent in front of an uncircumcised woman." -23-year-old Pulaar man, South Senegal

"A man couldn't do anything in front of an uncircumcised woman during marriage. He couldn't consummate his marriage."

-63-year-old Pulaar woman, South Senegal

Another factor believed to hinder an uncut woman's marriage prospects is not simply men's moral and aesthetic preferences for an excised wife, but the prospect of resistance by a man's extended family members, and the possibility of generating familial discord:

"For example, you can fall in love with an uncircumcised girl. You love that woman and that is your vision. But for the family....you know that you need your family's consent before getting married in our society. The man should first discuss with the family. You can marry an uncircumcised woman while you are the only one who agreed. No one agrees in the family. Even if you honour her, no one would respect her in the family."

-24-year-old Pulaar man, South Senegal

Although inter-ethnic and FGM/C discordant marriages are rare in this region, people agreed that the presence of an uncut wife would generate conflict in the extended family, and this concern underlies men's stated preference to marry excised women. By contrast, in Central Senegal, where 
FGM/C-discordant marriage is far from unheard of, men noted that harmony in the marital home is an issue that needs to be managed carefully, and stressed the importance of treating all women equally, whether excised or not. Most men and women in Central Sengal, however, insisted that there are no differences between cut and uncut women, sexually or otherwise, and that excision status has no bearing on considerations of a woman as a potential marriage partner.

\section{Responses to the law banning FGM/C}

Since passage of the 1999 law criminalising FGM/C, the international community has monitored Senegal's success at implementing the law. This is measured in terms of efforts to educate officials and the general public about the restriction imposed by the criminal code, setting up systems for monitoring and reporting suspected violators, carrying out prosecutions that result in conviction and strict application of penalties. Recent reports provide a mixed review of Senegal's "progress" at implementing the law (Ndiaye 2010; Middelburg 2016; 28TooMany, 2018). The tension between "crime" and "culture" appears to be recognised by Senegal's judiciary by handing down reduced or suspended sentences, despite criticism by the international community (28TooMany 2018). At the same time, there has been continued research on whether legal strategies are an effective component of efforts designed to accelerate the abandonment of FGM/C (Ndiaye, 2010; ShellDuncan et al. 2013; Middelburg 2016; Camilotti 2016).

Theories on the use of law in social reform fall into two main schools of thought (Shell-Duncan et al. 2013). First, the law and economics paradigm suggests that people look to the law as a source of rules and enforcement mechanisms, and that punitive measures for violation of laws serves as a deterrent for criminalised behaviours. By contrast, law and society scholars note that criminal sanctions may have a limited ability to discourage an outlawed behaviour if the legal norm stands in sharp contrast to the local cultural values and social norms. The influence of the expectations of the local social group may be quite powerful when there are strong social sanctions for violating social norms. In such cases, social norms can hold more sway than legal regulations (Posner 2000; Ellickson 1991). To this end, we ask: Do people know that FGM/C has become criminalised? Do they find the force of law to be a reason to abandon $F G M / C$ ? Does the spectre of criminal punishment outweigh the social values ascribed to the practice of $F G M / C$ ?

Concerns about enforcement of the law banning FGM/C varied dramatically across our two study sites. In Central Senegal, when focus group participants were asked about advantages or disadvantages of FGM/C, the issue of the legal ban was rarely raised. During individual interviews, questions about the law were raised directly. Although most respondents were aware of the existence of the law, many had only a vague understanding of its contents. Moreover, none of the respondents was familiar with any of cases of criminal prosecutions related to FGM/C in Senegal.

By contrast, the public discourse surrounding the criminalisation of FGM/C was sharply different in South Senegal. This may be influenced by the fact that this region has been disproportionately targeted, and there has been a recent (2015) criminal case leading to convictions of an exciser and her two assistants (28 TooMany 2018). The vast majority of community members were acutely aware that excision has been criminalised and believe that the law is being actively implemented in Senegal. Many informants reported hearing radio broadcasts informing the general public about the law, and others learned of the ban at school, in workshops convened by NGOs, and in bantabas (outdoor public meetings convened by the chief and elders). It was commonly understood that prison sentences could be issued not only to those who perform excision, but also to people who aid in making arrangements for $F G M / C$ to be carried out.

Several women were familiar with the details of the 2015 arrest and convictions, and many people knew of specific cases where suspected violators had been reported to the authorities and then apprehended. It was also widely understood that teachers and a variety of health professionals 
(e.g., nurses, midwives, bajen gox [older women trained to help younger women with health care], community health workers) in particular have a duty to report people suspected of violating the anti-FGM/C law. This has created an intense climate of fear and suspicion, and people now take extensive measures to protect the privacy of their views and involvement regarding excision. Notably, women in our South Senegal study sites were acutely aware that, as prime organisers of excision, their actions are under close scrutiny, creating gender-based differences in perceived surveillance and vulnerability to indictment. Their concerns are not unfounded, given that scaled up efforts to implement the law have led to disproportionate imprisonment of women (Middelburg 2016).

When asked about their views on the law banning FGM/C, South Senegal respondents held mixed opinions. For some, particularly those who were already ambivalent about FGM/C because of the health risks associated with the practice, but found it difficult to stand up to local social pressures to conform, the law was seen as legitimate and government support for its abandonment decision was welcomed: "The law is good because it can stop something that is harmful to health" (24year-old Pulaar woman, South Senegal). Many others, however, viewed the law as a coercive strategy designed to "break culture." With knowledge of ongoing surveillance efforts, fear of being reported to the authorities was cited by some as a key reason for abandoning the practice. In an interview with a 35-year-old Pulaar mother, the following exchange occurred:

"Mother: I do not dare do it (excise my daughter) because it is forbidden by the law.

Interviewer: Are you afraid of the law?

Mother: Of course l'm afraid of the law.... Nothing can happen in this village without the law knowing."

Notably, this was true not only for people who had come to oppose FGM/C, but also for some who still valued the social significance of the practice.

"If it's up to me to decide, the practice should not be abandoned. But it is forbidden because it causes health complications. I bow to the decision.... It is not my preference to leave my tradition, but respect for the law is stronger than upholding tradition."

-58-year-old Pulaar woman, South Senegal

It was not, however, universally the case that social norms, enforced through informal sanctions, were outweighed by the spectre of criminal punishment. Yet open resistance to the law was rare. Instead, the climate of suspicion and the fear of being reported has spawned a culture of secrecy surrounding FGM/C. As one informant stated, "This is something I have not heard about for many years," meaning the practice is no longer openly discussed, even among friends and certain family members; another more boldly stated, "It is not safe to talk about excision." Unsurprisingly, when asked about FGM/C, most people, at least initially, gave what was considered the appropriate answer: "We have abandoned the practice." Only in deeper and assuredly private discussions were more nuanced views expressed, involving feeling torn between compliance with legal regulations versus social expectation, or outright resistance to the criminal ban on FGM/C.

For many people in South Senegal, both men and women, young and old alike, the social meanings associated with excision provide a compelling impetus to continue the practice, despite the fact that is has been subject to censure and criminalised. One 35-year-old Pulaar man defiantly explained, "It is a traditional and cultural value....Even if we are imprisoned in Kolda, we cannot accept that men are circumcised and women are not." Criminalisation has, however, altered the way that $F G M / C$ is carried out: 
"There are some people who still maintain the practice. It is true the government has banned the practice, but it is still performed in the Pulaar community, though secretly. It is not known to everyone. Before, it used to be held on a large scale with the knowledge of all the community throughout whole groups. But now, it is held secretly. Girls can go for excision while people who live in the same house are not aware of it. All this is meant to hide the practice from the government. In the Pulaar community there is no way excision could stop. It is part of life."

$$
\text { -23-year-old Pulaar man, South Senegal }
$$

In summary, we find that responses to legislation banning FGM/C have been multiple and mixed. The law appears to have motivated abandonment by a small number of families who were already questioning the practice. Additionally, among those who support the continuation of excision, some have felt compelled to reluctantly abandon the practice. At the same time, for many the practice has been driven underground, viewed as an increasingly worrisome and risky affair. A practice that was once a celebrated rite of passage, ensuring inclusion and solidarity among women has now become a covert act veiled in a cloud of fear and suspicion. Our data show that when legal norms depart drastically from closely held social norms, the prospect of penal risk is insufficient to offset the desire to uphold a valued cultural practice. Instead, it drives the practice underground and erodes trust and community cohesion in a poor, rural, and minority community that relies heavily on social networks and social support to cope with precarity. Moreover, it results in gender-based differences in perceived risk of prosecution.

\section{Health risks}

Respondents in our study communities readily recited FGM/C-related health risks that have long formed the core of information and education campaigns and are now included in school curriculums. Health problems ranging from pain during sex, incontinence, hemorrhage, obstructed childbirth, and spread of infectious disease were described by numerous informants. The spread of HIV through the use of shared cutting instruments was commonly emphasised as a particularly worrisome possibility.

"If we circumcise an HIV-infected girl and use the same knife, others will undoubtedly be infected."

$$
\text { -18-year-old Pulaar woman, South Senegal }
$$

Despite the fact that many respondents were able to recount details of health-risk messaging, the degree to which this information has been internalised varies. In some instances, messaging on health risks was met with skepticism, and did not resonate with their own personal experiences, particularly pertaining to obstetrical complications.

"I have heard that an excised woman may have complications or difficulties in childbirth. I personally did not experience these difficulties when I had three children. And I am in my fourth pregnancy. If the opportunity presents itself and God gives me a long life and health, I would do it to my daughter, for I see no difficulty."

$$
\text { -28-year-old Sereer woman, Central Senegal }
$$

Among those who perceived a credibility gap between their own experiences and the campaign messages on health, a number felt that they need "more proof" of the harms of cutting, and stated that they would be willing to consider abandoning excision if and only if it can be shown to be truly dangerous. Others, by contrast, whole-heartedly endorsed the health-risk message, particularly if they personally witnessed an adverse health outcome or death. For some, direct experiences with a girl who suffered adverse effects were pivotal moments in the decision to abandon FGM/C.

"Interviewer: Ah! You did not circumcise all your girls? 
Mother: Yes, I have circumcised only my first daughter... She lost too much (blood) when she was circumcised....So I decided to not circumcise the other girls."

-33-year-old Mandinka woman, Central Senegal

Additionally, sensitisation on the health risks associated with $\mathrm{FGM} / \mathrm{C}$ has apparently become incorporated into the responsibility of a cadre of professionals, including village chiefs, health care professionals, community health workers, bajen gox, and community health promotion committee members. As part of their professional development, they are trained on the biomedical rationale for opposing FGM/C. Some have embraced this message and expressed a strong commitment to working to end FGM/C. Others, however, have contradictory views, expressing on one hand a strong belief in the health risk message, but on the other hand still holding support for the cultural norms and values associated with the practice.

In both Central and South Senegal, health-related worries regarding FGM/C have become compounded by concerns that because of the condemnation and criminalisation of $\mathrm{FGM} / \mathrm{C}$, care will be denied to those seeking treatment for FGM/C-related problems.

"Many difficulties are related to health. When the circumcised girl has complications, you cannot find anywhere to treat her."

-46 year-old Pulaar woman, South Senegal

Moreover, women widely believe that healthcare providers are mandated to report violators of the anti-FGM/C law; thus, fear of being reported and prosecuted for performing FGM/C has become a powerful rationale to avert seeking treatment at a clinic.

"They said that the practice must stop because there are difficulties. If we encounter any, we cannot ask for health care.... If you excise and have difficulties that require a consultation at the health facility, you can be arrested."

-45-year-old Pulaar woman, South Senegal

"If you secretly excise your daughter and there is bleeding, you will not dare to bring her to the hospital. If you do, the midwife will ask you the source of these complications and you are obliged to tell the truth. In this case, you will be reprimanded and imprisoned."

-58-year-old Pulaar woman, South Senegal

Thus, for girls and women who are at an elevated risk of reproductive health morbidity due to FGM/C, care is being denied or discouraged. Given that excised women forever carry evidence of this crime on their bodies, the hesitancy to seek reproductive health care may be prolonged among a group with known elevated risk of reproductive morbidity arising from FGM/C, serving to exacerbate health disparities.

\section{An emerging norm: Male preference for an uncut marital partner}

In Central Senegal, FGM/C is no longer considered a prerequisite to marriage. At the same time, a new norm regarding marital preferences is beginning to emerge. It is believed that younger men are now beginning to prefer an uncut woman as a marital partner because she will be more sexually responsive to her husband. A number of older women in Central Senegal expressed awareness of men's shifting preferences regarding women's expressions of sexual desire and pleasure:

"Non-excised girls will have a husband more easily, because there are men who don't want to be with those who were excised."

-60-year-old Serahulé woman, Central Senegal

"If the circumcised and uncircumcised share the same husband, the uncircumcised will win his heart... The circumcised (wife) has fewer feelings to (sexually) satisfy 
her husband, in comparison to the uncircumcised wife, who does not feel shame to entice or satisfy her husband."

$$
\text { -42-year-old Serahulé woman, Central Senegal }
$$

This fits with a broader trend in Senegalese society concerning changing values regarding sexual relationships. As Falcáo (2018: 184) describes, with permeating influences through television, music, and tabloid press, "new relational categories" like romantic love and pleasure are today recognised as important to sustaining marital relationships. In response to this discourse, women in Central Senegal are reconsidering values associated with the notion of sexual pleasure, and new gender norms regarding women's sexuality are emerging:

"Because men like the ones who do not practise it, ah! Also make sure that our daughters enjoy their marriage. We had lost (sexual pleasure), but our daughters will not lose, and will satisfy their husbands."

-30-year-old Mandinka woman, Central Senegal (women's leader)

\section{Summary}

A regional comparison of the overarching themes surrounding FGM/C is summarised in Table 2 (gender and generational patterns will be reported elsewhere because of length limitations of this report). In South Senegal, the social benefits of FGM/C are crucial for defining gender roles, assuring social support and acceptance, structuring social hierarchies between older and younger women as well as between men and women. Seen as essential for ensuring social order and cohesion, they provide a strong rationale for the continuation of excision. These benefits are appraised in light of the risks of performing FGM/C, which include the possibility of being indicted for violation of the criminal law banning $\mathrm{FGM} / \mathrm{C}$, and lacking access to health care should complications arise.

In Central Senegal, we find that the social benefits that encourage the practice of FGM/C have diminished greatly. Excision is no longer considered a prerequisite to marriage, and with the growing acceptability of inter-ethnic marriages, FGM/C no longer defines social acceptance and access to social support from other women. Additionally, the training on feminine virtue that once took place during initiation now occurs throughout childhood and in the absence of cutting. At the same time, concerns about health risks potentially arising from FGM/C, and to a lesser extent, concerns about the legal ban, now provide a powerful disincentive to carry out the practice. Moreover, a new norm regarding male preference for an uncut wife has begun to emerge. Thus, consistent with our earlier work in Senegambia (Shell-Duncan et al. 2018), rather than being viewed as static, unchanging, and deeply rooted, we find that social norms are being reassessed, and in certain instances, altered. Over time, existing norms may weaken or disappear, and new norms may emerge. We suggest that the dynamic nature of norms may provide raw material for intervention programmes aimed at ending FGM/C.

Also in line with our earlier work in Senegambia, our data suggest that the construction of a person's opinion about the $\mathrm{FGM} / \mathrm{C}$ involves an ongoing process of reassessment vis-à-vis fluctuating needs and realities. Similar to Bledsoe's (2002) work on reproductive decisions, we found that people's positions on FGM/C are often "far more complex than the image of a large sea of 'unpersuaded' traditionalists surrounded by an island of enlightened 'acceptors' of the desired innovation" (Hernlund and Shell-Duncan 2007: 44). The data point to something much more complex and fluid than diametrically opposed camps of "supporters" and "opponents" of FGM/C. "Even within a single individual, seemingly oppositional views may compete and coexist, attuned to shifting relationships, contexts and experiences" (Hernlund and Shell-Duncan 2007: 44). In reality, goals and norms are continuously reappraised, and views are often reexamined in light of 
changing social circumstances and novel challenges; in this process, people may be internally conflicted about the best course of action, as they weigh the benefits of FGM/C against the risks.

In Central Senegal, the norms that link FGM/C to embodiment of feminine virtue and marriageability have eroded and reversed; respondents agreed that $\mathrm{FGM} / \mathrm{C}$ is no longer a prerequisite to marriage nor needed to assure a woman's moral virtue. Furthermore, a new norm regarding men's preference for an uncut marital partner has emerged in Central Senegal, but not South Senegal. In South Senegal, FGM/C is still strongly considered a prerequisite to marriage and essential for feminine virtue.

Table 2. Regional variation themes surrounding FGM/C

\begin{tabular}{|c|c|c|c|c|}
\hline & & & \multicolumn{2}{|c|}{ Region } \\
\hline Domain & & Overarching theme & South & Central \\
\hline \multirow{3}{*}{$\begin{array}{l}\text { Factors encouraging } \\
\text { FGM/C } \\
\text { social benefits (norms) }\end{array}$} & 1. & Embodiment of feminine virtue & ++ & - \\
\hline & 2. & $\begin{array}{l}\text { Pressure to } \\
\text { Conform }\end{array}$ & ++ & + \\
\hline & 3. & Marriageability & ++ & - \\
\hline \multirow{3}{*}{$\begin{array}{l}\text { Factors discouraging } \\
\text { FGM/C }\end{array}$} & 4. & Legal ban on excision & ++ & + \\
\hline & 5. & Health risks & ++ & + \\
\hline & 6. & $\begin{array}{l}\text { Male preferences for an uncut } \\
\text { marital partner }\end{array}$ & - & + \\
\hline
\end{tabular}

$+\quad$ raised with moderate emphasis, with positive consensus

$++\quad$ raised with strong emphasis, with positive consensus

- $\quad$ raised with moderate emphasis, with negative consensus

In a handful of instances, respondents expressed clearcut support for the continuation of FGM/C:

"In my view this campaign is not good.... Since I became an adult, I have never heard of a time or place where girls are exempt from excision. Every group of people has their own traditions. My family practises excision because it is a good thing."

-32-year-old Pulaar man, South Senegal

"I am against the law. I am for the continuation of excision because it constitutes a benefit for the girl.

$$
\text { --25-year-old Pulaar woman, South Senegal }
$$

And in some cases people were resolute in their opposition to the practice of FGM/C:

"We have to stop this practice. Stopping this practice is the source of better health and well-being. There were a lot of complications in childbirth.... It's the reason we decided to stop this practice and no longer bring either our daughters or granddaughters."

-56-year-old Sereer woman, Central Senegal

Yet, in many instances people expressed views that were more nuanced, reflecting an unresolved tension between conflicting rationales for upholding or abandoning FGM/C. This ambivalence 
arose as people were reappraising the value of upholding or discarding social norms and the associated values, the desire to avert sanctions for nonconformity, and the imperative to manage new and growing risks that accompany performing FGM/C (Figure 5). Despite the fact that fear of prosecution looms large in South Senegal, the social norms that encourage FGM/C make it difficult for people to easily discard the practice; those who abandon FGM/C still face tremendous social costs for failing to comply with dominant social norms. By contrast, in Central Senegal, where the prevalence of $\mathrm{FGM} / \mathrm{C}$ is low, the erosion of social norms that once upheld FGM/C and the reduced discrimination against uncut girls and women open the possibility of abandonment without suffering ostracism. Notably, many behaviour change communication strategies aimed at ending FGM/C focus on education on the health risks and legal sanctions. Here we find that a shift in support for $\mathrm{FGM} / \mathrm{C}$ is driven in large part by the de-valuation of the positive normative associations with FGM/C, most notably marriageability, and a shift in defining insider/outsider status as linked to social inclusion and aversion of stigma. How might programmes aimed at ending FGM/C build upon this finding? How might stigma reduction efforts (perhaps modelled after those aimed at reducing stigma associated with HIV) and messaging about changing norms regarding feminine virtue and marriageability be incorporated into anti-FGM/C programmes?

The factors discouraging $\mathrm{FGM} / \mathrm{C}$ and the norms encouraging the practice vary between regions and have shifted over time. In South Senegal the norms encouraging FGM/C have remained strong, whereas those related to insider/outsider status and marriageability have eroded in Central Senegal. At the same time, a new norm regarding preference for an uncut wife has emerged in Central Senegal.

Figure 5. Factors discouraging and encouraging the practice of FGM/C

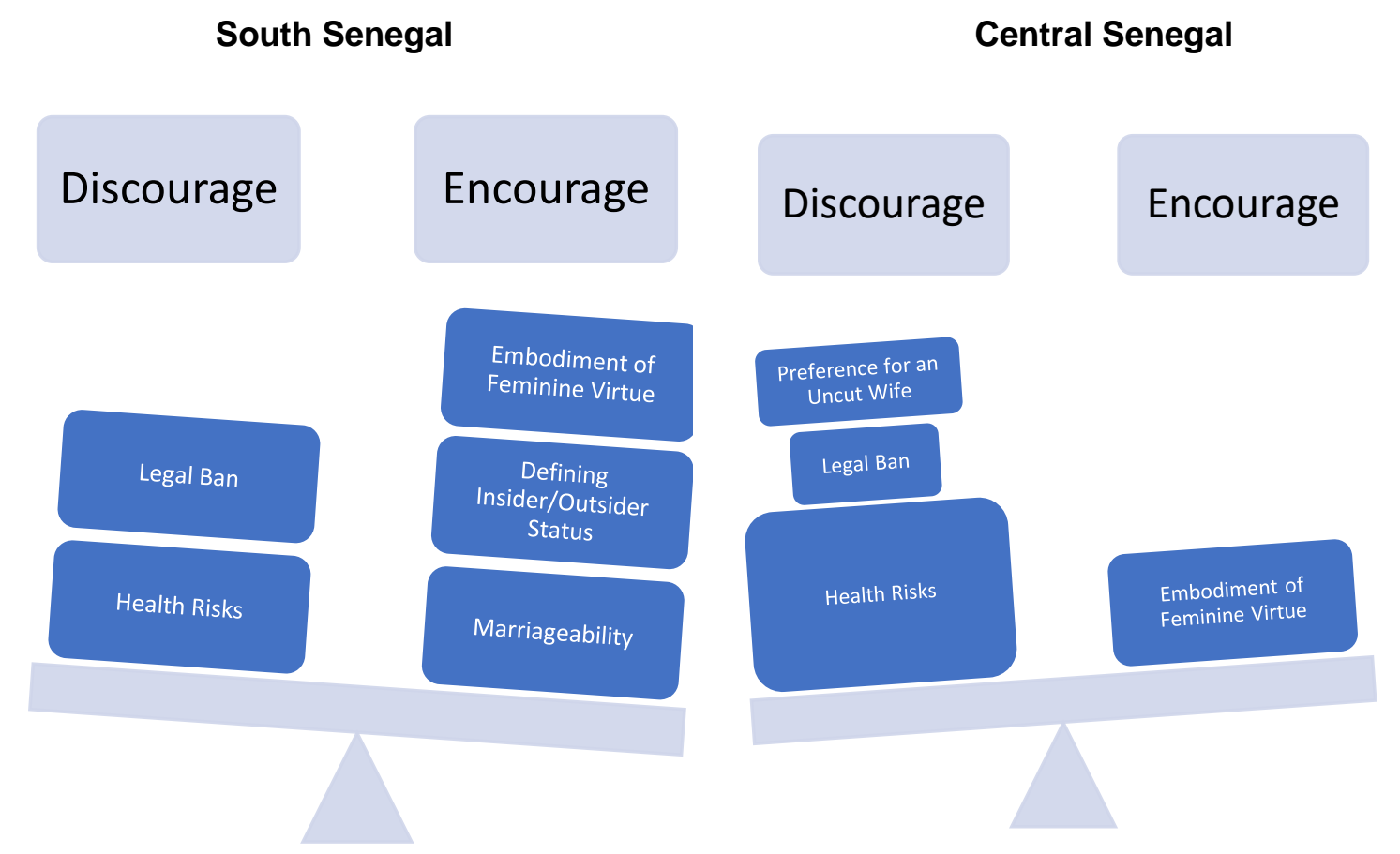

\section{Network Composition}

To explore the composition of social networks influencing the practice of FGM/C, as well as the nature of interactions and patterns of power and influence, we conducted in-depth qualitative network interviews. In our snowball sampling strategy, a total of 40 women, 20 in each region were selected as "seed" informants. The inclusion criteria were 1) having a daughter between the ages 
of 3 months and 5 years, and 2) coming from a family that once practiced FGM/C. Interviews were also conducted with one to two influential network members (termed here alters) named by the mother (termed here the ego). In these interviews, the influential network partner became a secondary respondent, taking the role of ego in their interview.

\section{Networks of care are a good approximation for identifying the salient social referents for FGM/C in Central Senegal.}

Characteristics of the primary and secondary respondents are shown in Table 3. Forty mothers (primary respondents) were interviewed, but audio recording failed during one interview in south Senegal. Additionally, interviews were conducted with 51 secondary respondents, for a total of 90 ethnographic network interviews. The age range of primary and secondary respondents was similar in both sites, and men made up a somewhat higher proportion of secondary respondents in South Senegal sites (46\%) as compared to Central Senegal sites (37\%). The vast majority of respondents in our South Senegal sites were ethnic Pulaar, consistent with the ethnic homogeneity of this region. By contrast, the ethnicity of network interview respondents is much more varied in Central Senegal, reflecting the overall ethnic diversity in this region. Inter-ethnic marriage was also more common among respondents in Central Senegal.

Table 3. Characteristics of respondents of ethnographic network interviews

\begin{tabular}{|c|c|c|c|}
\hline \multirow[b]{2}{*}{ Ego characteristics } & \multicolumn{2}{|c|}{ Region } & \multirow[b]{2}{*}{ Total } \\
\hline & Central & South & \\
\hline Number of primary respondents & 20 & 19 & 39 \\
\hline Number of secondary respondents & 27 & 24 & 51 \\
\hline Total number of respondents & 47 & 43 & 90 \\
\hline Proportion of secondary male respondents & $37 \%$ & $46 \%$ & \\
\hline Average age of primary respondents (range) & $30(21-60)$ & $27(18-64)$ & \\
\hline Average age of secondary respondents (range) & $42(23-65)$ & $38(19-64)$ & \\
\hline \multicolumn{4}{|l|}{$\begin{array}{l}\text { Ethnicity (primary and secondary respondents } \\
\text { combined) (\%) }\end{array}$} \\
\hline Sereer & $37 \%$ & 0 & \\
\hline Mandinka & $29 \%$ & $2 \%$ & \\
\hline Pulaar & $6 \%$ & $91 \%$ & \\
\hline Diola & $2 \%$ & 0 & \\
\hline Serahulé & $18 \%$ & 0 & \\
\hline Bambara & $2 \%$ & 0 & \\
\hline Socé & $6 \%$ & 0 & \\
\hline Jahanke & 0 & $2 \%$ & \\
\hline Laobe & 0 & $5 \%$ & \\
\hline \multicolumn{4}{|l|}{ Marital status } \\
\hline Married & $94 \%$ & $95 \%$ & \\
\hline Unmarried/widowed/divorced & $6 \%$ & $5 \%$ & \\
\hline Proportion in inter-ethnic marriage & $30 \%$ & $7 \%$ & \\
\hline Number of children & $4.8(2.7)$ & $4.8(2.4)$ & \\
\hline \multicolumn{4}{|l|}{ Proportion who know of the law banning FGM/C } \\
\hline Female respondents & $53 \%$ & $82 \%$ & \\
\hline Male respondents & $60 \%$ & $87 \%$ & \\
\hline \multicolumn{4}{|l|}{ Proportion who support continuation of FGM/C } \\
\hline Female respondents & $3 \%$ & $24 \%$ & \\
\hline Male respondents & $0 \%$ & $45 \%$ & \\
\hline
\end{tabular}

Our network interview began by asking a series of 16 generalised name-generator questions designed to elicit a comprehensive list of network partners (see Shell-Duncan et al. 2019b for more details and copies of our instruments). We recorded the name of each alter and the question(s) that elicited the name. The majority of names were generated by the first three questions on 
affective support. The network size in both regions and for men and women alike is very large: in Central Senegal the average network size was 19 and 22 people for women and men, respectively; in South Senegal the average network size was 23 and 21 people for men and women, respectively. Moreover, the density (proportion of connections between nominated network members) reported by respondents was high: all nominated network partners were reported to know one another. This finding confirms our assertion from prior research in which we suggested that in rural Senegal, where poverty is common, crises frequent, and opportunities scarce, people rely heavily on expansive social networks (termed social capital) to access resources and support (Shell-Duncan et al. 2011). Social support and resources from members of a person's social network may be accessed after gaining inclusion and acceptance, and FGM/C may be pivotal in this process. Support accessed through network members can take a variety of forms: emotional, instrumental (direct help), financial, and informational support. For example, contacts may be used to access job and business opportunities, family may be relied on for childcare or helping to cover expenses, and both family and social contacts relied on for public and social support (e.g., in disputes, in childrearing, for emergency resources, or for employment opportunities. According to Zaoual (1997: 32), across many African societies, "local milieu work...on the principle of social links," and contribute to the strong cultural value placed on relationships, sharing, and solidarity. What emerges is a system of reciprocity that improves the security of a group's members by reducing vulnerability to hazards and misfortune. Such a system relies on social networks and social cohesion, resulting in a group that is bound through mutual trust and obligation (see also Cobbah 1987; Carney and Watts 1991; Schroeder 1999, Ahmadu 2005, Shell-Duncan et al. 2011).

From the full list of network partners, respondents were asked to identify individuals who influence or are involved in decisions regarding the well-being of young girls. Our prior research in Senegambia revealed that FGM/C is considered to be a matter of "proper parenting" (Shell-Duncan et al., 2011; Shell-Duncan et al. 2018). This term describes the expectation that families raise young children to be well-mannered and socialise them to conform with culturally shaped gender norms, a process that involves circumcision for both boys and girls. We therefore posited that the salient reference group for $\mathrm{FGM} / \mathrm{C}$ would be those core network members who influence decisions on important matters regarding the well-being of young girls. Alters were designated as either decision-makers (those people identified by the ego as participating in direct decision-making regarding young girls) or core influencers (those not participating in decisions, but who influence the decisions made). There was no limit on the number of decision-makers identified by the ego, but the number of influencers was capped at a maximum of five people; this limit did not turn out to be important, as none of the respondents nominated more than five influencers. These individuals were designated to be the core members of networks of care, and their names formed the basis for the creation of a social network map, or sociogram, constructed interactively with the respondent. This task guided the subsequent interviews and included obtaining select demographic data which were provided about each core network member.

Summary characteristics of core network members are shown in Table 4. Our focus group participants described routine care of children as highly gendered, with mothers and other female family members providing the majority of direct care. Nonroutine networks of care were described as being broader, drawing on advice and support from a larger network of family and friends. One of the key questions we ask is: Who is included in core networks of care? Are men included in these networks?

Core networks are large, predominantly made up of kin, and commonly include men both as decision-makers and influencers. 
Table 4. Core network members influencing or involved in decision-making.

\begin{tabular}{|c|c|c|c|}
\hline \multicolumn{4}{|c|}{ Region } \\
\hline Alter characteristics & Central & South & Total \\
\hline Average size of complete core network & 7.8 & 7.0 & 7.4 \\
\hline Average number of decisionmakers & 4.8 & 4.5 & 4.6 \\
\hline Average number of influencers & 3.0 & 2.5 & 2.8 \\
\hline \multicolumn{4}{|l|}{ Complete core network characteristics } \\
\hline \% live in same household & $51 \%$ & $59 \%$ & $55 \%$ \\
\hline$\%$ male & $47 \%$ & $54 \%$ & $50 \%$ \\
\hline \% leaders (not kin) & $5 \%$ & $5 \%$ & $5 \%$ \\
\hline$\%$ kin & $84 \%$ & $84 \%$ & $84 \%$ \\
\hline \% same ethnicity (as ego) & $66 \%$ & $94 \%$ & $79 \%$ \\
\hline \multicolumn{4}{|l|}{ Decisionmaker characteristics } \\
\hline \% live in same household & $64 \%$ & $76 \%$ & $69 \%$ \\
\hline$\%$ male & $49 \%$ & $61 \%$ & $55 \%$ \\
\hline \% leaders (not kin) & $1 \%$ & $3 \%$ & $2 \%$ \\
\hline$\%$ kin & $92 \%$ & $93 \%$ & $92 \%$ \\
\hline \% same ethnicity (as ego) & $69 \%$ & $93 \%$ & $80 \%$ \\
\hline \multicolumn{4}{|l|}{ Influencer characteristics } \\
\hline \% live in same household & $31 \%$ & $31 \%$ & $31 \%$ \\
\hline$\%$ male & $44 \%$ & $41 \%$ & $43 \%$ \\
\hline \% leaders (not kin) & $10 \%$ & $9 \%$ & $10 \%$ \\
\hline$\%$ kin & $72 \%$ & $70 \%$ & $71 \%$ \\
\hline$\%$ same ethnicity (as ego) & $61 \%$ & $95 \%$ & $77 \%$ \\
\hline
\end{tabular}

Our data show that men feature prominently in networks of care: overall $50 \%$ of nominated core network members, decision-makers, and influencers combined are male. The majority of core network members live in the same household as the ego and are kin. Leaders listed in Table 6 are non-kin to avoid conflation of the effect of leadership and family status (we compare kin and nonkin leaders below). Common leadership positions included a variety of health professionals: community health workers, midwives, nurses, and bajen gox. Other leaders included heads of women's groups, and to a lesser extent, the Alkalo (village chief) or religious leaders. Leaders who were not kin were not common in networks of care $(5 \%)$.

One key difference between our study sites in South and Central Senegal is the amount of ethnic diversity. South Senegal sites were relatively homogeneous, comprised largely of ethnic Pulaar. Central Senegal sites were quite ethnically diverse. One important question is whether networks of care in Central Senegal segregate along ethnic lines. We do not find this to be true: a third of core network members in Central Senegal were reported to be from a different ethnic group than the ego.

Among core network members who are kin, the type of relationship to ego is broken down in Table 5. Over $80 \%$ of women in both regions listed their husbands as decision-makers, and brothers, brothers-in-law and uncles featured prominently as core network members. For men, their own brothers were listed as decision-makers by $50 \%$ of men in Central Senegal and by $73 \%$ of men in South Senegal. These findings indicate that men are most certainly involved in and influential in decisions regarding FGM/C. And in South Senegal women commonly nominated their mother-inlaw as a decision-maker (40\%), but this was less common in Central Senegal (13\%).

For both men and women, and across regions, the most frequently nominated kin decision-makers were spouses. For men in particular, their own mothers were frequently listed as decision-makers, and brothers were frequently nominated as decisionmakers and influencers. 
Table 5. Average percent of type of kin nominated as influencers or decision-makers

\begin{tabular}{|c|c|c|c|c|}
\hline \multirow{3}{*}{ Relation (to ego) } & \multicolumn{4}{|c|}{ Region } \\
\hline & \multicolumn{2}{|c|}{ Central } & \multicolumn{2}{|c|}{ South } \\
\hline & Men & Women & Men & Women \\
\hline \multicolumn{5}{|c|}{ Relationship of kin core influencers (to ego) } \\
\hline \% spouse & $0 \%$ & $5 \%$ & $0 \%$ & $0 \%$ \\
\hline$\%$ mother & $10 \%$ & $8 \%$ & $9 \%$ & $9 \%$ \\
\hline$\%$ mother-in-law & $0 \%$ & $3 \%$ & $0 \%$ & $12 \%$ \\
\hline$\%$ father & $10 \%$ & $0 \%$ & $0 \%$ & $6 \%$ \\
\hline$\%$ at least one brother & $50 \%$ & $13 \%$ & $73 \%$ & $10 \%$ \\
\hline$\%$ at least one brother-in-law & $10 \%$ & $10 \%$ & $0 \%$ & $10 \%$ \\
\hline$\%$ at least one uncle & $10 \%$ & $10 \%$ & $18 \%$ & $6 \%$ \\
\hline \multicolumn{5}{|c|}{ Relationship of kin decisionmakers (to ego) } \\
\hline$\%$ spouse & $80 \%$ & $87 \%$ & $82 \%$ & $100 \%$ \\
\hline$\%$ mother & $60 \%$ & $27 \%$ & $45 \%$ & $12 \%$ \\
\hline$\%$ mother-in-law & $10 \%$ & $13 \%$ & $10 \%$ & $40 \%$ \\
\hline$\%$ father & $10 \%$ & $8 \%$ & $55 \%$ & $6 \%$ \\
\hline$\%$ at least one brother & $50 \%$ & $13 \%$ & $73 \%$ & $10 \%$ \\
\hline$\%$ at least one brother-in-law & $10 \%$ & $10 \%$ & $0 \%$ & $10 \%$ \\
\hline$\%$ at least one uncle & $20 \%$ & $10 \%$ & $18 \%$ & $3 \%$ \\
\hline
\end{tabular}

As our interviews shifted from the topic of the well-being of girls to excision, we explored whether and how networks of care are a good approximation for identifying the salient social referents for $\mathrm{FGM} / \mathrm{C}$. We find that excision networks are more constricted than networks of care, meaning that certain core network members are excluded from direct involvement in discussions and decisions regarding $\mathrm{FGM} / \mathrm{C}$.

In both Central and South Senegal, leaders, including those with health expertise, are often excluded from discussion and decisions regarding excision due to their duty to report violators of the ban on FGM/C.

It is commonly understood that community development initiatives may be optimised by leveraging the strengths of influential leaders (Valente 2010). Influential leaders may also be people with officially recognised positions, such as the village chief (Alkalo) or president of the women's group. From a network perspective, important change agents may be informal leaders of highly influential subgroups, in this instance, fathers and senior women. Since our study is not a full network study, involving interviewing all members of the community, it is not possible to identify the individuals who are most centrally located in these subgroups. Nonetheless, we are able to examine the influence of formal leaders and describe their influence when interacting with high-influence core network members who are not leaders.

Our key informant and network interviews revealed that certain community leaders have been formally appointed roles in anti-FGM/C advocacy and enforcement of the law banning $\mathrm{FGM} / \mathrm{C}$. Several women indicated that there is a need for "suture" (discretion) in the presence of the Alkalo because he was visited by government officials and given written orders to inform community members about the law, and to order them to stop practising FGM/C. As one 34-year-old Pulaar mother recounted, "There was an awareness meeting... at the village chief's house. He summons people from time to time to tell people that excision is forbidden, and if he sees someone doing it, he will denounce it."

A statement from a female government official in Central Senegal revealed her awareness that threats of legal sanctions have caused women in the community to exclude her from excision discussion: 
"There is a law against female circumcision. As a government official, in addition to being a victim of the practice and all my anger, I use this law to threaten women who wish to have their girls circumcised. I refer to the security forces ["the gendarmerie brigade"] to frighten them. That is why they hide their practises and keep me out of reach. They do it secretly. As a government official, I comply with the laws of the state."

-57-year-old Mandinka woman, community leader, Central Senegal

In addition to the Alkalo and other government officials, a cadre of health professionals report having been tasked with 'sensitisation' about the health risks of and legal restrictions on $\mathrm{FGM} / \mathrm{C}$; they also appear to have a duty to report violators. These include nurses, midwives, community health workers, leaders of village health committees, and bajen gox.

In cooperation with the Alkalo, community health workers and nurses hold information sessions and home visits.

"Q: "You are a nurse; do you do sensitisation on this issue?

A: Yes, I do it with ___ [a community health worker who works with the village health center]. We do home visits and talk to women. We also organise meetings with the village chief. We raise awareness about the harms of female circumcision."

-35-year-old Pulaar nurse, South Senegal

Health professionals also explained very clearly that they are mandatory reporters of violators of the anti-FGM/C law:

"The law formally forbids the practice of excision. If one sees someone else doing it, they are reported at the health post and the mother of the daughter as well as the exciser are arrested for violation of the law."

-32-year-old Pulaar woman, community health worker, South Senegal

A chief nurse from Central Senegal commented on the shortcomings that arise from this reporting requirement:

"My personal feeling is that because female circumcision is illegal, no one will come
to the facility telling me 'I want to get my daughter circumcised.' I represent the
state and it is as if someone came to tell you 'I want to abort my daughter' [abortion
is illegal in Senegal], you see what it does! They know that female circumcision is
illegal, so they will never tell me that they want their daughters circumcised. I think
it would be better for people to come to the health facilities than to go smuggling.
But as this practice is illegal, it will always be done in hiding and it is more
dangerous."

—Sereer male, head nurse (age not recorded), Central Senegal

Some health leaders very clearly articulate the legal and health risks associated with $\mathrm{FGM} / \mathrm{C}$, but at a personal level are much more ambivalent. Some are not convinced of the dangers and privately support the continuation of FGM/C because of its social benefits. During an interview with a 30-year-old Pulaar woman who is a community health worker, she forcefully argued for the need to abandon FGM/C due to health risks. Yet, she confessed that she has never seen a woman have complications linked to the practice of excision and worries that an uncut girl will never be recognised in this community as a "real woman." Other health professionals suggest that framing opposition to FGM/C as a health matter, rather than a cultural matter, is a strategy for legitimating government mandates to report violators of the anti-FGM/Claw:

"The health problem remains the main reason provided by the state to combat the practice of female circumcision, with several reasons for reproductive health in the context of girls' marriage. This is not a fight against cultural practises, but it takes charge of a public health 
problem. Excision is the cause of several health complications of women of reproductive age."

-50-year-old Pulaar man, community health agent, South Senegal

Nonetheless, the predominant response to mandating reporting of $\mathrm{FGM} / \mathrm{C}$ has been to drive the practice underground and restrict leaders from excision networks. Might anti-FGM/C programmes that operate through leaders benefit from engaging nonformal leaders rather than formal leaders? Who are the nonformal leaders? We explore this question below.

\section{In South Senegal, excision networks have become further constricted, often excluding men in core networks of care.}

The role played by men, either as a decisionmaker or core influencer, sometimes differed for the issue of excision, in comparison to networks of care, particularly in South Senegal because of the constriction of excision networks. This appears to be related to the rising fear of being reported and indicted for violating the ban on FGM/C.

In the past, when excision was carried out on large groups of girls in the bush, elder women held the responsibility for assembling initiates, selecting a circumciser, caring for girls during their convalescence, carrying out training while girls were in seclusion, and hosting a community-wide coming-out celebration. Typically, the father of the girl was asked to provide permission for his daughter's participation in this rite of passage and was often asked to contribute money for the celebration but was not directly involved in planning or carrying out the event. As pressures to end $\mathrm{FGM} / \mathrm{C}$ mounted across decades of programming, the practice of $\mathrm{FGM} / \mathrm{C}$ began to shift from being a public celebration to a private affair carried out at home with little or no celebration and involving only immediate family and friends. Typically, however, older women in the family still made the arrangements for FGM/C to be carried out, fathers were asked to condone it, and often asked to contribute money to cover costs.

\section{Case 30: Older women commonly arrange and carry out FGM/C, but in the past, fathers} were asked to condone and finance it.

Saffie is a 24-year-old Jahanke mother of two, who lives in South Senegal. She explained that excision is now practiced underground in her community. At the beginning of the interview, she declared that her four-year-old daughter was not cut. But later, as she became comfortable with the interviewer, she admitted that her daughter had indeed been cut. This decision, she explained, was initiated by her late grandmother, but her husband's consent was sought:

"Q: Has your daughter been circumcised?

A: Yes, at that time my grandmother was alive, when she spoke to my husband, he said that it's also his tradition, and she was circumcised.

Q: Your daughter was taken for circumcision by your late grandmother who came for her?

A: Yes...it was my grandmother to whom it was important.

$Q$ Who participated in the discussion for your girl to be circumcised?

A: My grandmother, my husband and I.

A: What did you discuss?

A: She just said that she will circumcise my daughter, and my husband gave her money.

Q: Were there any disagreement?

A: No, we all agreed." 
At times fathers are still asked to provide consent, and asked for money to cover the costs, but $\mathrm{FGM} / \mathrm{C}$ is now considered a private and secret family matter. Saffie's husband, when interviewed separately, did not admit that his daughter had been cut. This was not surprising, as Saffie had explained that most people do not discuss excision in public except to say they are stopping. "We do not discuss [excision] because of the gendarme." She recounted witnessing the arrest of a circumciser who was later jailed. Since that time, she no longer talks about excision with anyone in the community, including her close friend or neighbour, both of whom were listed in her network map, and, she believes, come from families that once practiced excision.

Other community members reported that increasingly, in an effort to assure that excision is carried out discreetly and limit the risk of detection, extended family members are no longer notified, and the procedure can be hidden even from those living in the very same compound. Circumcisers are reported to arrive at night, while sleeping family members are unaware of what is taking place.

"In the past, if you had to circumcise your daughter, you told everyone up to and organised a ceremony without fear. Now that it is prohibited, no one dares to talk about it. Even if you want to do it, you hide because you fear being reported and getting arrested. Now, even a father does not know if his daughter has been circumcised. Everything is kept secret between the mother, the grandmother, and the circumciser."

-40-year-old Pulaar man, South Senegal

Although there are still cases when southern Senegalese men are directly involved in decisionmaking regarding FGM/C for girls in their family, it is becoming increasingly common for men to be uninvolved. Some fathers insisted that as "chef de famille" or head of the family, they should be consulted on all important matters in their family, including excision. But in reality, many did not assert this authority when it came to excision and allowed the arrangements to become furtive "women's business." Thus, networks of excision are constricted, excluding men who are in broader networks of care. This protects men (and other excluded family members) from being indicted on criminal charges, and also enhances the ability of men to adopt a public stance in favour of abandonment of FGM/C while possibly privately supporting the continuation of the practice. Thus, it is disproportionately women who are culpable and vulnerable to criminal prosecution.

\section{Patterns of Influence and Differential Power over Decision-making on FGM/C}

To understand the role and relationship of people involved in networks of care and possibly influencing FGM/C, we worked with participants to collaboratively create a sociogram, a visual representation of the core network of care. For people who were identified as core network members, either as decision-makers or influencers, questions were asked about support given in several categories: advice, emotional support, direct care or help, and financial support. This was drawn on the map, and served as a springboard for a deeper conversation about the nature of social interactions with respect to care for young girls, and then about the informant's perception of network partners' views on FGM/C. This differs from survey methodologies that inquire about participants in direct decision-making about excision, as network theory suggests that decisions made by individuals or groups are influenced by their perception of what others in their network expect (that is, social influence). Indeed, it is important to recall that network studies on other health behaviours have found that perceptions of network partners' preferences are often more important than an individual's own preference in guiding decision-making. Thus, we chose to examine patterns and levels of influence among the more generalised core network of care. We captured this in our interviews, and also asked informants to quantify level of influence by creating a tower of influence. The tower was visually created by stacking chips, ranging from 1-5 chips. Each additional chip represented a higher level of influence. We recorded the level of influence on the network maps, and also in the database created from the network interviews. Figure 6 shows the 
average influence scores reported by women, both primary and secondary respondents, broken down by their relationship to each decision-maker or influencer on their network map.

In both regions of our study, husbands were listed as decision-makers and not as influencers in networks of care, and have the highest reported average influence scores; this is followed by other male relatives: brother, son, and brother-in-law (especially in South Senegal). Senior women, particularly mothers-in-law and mothers, also have high reported influence scores. And notably, the influence score for non-kin leaders differs across regions: leaders have a much lower reported influence score in South Senegal, possibly because of the greater fear of being reported for violating the law in this region.

Women report that husbands, as well as other male relatives, have high decision-making influence, and among those not directly involved in decision-making, mothers and mothers-in-law have high influence.

Figure 6. Women's average reported influence scores of decisionmakers and influencers (primary and secondary informants, $n=69$ )
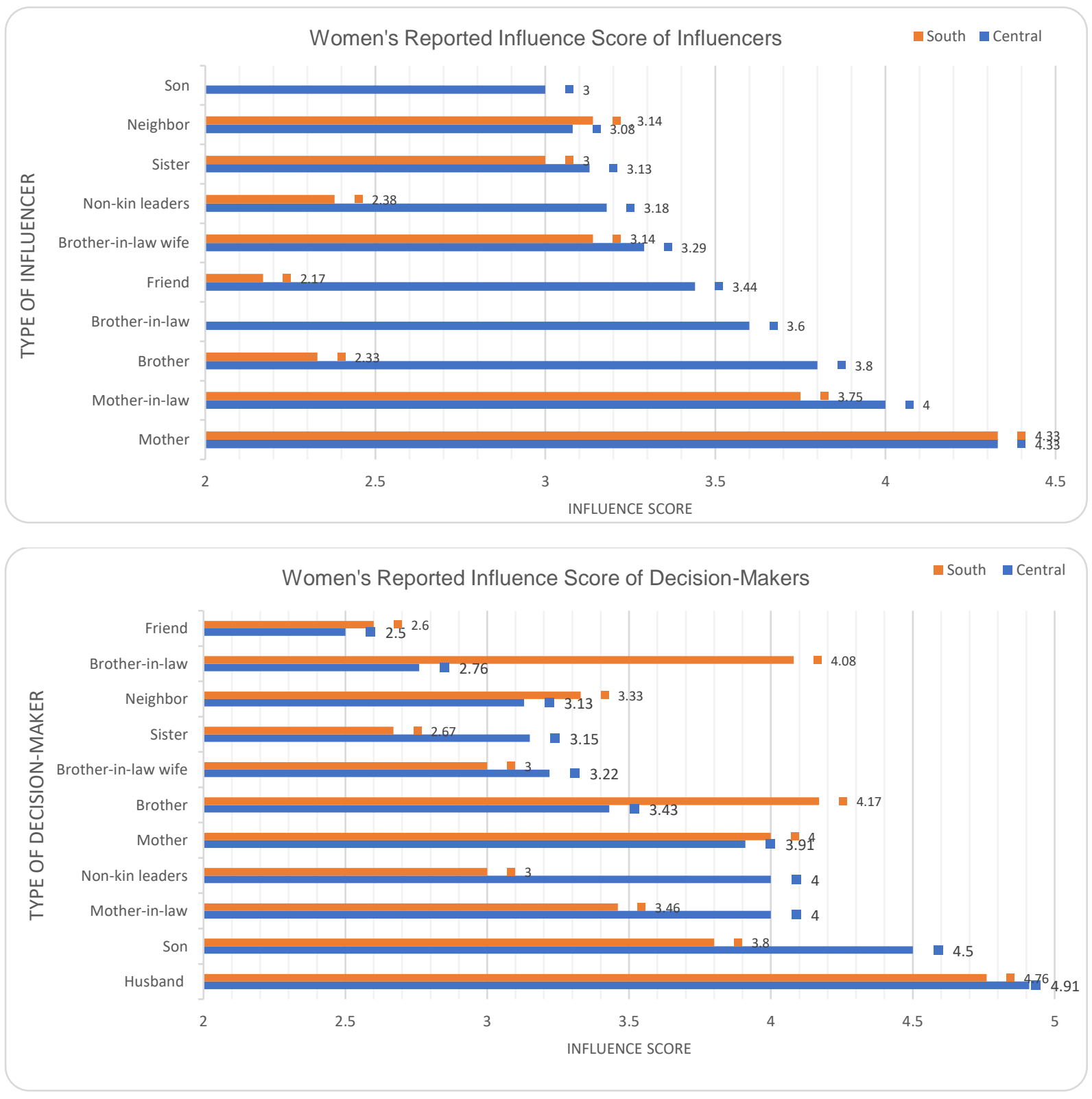
Figure 7 shows the average influence scores reported by male secondary respondents, broken down by their relationship to each decision-maker or influencer on their network map. Bearing in mind that the total number of male respondents is small $(n=21)$, there are some notable patterns. Both wives and mothers are reported to be highly influential. Thus, while men are widely recognised as authoritative in terms of being the head of the family, their wives and mothers are recognised as having a strong influence over matters regarding the well-being of young girls in their family. In South Senegal, men report a much higher level of influence of leaders than do women, perhaps because they do not share women's concern about being reported for violating the anti-FGM/C law.

Men report a high influence of wives, male relatives, and their own mothers.

Figure 7. Men's average reported influence scores of decision-makers and influencers (secondary informants, $n=21$ )
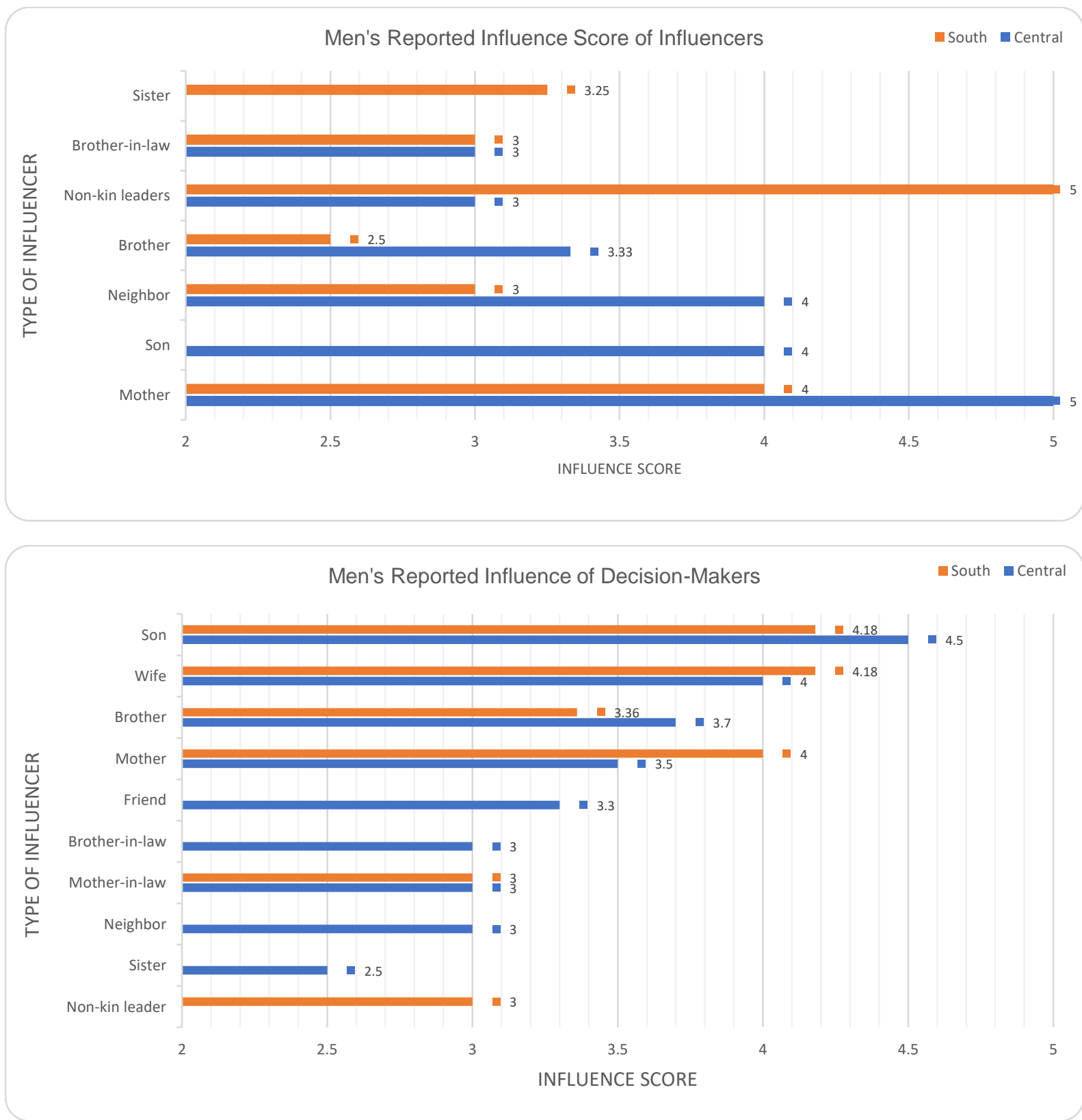

Core network members in some instances held a dual role, as both kin and leaders. For the sake of clarity, above we compared the influence score of non-kin leaders to that of family members. In 
Figure 8 we compare the influence score of leaders who are kin and those who are not kin. The data show that kin leaders have higher influence scores than non-kin leaders in both study regions. While leaders of both types are commonly excluded from excision networks because of their duty to report violators of the ban on $\mathrm{FGM} / \mathrm{C}$, as local elites their opinions are likely known, and may influence the deliberation of excision decisions (as we explore below).

Kin leaders have substantially higher influence scores that non-kin leaders.

Figure 8. Average influence score of kin and non-kin leaders in networks of care

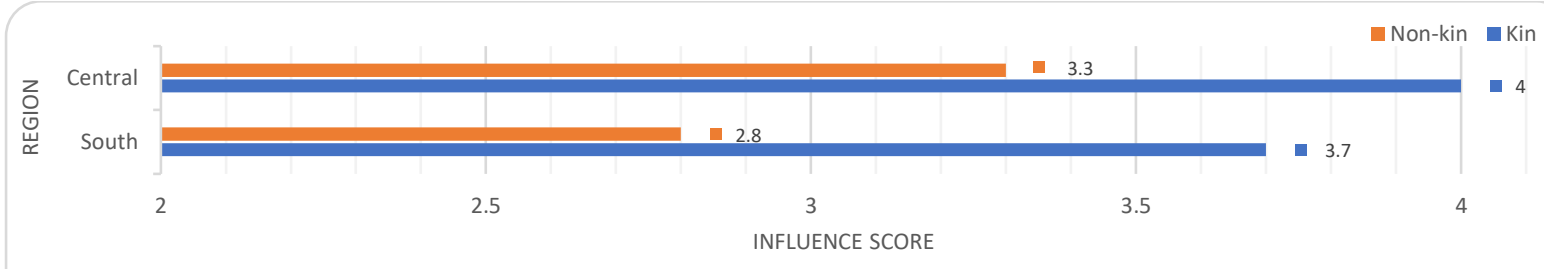

Analysing the qualitative network interviews, along with the network maps, we examine how patterns of influence and power in decision-making regarding $\mathrm{FGM} / \mathrm{C}$ potentially intersect along several lines: 1) generation, 2) gender, and 3) holding positions of leadership. Additionally, we investigate whether and how key structural factors influence $\mathrm{FGM} / \mathrm{C}$ preferences and practices across each study site.

\section{Generation: The power of older women over younger women}

In prior research in Senegal and The Gambia, Shell-Duncan and colleagues (2011) tested predictions grounded in social norms theory and found that FGM/C is best understood as a social coordination norm that can be described as an intergenerational peer convention among women, with older women holding considerable more authority and influence over FGM/C decision-making in comparison to younger women. They suggested that $\mathrm{FGM} / \mathrm{C}$ regulates relations of power and support between older and younger generations of women. Initiates are trained to "know the eye," meaning having been indoctrinated into the social hierarchy among women and know how to show deference to those in higher social strata (Shell-Duncan et al. 2011). Circumcision, they suggest, serves as a signal to other circumcised women that a girl has been trained to be obedient and to respect the authority of her circumcised elders. In this regard, the intergenerational peer convention serves to uphold women's hierarchies of power and authority and regulate access to social support and resources.

Embarking on this current study we ask: Do data on social networks and patterns of power and influence support the assertion that there are intergenerational hierarchies of power that have bearing on decision-making regarding $\mathrm{FGM} / \mathrm{C}$ ?

\section{There are intergenerational hierarchies of power among women, with young mothers, new} to their marital homes, having relatively little self-efficacy.

Our current research suggests that the intergenerational dynamics of power and influence of older women over younger women are at play in both study regions. Young mothers appear to be well aware of their relative powerlessness in hierarchies of women in their core networks. When asked about their own personal preferences regarding $\mathrm{FGM} / \mathrm{C}$, the question was often perplexing or difficult to answer since women had low self-efficacy, defined as their belief in their ability to influence the course of action (Bandura 1982). Commonly they reported that decisions would be made by those with greater decision-making authority. For instance, when asked about her 
preferences regarding whether her daughter would be cut, one young Pulaar mother in South Senegal explained, "If others decide yes, she will be excised." She added that, "When elders make a decision, one cannot refuse." The people who decide about excision, she explained, are elder women.

The intergenerational differences in power among women were evident in a number of cases.

\section{Case 31: A young mother has low perceived authority over FGM/C decision-making, while older women in the family hold a high level of influence.}

Awa is a 19-year-old South Senegalese Pulaar, married mother of two, with one boy and an infant daughter. When the topic of excision was first raised in the interview, she provided a stock response: excision should stop because it is "not good." Because of her ease with our interviewer, herself a Pulaar woman, Awa gradually opened up. She recalled the day when many in the village attended a bantaba, an open-air meeting held under a tree in the town centre. Presenters had come to the community to explain that excision is harmful, and that because of their understanding of the health risks, members of nearby communities were now abandoning the practice. Men and women in attendance were asked to agree to also stop performing excision. Afterwards, women discussing among themselves decided that it is fine for men to publicly pledge to abandon excision because, "it is not their problem." However, the women were united in their refusal to support this stance.

In recent years, excision has increasingly been organised and carried out in secret. A travelling circumciser comes to the home of the girl or a close relative in the pre-dawn darkness, performs excision, and departs before daybreak. In our interview with Awa, she shared the many benefits of excision: girls who have been excised are well mannered; men will prefer such a refined woman as a bride, as she will be respected by his family and community, and she would never be subjected to the insults and exclusion what would befall an uncut woman. "An uncut woman," Awa explains, "when people talk to her, they would say, 'Get out of here! You have not been excised.' She could be the victim of mockery and accused of being sterile.... They would say, 'she will not give birth." In this community, an uncut woman would be violating the dominant gender norms, and would influence perceptions of private sexual behaviours and fertility. Violating norms related to the formation of gender identity, sexual restraint, and feminine virtue are associated with images of an incomplete woman who would not be deemed worthy of being a wife and mother. She would also be excluded from the networks of social support offered by older women in the marital family. While Awa sees herself as having little influence, Awa's mother-in-law Sadio is, from Awa's perspective, a highly influential decision-maker, and since men in her family are not directly involved in excision decision-making, Sadio's authority is paramount. Sadio is influenced, in turn by her own motherin-law, clearly illustrating the structure of intergenerational hierarchies of authority among women. Sadio explained that the decision regarding whether to proceed with excision is now a difficult one, given that the practice has been banned by law. She notes that if there are health complications, "we will not dare" to bring girls to the hospital, for fear of being reported and prosecuted. Yet she concludes that "if it is up to me to decide, the practice should not be abandoned."

Primary respondent $A B$ is a young mother who opposes excision for her daughter but has little influence. Her mother-in-law, SS, is reported to be a highly influential decision-maker who supports FGM/C. SS reports that, in turn, her own mother-in law, KB, is highly influential, and also supports the continuation of $\mathrm{FGM} / \mathrm{C}$. 
Figure 9. Sociogram from case 31: Intergenerational influence among women

M31_A1_MAP_SSB_AB_120ct2016_ATL\&HB COMBINED
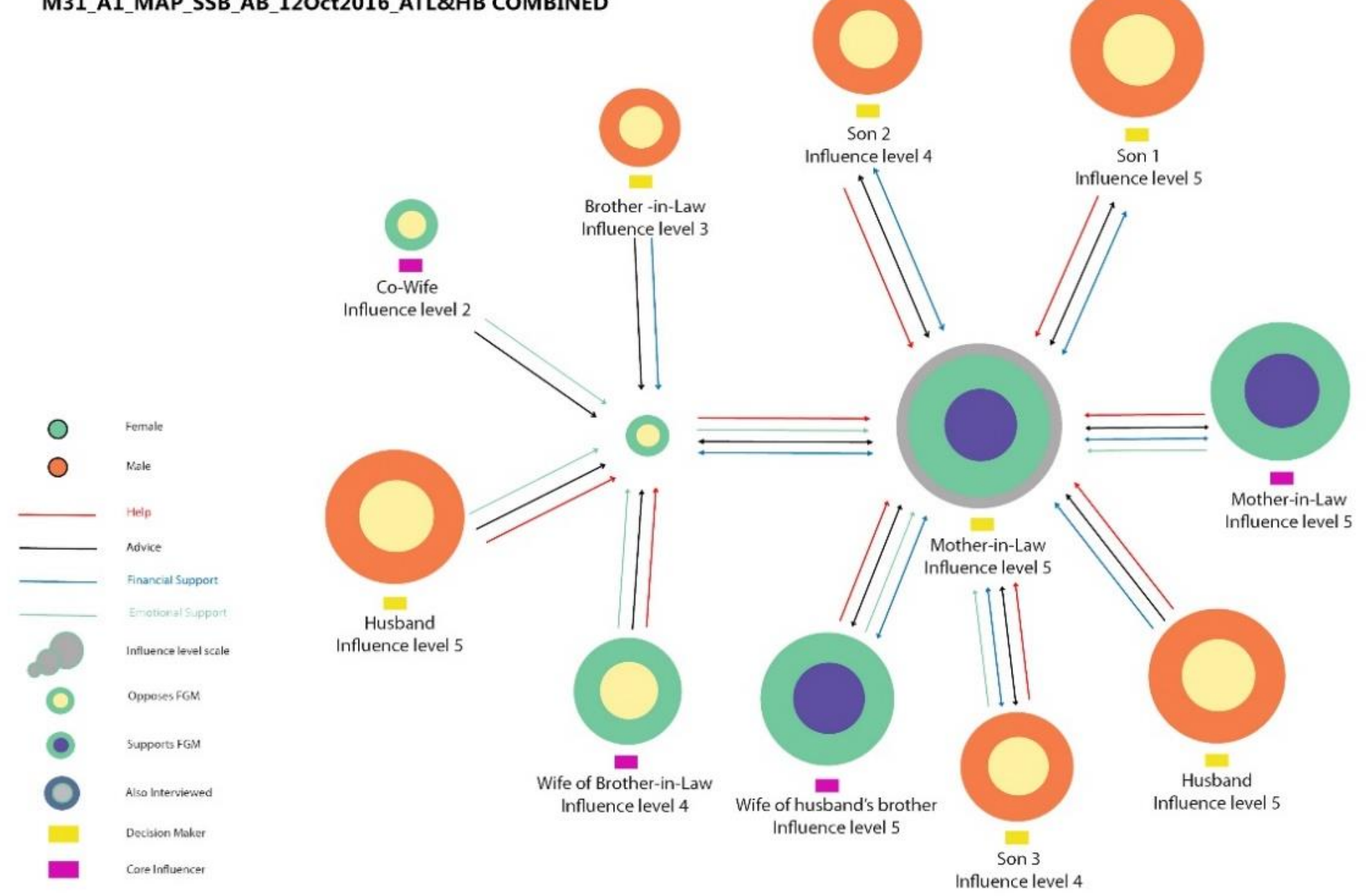
For younger community members to question older women's opinion on FGM/C (whether they now support or oppose the practice) is viewed as an affront, as well as a threat to community solidarity anchored in filial piety.

"If you find an established way of life you threaten to dismantle or to disobey, the parents will think that you are disrespecting the tradition... They will say you don't respect their culture.... If you don't follow their tradition, they will think you are not part of the community."

-18-year-old unmarried Pulaar woman, South Senegal

Hence, both younger women, as well as younger men, are in some instances unable to question decisions regarding $\mathrm{FGM} / \mathrm{C}$, as it is seen as a contemptuous challenge of the authority of older women and a threat to hierarchies of power that sustain the order and cohesion of their society.

Aubel and colleagues (2011) note that child health initiatives often target young mothers, assuming that they have the power to enact behaviour change; they argue that in many collectivist societies, this assumption is false, and that older women have much greater decision-making authority. In previous research on FGC in Senegambia, Shell-Duncan and colleagues (2018) found this to be true; this study further supports this finding. Hence, education programmes on the adverse effects of FGC that target young mothers may be reaching out to the people who have the least power of persuasion and authority to enact change. Instead, it may be more fruitful to reach out to older women as change agents for FGM/C.

\section{Older women, despite bearing the role of guardians of tradition, are not always resistant to change, and can have the power to advocate for change.}

Older women are generally considered to be custodians of tradition, and play a central role in organising events such as naming ceremonies, weddings, and in the past, coming-of-age ceremonies that once included FGM/C. Their role in passing down cultural histories, customs, and values is viewed as a crucial means of retaining cultural identity and maintaining social order.

A common negative stereotype is that older women, as guardians of tradition, are resistant to changes regarding FGM/C (Aubel 2011), and that it is the younger generation of women who most readily embrace messages calling for abandonment of the practice. This assumption has been challenged by recent research findings from Sudan (Vogt et al. 2016) and Senegambia (ShellDuncan et al. 2018) that show that older women can be open to reassessing the norms and practices of FGM/C as they seek solutions to shifting social realities. Moreover, because of their position of authority over younger women and their role in the promotion of social continuity, older women have the power and often the desire to be change leaders (Aubel et al. 2004; Aubel 2011).

Our network interviews lend support to this claim. Indeed, we found in certain instances, older women have become vocal advocates for abandonment of FGM/C. In South Senegal, this is motivated in large part by the fact that they are aware of the law banning FGM/C, and recognise that women, in particular, are under active surveillance as potential violators of the law. Fear of detection and criminal punishment and its deterrent effect on seeking health care have motivated some women to end FGM/C in their own families, and to become outspoken opponents of the practice within the community. For instance, a 26-year-old Pulaar mother explained, "Elders are sensitised, and they are getting to know the effects of excision.... Some are also advising people to stop. This is how things are unfolding in our community." In a separate interview, her motherin-law confirmed this view:

"We, the older women, no longer encourage the practice of excision....In the past, it was done but the children were all grouped in one place. And if problems occurred, they were brought to the hospital for treatment....But now, since it is 
forbidden, no one dares to have girls treated at the hospital; it is a real problem that keeps people from continuing to practise excision."

-46-year-old Pulaar woman, South Senegal

In Central Senegal, fear of prosecution plays a smaller role. Abandonment of FGM/C has more commonly resulted from the reduced social benefits of practising FGM/C, acceptance of the healthrisk messages, and in some instances, long-standing working relationships with anti-FGM/C projects. Yet mixed opinions still exist, not just across the communities, but even within extended families. When differences of opinion regarding excision arise among women within networks of care, senior women have considerable influence.

\section{Case 8: An older woman who successfully advocated for ending FGM/C}

Rama is a 25-year-old Sereer woman with five children who lives in Central Senegal. When she was very young, she explained, there was an "awareness campaign against excision." As a result, she was not excised, and she personally does not want her girls to be excised. Family members in her network of care, however, have conflicting views. Rama's in-laws hosted anti-FGM/C campaigners for years while they worked in the community, and many family members, including her husband and mother-in-law Kalilou, came to oppose excision because of the health risks. "We were made aware of the risks of excision during teaching sessions," Kalilou explained. "We have stopped the practice because it was a suffering inflicted on girls.... My youngest daughters were not excised." Rama's aunt Binta, a 30-year-old Mandinka woman whose own mother was an exciser, is a staunch and outspoken supporter of excision. She firmly rejects the health-risk messages delivered in anti-FGM/C workshops: "I am not sick, and excision did not ruin anything in me. I hear talk that excision can create difficulties during childbirth, but personally, l've never seen that!" She views this information as campaign propaganda: "Myself, I think they just wanted to make us stop the practice." Although many of our Central Senegal study participants describe a reduction in the stigma surrounding being uncut, Binta expressed strong discrimination: "Thanks to excision, we become real women.... When a woman is not excised, people say 'this girl doesn't know anything.' Others say that an uncut girl should not cook for other people." She further adds that, "When I see a woman and I know that she was not excised, I tell myself that I am worth more than her. I tell myself that this woman abandoned her tradition." Despite the scorn expressed by Binta for uncut women, Rama has the support of her mother-in-law Kalilou. Due to Kalilou's seniority among women in the extended family, Kalilou's granddaughters, including Rama's girls, have remained uncut.

While older women can be powerful advocates for change, they are not alone in calling for abandonment of $\mathrm{FGM} / \mathrm{C}$. When younger women, as well as young men, desire to convince others to stop practising $\mathrm{FGM} / \mathrm{C}$, they must do so by forging alliances with network members who have the authority to effect change. These people include not only older women, but also men, particularly fathers of young girls who are recognised as household heads.

A young Sereer woman (RS) has daughters who are not cut. This decision is supported by her mother-in-law (KJ), whose influence outweighs that of an aunt (BS) who strongly favours the continuation of $\mathrm{FGM} / \mathrm{C}$. 


\section{Figure 10. Sociogram from case 8: The power of older women in advocating for abandonment of FGM/C}
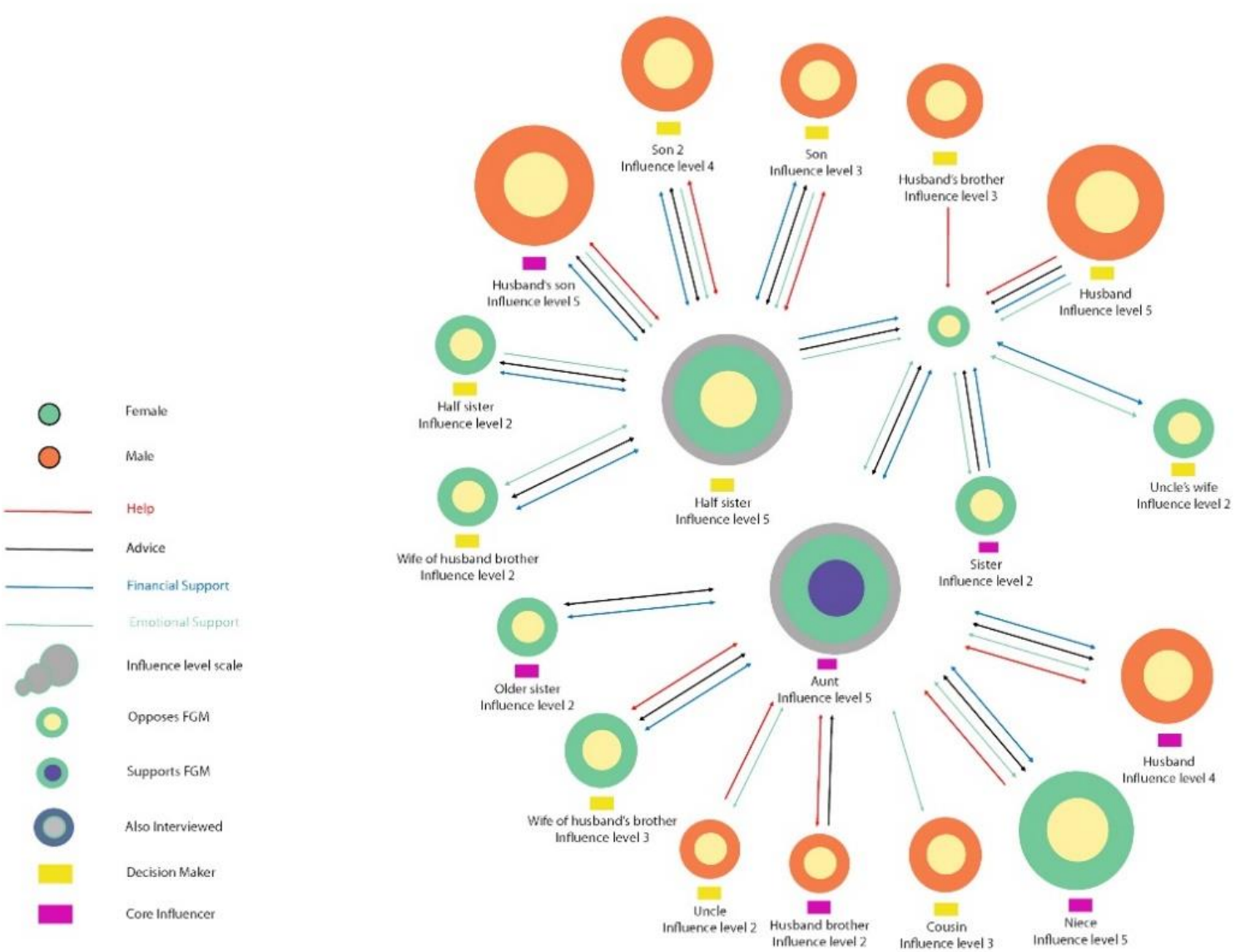

\section{The role of gender in structuring hierarchies of power and authority}

As described above, the literature on the role of men and masculinity in perpetuation of $\mathrm{FGM} / \mathrm{C}$ points to two divergent predictions. Feminist analyses long promoted the view that $F G M / C$ represents a manifestation of patriarchal structures, serving to perpetuate women's subordinate status. As such, men are predicted to view ending FGM/C as a threat to their power and authority and should be strongly vested in the continuation of the practice. By contrast, the "women's business" argument suggests that women have primary authority over decisions that pertain to certain domains of reproductive health and gender socialisation, including FGM/C. Hence, it predicts that men are hands-off in the decision-making process and should have limited interest in whether FGM/C continues or ends.

Our data from southern Senegal paint a picture of the role and influence of men that is more complex and fluid than predicted. As noted above, men, and especially fathers, were commonly listed as decision-makers regarding "important matters" for young girls. Regarding the issue of $\mathrm{FGM} / \mathrm{C}$, we found much more variability in the opinions, roles, and influence of men. In both regions men articulated compelling rationales for supporting or opposing $\mathrm{FGM} / \mathrm{C}$, and at times were internally conflicted regarding the proper course of action for girls in their family. Notably, even though $\mathrm{FGM} / \mathrm{C}$ has been traditionally organised and carried out by women, men, as husbands and fathers, often expressed a vested interest in whether the practice of FGM/C will be perpetuated and were found to influence decisions regarding excision either directly or indirectly.

How does the influence and power of men intersect with that of women? 
When men are directly involved in decision-making regarding excision, they typically have a high level of authority and influence over the final outcome, and can overrule the input of women, including those senior in women's hierarchies of power.

Above we showed that men are commonly nominated as core network members involved in "important matters" regarding the well-being of young girls. Fathers and other male family members are reported to have a high level of influence in these networks of care. It is more variable as to whether men are directly involved in excision networks, especially in South Senegal. Our data show that in both Central and South Senegal, when men are directly involved in excision networks, they typically have a tremendous amount of authority regarding the final decision, whether it is to uphold or abandon FGM/C. When differences of opinion exist among network members, men can have the power to respectfully override the preferences of women, including senior women such as their own mothers.

\section{Case 12: A father can have the authority to overrule the input of his own mother regarding whether his daughter will undergo FGM/C}

Dallo is a 33-year-old Mandinka woman who moved to Central Senegal 18 years ago when she married a Serahulé man, Bunama. Together they have seven children. Dallo's eldest daughter underwent excision at the age of three. The women who attended the event knew something was gravely wrong when the young girl fainted, and heavy bleeding continued. Binta and her "sister" Tata (fictive kinship; she is really a friend) rushed the young girl to the clinic. Dallo explained, "the doctor refused to treat her. He said I deliberately circumcised her." Because the doctor blamed her for causing the injury, the young girl was denied care. Binta boiled herbs, and gave this to the girl to drink. "She recovered, but I decided to not circumcise my other girls." Bunama and Tata supported this decision. "You could lose too much blood," Tata explained sadly. Bunama's mother remained unconvinced that girls in their family could be raised properly without undergoing excision, and she remains one of the rare outspoken supporters of excision in this community. "As you can see," Bunama explained, "in this world, consensus cannot be all the time." His delicate role has been to convince his mother to honour their decision, and not "take" the girls for excision despite the parents' wishes, something that most agree grandmothers have the right to do. Even though filial piety is a core value, as men age and become fathers, they gain stature in their own home, and acquire the authority to engage elder women, including their own mothers, in discussions about matters pertaining to the welfare of their own children.

Bunama, like many men in Central Senegal, has come to oppose the practice of FGM/C. But some men, particularly in South Senegal, express clear support for the continuation of FGM/C in their families, and can hold great sway when directly involved in the decision-making process.

The mother interviewed, DM, and her husband (BS) decided to abandon excision after their first daughter bled heavily and was denied medical care. The husband's mother (IN) is a strong supporter of $\mathrm{FGM} / \mathrm{C}$, but her son has convinced her to not have his other daughters excised. 


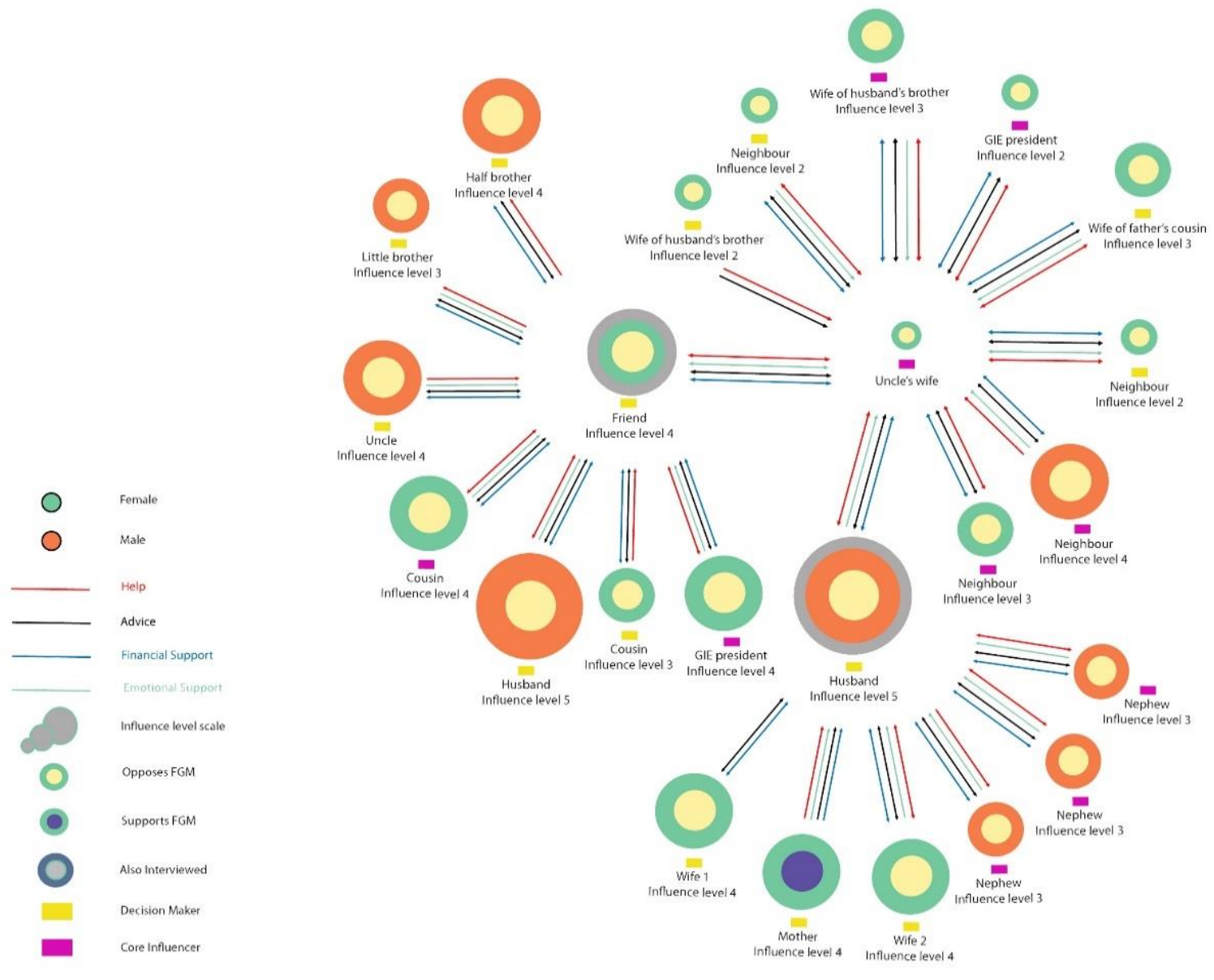

\section{Case 35: The power of men to preserve the practice of $F G M / C$ in their own family}

Khady is a 36-year-old married Pulaar woman who is a mother of seven. She resides in South Senegal in a compound shared by her husband and his second wife, her mother-in-law and fatherin-law, and her husband's two brothers (by a different mother) and their wives. Khady underwent excision at an early age, and recognised the importance of the practice in terms of the formation of women's identity and their inclusion and social recognition among other cut women. She was keenly aware that the practice has been subject to debate in her community primarily because of the criminalisation of excision. "In my knowledge...the opinions are divided," Khady explains. "Some say that because it is tradition, it must be respected, and an uncircumcised girl will have troubles finding a husband. Even if she does, she may not be treated well. For others, however, excision is prohibited by law, and that must be respected." Similarly, Khady herself is conflicted about the continuation of the practice. Early in the interview she stated that, "For me, since excision is forbidden, it should be stopped." Later her position shifted, as she noted that girls who remain uncut will still suffer from discrimination, being called "solima." She concluded that "In my opinion, we should not stop excising girls because it is a tradition and gives the girl a certain grandeur." At the same time, she acknowledged that she personally has little power or authority over the decision regarding excision for her own daughter, noting that "decisions are not shared [equally] in the family, and I do not have the last word." Notably, Khady's mother-in-law, who worries about being reported to the authorities if her granddaughter is excised, is represented in the sociogram as having much less influence than many grandmothers are accorded. The interview with Khady, as well as her brother-in-law Mamadou, revealed that the men in her marital family have the greatest 
authority over decision-making regarding excision, and while they are concerned about the law banning the practice, they ultimately have decided that it is important for girls in their family to undergo FGM/C. Mamadou explained that excision should be preserved "because it is our tradition, because we were born into it." He added that "the uncircumcised girl is difficult to penetrate, and the intervention of the circumciser is necessary." Mamadou's opinion, along with that of his brothers and father, stood in contrast to those of many older and some influential women: Khady's mother-in-law, Mamadou's mother, Mamadou's wife, and a family friend who is the president of the women's group (SD). While a final decision had not yet been reached, it appears that it will be difficult to overrule the wishes of these powerful men.

This case illustrates a number of important network features. Some people feel a tension between upholding social norms and legal norms. Members of the excision network are not all in agreement on the best course of action. Senior women, who are acutely aware that they are under surveillance and can be reported for violating the ban on FGM/C, are hesitant to carry out FGM/C for fear of prosecution. And finally, the power and influence of male relatives directly involved in $\mathrm{FGM} / \mathrm{C}$ decision-making may outweigh that of senior women in their network.

Regarding FGM/C programming, this evidence suggests that it is important to engage men, particularly fathers of young girls, and informal opinion leaders among this group of men.

A Fula mother $(\mathrm{KK})$ has powerful male relatives who support the continuation of $\mathrm{FGM} / \mathrm{C}$ (her husband, his brothers, and her father-in-law). Their influence outweighs that of older female relatives who oppose carrying out FGM/C for fear of prosecution. 
Figure 12. Sociogram from case 35: Male relatives who favour FGM/C have greater influence than older women who oppose the practice
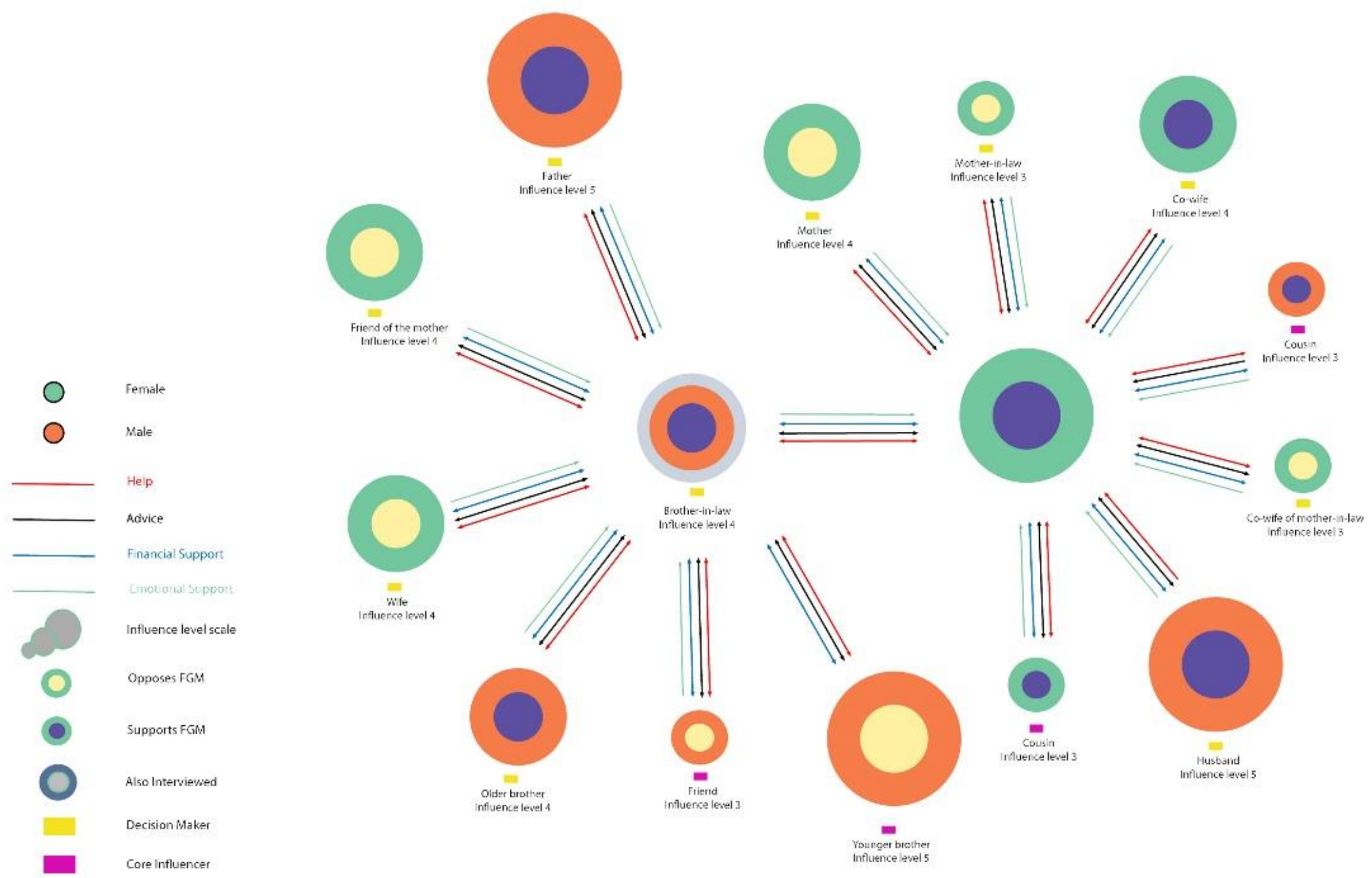


\section{When leaders and/or men are not directly involved in decision-making regarding excision, their tacit approval may be understood, and their influence may operate through women in their networks of care.}

Interviews with both men and women revealed that despite the fact that leaders and/or men are at times not directly involved with FGM/C decision-making, particularly in South Senegal, their preferences are commonly known, and exert influence on decision-makers. Gender norms define the importance of deference to men, as chef de famille (head of the family), as well as the gravity of going against their expressed or understood wishes. It appears that in South Senegal, men's negative perceptions of uncut women as wanton and insatiable; their repulsion with the image of uncut genitals; and their concerns over the standing of their family and with the moral education of their daughters can exert considerable influence over the continuation of excision, despite their lack of direct involvement in making the decision or preparing arrangements for excision to be carried out.

For instance, in case 31 (depicted above in Figure 9), men were described as uninvolved in decision-making regarding excision. Nonetheless, interviews with Awa and her mother-in-law, Sadio, revealed that they gave careful consideration to the views and preferences of men in their family. Sadio described that, along with her male relatives, she feels compelled to uphold the law banning FGM/C, yet still personally values the social benefits of the practice. Awa, for instance, recounted how men prefer cut women as potential marital partners, as they are well mannered and refined, and do not suffer the type of discrimination that uncut women experience. She believes that men feel uncut women are violating dominant gender norms, undercutting their moral transformation into fully mature and respected women, and possibly threatening their procreative potential. Awa's neighbour agreed, adding that men prefer to marry uncut girls "because they have the possibility to reproduce more easily." Thus, the perception that men prefer conformity with feminine ideals serves to influence continuation of FGM/C.

While government officials and health professionals do appear in networks of care, and are respected for their expertise, they are commonly excluded from discussion on FGM/C because of their duty to report violators. Nonetheless, as core network members, their opinions are likely known, and can possibly influence FGM/C decision-making. As we explain below, their influence appears to be contingent on their positionality (age, gender) in relation to other network members.

\section{Leaders: Shifting influence}

NGOs have been carrying out information and education workshops and implementing intervention programmes for decades, and residents in each of our study communities have had direct experience with a number of programmes. Many of our key informants, as local elites, have worked closely with or been employed by these programmes, and were well-versed in anti-FGM/C advocacy messages and strategies. They recounted experiences with educational workshops aimed at raising community awareness, intergenerational dialogues, group discussions aimed at fostering critical reflection, and public declarations to abandon FGM/C. People who had been employed by intervention programmes did appear in some network maps, and particularly when they were close family, they seemed to have an influence on persuading other network members to abandon FGM/C. However, similar to the findings of O'Neill (2013) in northern Senegal, support for their advocacy was intertwined with support for their economic opportunities through development work.

In South Senegal, a school director described how meetings with parents were an opportunity to conduct awareness-raising around the risks associated with FGM/C:

"[W]ith the awareness-raising and the mobilisation of partners who discuss the dangers of excision, all these practices and problems begin to disappear, at least decrease by a 
considerable amount...It's the role of sensitisation....[A]t each meeting, those that gather the students' parents, those at the end of the year...every time there was an opportunity that presented itself, we took advantage....So the awareness-raising continues."

-47-year-old Pulaar man, school director, South Senegal

During ethnographic network interviews, some respondents from this same community remarked that teachers have a duty to report violators of the ban on FGM/C. Notably, teachers did not appear in networks of care in any of our interviews in South and Central Senegal. However, as described above, health professionals, who are also understood to be mandatory reporters, did appear in networks of care, and particularly if they were close family members. However, because of their duty to report, they were excluded from excision networks.

It is necessary for community-based programmes to engage formal leaders; to not do so would be inappropriate. However, the findings of this study suggest that because of the exclusion of formal leaders from FGM/C networks, it may be important to also engage nonformal leaders. Regarding the issue of $\mathrm{FGM} / \mathrm{C}$, these would be nonformal leaders among older women, and nonformal leaders among fathers.

\section{Structural inequalities}

\section{Major structural factors linked to FGM/C are widening gendered disparities in health and well-being. These factors include responses to the law, gendered vulnerability to prosecution, reduced community cohesion and social support, and deterrence from seeking healthcare services.}

Patterns of power and influence revealed in our comparative case analysis of network interviews showed that community members are aware that they are embedded in a larger context of structural factors that include law, government structure, criminal justice, and access to health services.

In addition to differences in power and authority that vary along the lines of age, gender, and leadership status, within our study sites larger-scale structural factors are also at play, influencing attitudes towards legal reform strategies for ending FGM/C, perceptions of vulnerability to criminal surveillance and prosecution, and producing differential access to health care. Notably, the residents of our study sites are predominantly poor, rural, ethnic minorities with limited education. Many reported feeling relatively powerless in comparison to urban, educated elites, particularly in comparison to the Wolof, Senegal's largest ethnic group, who make up $43 \%$ of the population, dominate the government, and importantly, do not, for the most part, practice FGM/C. The term "Wolofisation" refers to an ongoing language shift among non-Wolof Senegalese, but because of the close link between language and ethnic identity, it also connotes a broader process of acculturation. Senegalese Pulaar groups, in particular, are noted for resisting these assimilative forces (McLaughlin 1999), and reactions to the legal ban on FGM/C must be understood in this context. Similar to findings reported by O'Neill (2013) regarding Pulaar communities in northern Senegal, the South Senegalese participants in our study frequently expressed resentment for having been excluded in the consultative processes that led to the drafting and adoption of legislation outlawing $\mathrm{FGM} / \mathrm{C}$, and some described the ban as an effort to "break" their culture. When respondents were asked who they believe is driving efforts to end $F G M / C$, they commonly pointed to "the government, backed by white people," (42-year-old Pulaar woman, South Senegal). Again, this resonates with O'Neill's (2013) finding that "NGO's can be seen as outsiders bringing a subtle form of cultural colonialism disguised as development. The state is seen to be corrupted by the international community." For others the law signifies the structural inequality of Senegalese ethnic minority groups who have long practiced FGM/C, and blame is pointed at the dominant ethnic group: "The Wolofs want it to stop...They said that it's not good" (24-year-old Jahanke woman, South Senegal). 
Kandala and Komba (2015) report that a nongovernmental organisation began working in 2002 in South Senegal to raise the level of acceptance of the anti-FGM/C law. Education and sensitisation were tactics aimed to "ensure that the local population did not see the ban as a central government meddling in their affairs but something that is well-founded and rational" (2015: 845). Indeed, the framing of opposition to FGM/C as a concern for health and human rights was meant to cast the ban on FGM/C as a protectionist measure rather than an assault on culture (Economist, 1999). Yet, as we explain above, in our study sites there were a wide range of responses to the law. $A$ small number of respondents considered the law to be legitimate, having been implemented to protect the health of young girls. Others, however, were not fully convinced of the health risks, nor the legitimacy of criminalising a valued cultural practice:

"In my view, excision is good for us, because, thank God, we never had any trouble in performing the practice. If there is no harm in the practice and the government is deciding simply because it wants to to fight against traditional values, then the law is not good. If anyone breaks the law and it leads to some harm he shoud be dealt with, but if there is no danger, he should not be seized because of performing excision."

-39-year-old Pulaar man, South Senegal

A clearly expressed sentiment regarding the ban on FGM/C was a feeling of powerlessness in the face of governmental efforts to end the practice. Many community members described experiencing the ban as a coercive measure requiring legal obedience in light of the power of the government. As one man explained:

"Given that the government has prohibited the practice, we have to give it up.... For me, it is a tradition inherited from our ancestors. The government's position against the practice is very recent. But given that I am not a government official, I have to obey the law... People should obey the law. In Senegal the law is very powerful. The law can be compared to God's power. People need to respect it."

-32-year-old Pulaar man

As we describe above, the criminalisation of $\mathrm{FGM} / \mathrm{C}$ has placed pressure on practising families to avoid detection and criminal punishment. Responses to this pressure are mixed; some people reportedly abandoned FGM/C because of fear of the legal repercussions, while others continued FGM/C as a covert underground practice. Networks of excision are altered in two key ways: first, by excluding leaders who have a duty to report violators of the ban on $\mathrm{FGM} / \mathrm{C}$, and second, by excluding men who would otherwise also be culpable for breaking the law. The latter change is found predominantly in South Senegal, where social networks are relatively homogeneous in terms of ethnicity and FGM/C norms. In Central Senegal, where communities are ethnically mixed and have diminished pressure to conform with the social benefits of FGM/C, abandonment of the practice is possible without suffering from severe social sanctions and stigmatisation. In South Senegal, where the social norms upholding FGM/C have not weakened, practising families face two unpalatable choices: to abandon a practice that is widely expected and is crucial to assuring social acceptance, cohesion and support, or to continue a culturally valued practice despite the threat of legal sanctions and inaccessibility to health care. The pressure to uphold the practice of $\mathrm{FGM} / \mathrm{C}$ is not rooted solely in gender norms concerning the domination of men over women, sexually or otherwise. Instead, it is tied to concerns over how to assure the well-being of a young girl in a community characterised by low levels of education, few opportunities beyond the role of wife and mother, a high level of uncertainty in the face of crisis, and reliance on social networks to cope with that uncertainty. Legal measures are intended to protect the health and human rights of girls and women, but fail to afford alternatives for women's empowerment and welfare. Thus, the major structural factors at play include high levels of poverty, gendered vulnerability to prosecution, eroding social cohesion and support as networks constrict and FGM/C is driven underground, and 
deterrence from seeking health care. Together these factors combine to widen gendered disparities in health and well-being.

\section{Intersecting axes of power and influence over FGM/C}

\section{Power dynamics are often influenced along intersecting axes of generation, gender, social status, and locality, along with structural inequalities.}

Our data suggest that there are important intersections along the axes of generation, gender, locality (the diversity of the reference group in terms of ethnicity and FGM/C practices), and leadership status that appear to be important in influencing the process of weighing social benefits of $\mathrm{FGM} / \mathrm{C}$ against the potential health and legal risks of carrying out the practice. These factors are also intertwined with the influence of structural inequalities. This is illustrated in the following case:

\section{Case 24: The simultaneous influence of generation, gender, and leadership status}

Aminata is a 24-year-old Pulaar mother of three from South Senegal, and her 19-year-old sisterin-law (wife of her husband's brother), Binta, was also interviewed. Both women stated that girls in their family will not be excised, and their stated rationale was couched in terms of both the need to comply with the law and to avert legal sanctions. While both women cited the risk of contracting HIV from shared cutting instruments, Aminata was ambivalent about the risks to reproductive health. In particular, she claimed that excised women "can deliver children a lot more easily than non-excised women." Both Aminata and Binta are fearful of the ban on excision and know that penalties can be levied against women who arrange for their daughters to be excised, as well as the exciser. Binta, in fact, witnessed a person being arrested for performing FGM/C in a town not very far away from their community. Binta and Aminata's mother-in-law Mariama, however, is not concerned about the law, and values the social benefits of upholding the practice. She has told her daughter-in-laws that, "if they [young girls] are not excised, they will have no value whatsoever," and added that "a girl who has not been excised has been marked as impure." The women's network includes three health professionals, two female midwives, and a male neighbour who is a community health officer; each of them play an important role in disseminating information on the health risks of $\mathrm{FGM} / \mathrm{C}$ and are thought to have a duty to report people who violate the criminal ban. While the level of influence of these health professionals is reported to be low and they are excluded from discussions on excision, their presence likely influences dynamics in the rest of the network. Traditional hierarchies of power are evident in this network map. The husbands of Aminata and Binta have a high level of influence, as does their mother-in-law, Mariama. Additionally, the direction of support and influence runs from Mariama to her daughter-in-laws, a reflection of the traditional hierarchies of authority of older women over junior women in their families. Thus, Aminata and Binta are relatively powerless to oppose Mariama's support for having excision carried out. The husbands of both Aminata and Binta are convinced that there is a high risk of legal sanctions against women in their family, should excision be carried out, perhaps because of the family's close ties to health personnel who are believed to have a duty to report violators of the ban on $\mathrm{FGM} / \mathrm{C}$. Because these men have strong concerns over legal sanctions, they have been able to challenge their mother's position on FGM//C. And with their backing, the young daughters in this family have reportedly not been excised.

$A D$ and her sister-in-law (wife of husband's brother) BB oppose FGM/C, as do their husbands, for fear of prosecution. Their mother-in-law MB favours excision and has great authority over her daughters-in-law, but is overruled by her sons. Several network members who are health professionals ( $A D$ and $M B$ are midwives, $Y B$ is a community health worker) advocate for abandoning $\mathrm{FGM} / \mathrm{C}$ and are believed to have a duty to report violators; although they are excluded from the excision network, they may influence the decisionmakers. 
Figure 13. Sociogram from case 24: Intersecting influences of gender, generation, and leaders who advocate for ending FGM/C, and gendered fear of prosecution

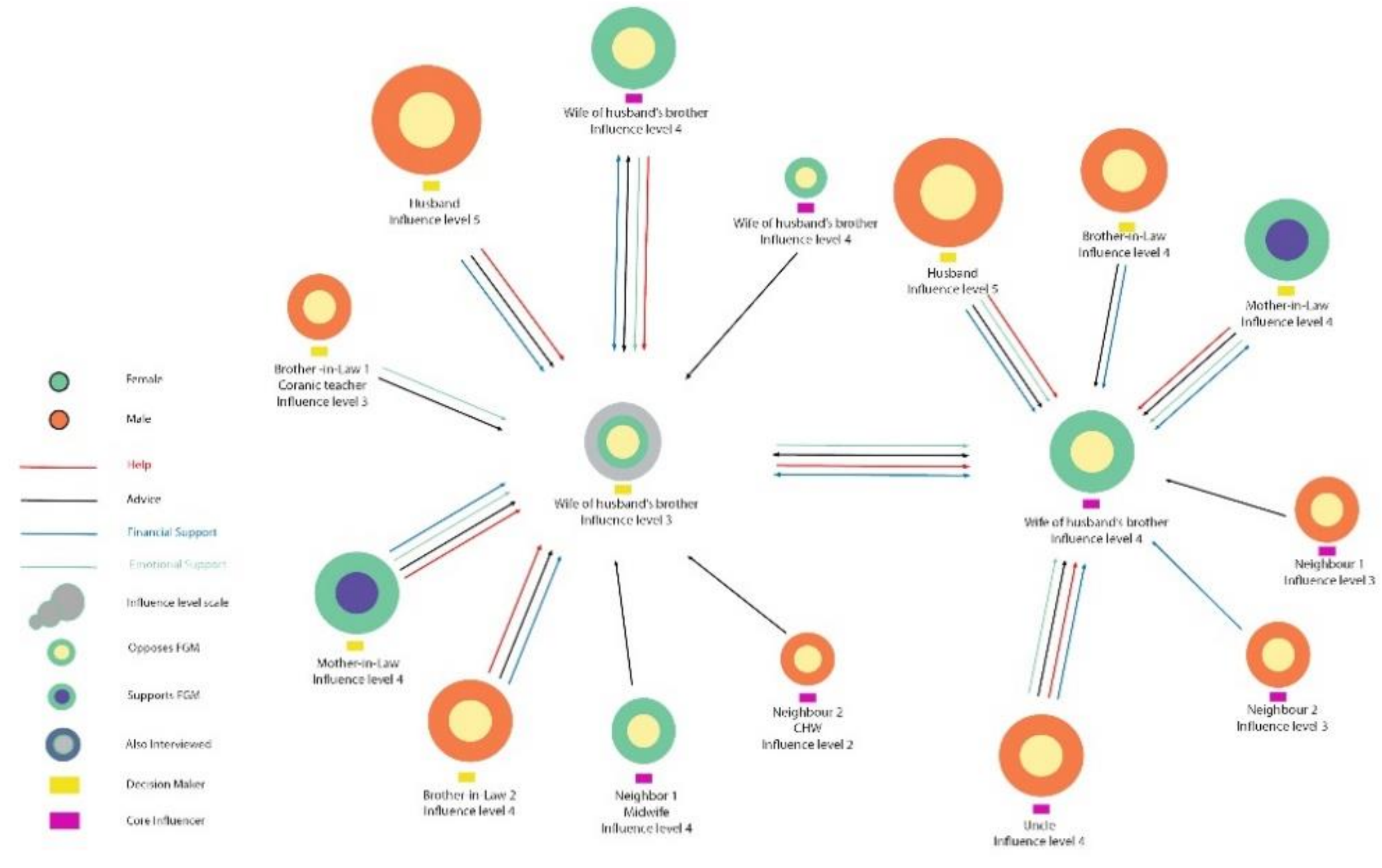


The main intersecting axes of power influencing FGM/C are visually summarised in Figure 14. Importantly, we find that characterising FGM/C as a form of patriarchal oppression of women is overly simplistic. FGM/C most certainly is an important element of feminine gender identity, but the social norms surrounding this, particularly in relation to marriageability and inscribing feminine virtue, have weakened and all but disappeared in Central Senegal; these changes are found among men and women. Notably, the power and influence of men and women regarding FGM/C shift across their life course. Men acquire power and influence as they become fathers and recognised as the head of the family - that is patriarchs. At the same time, women acquire power as they age, becoming matriarchs. Thus, patriarchy and gerontocracy are simultaneously at play.

Another important axis of power and influence concerns leaders, who are local elites. Their influence has become complicated by the fact that many leaders have collaborated or worked for anti-FGM/C initiatives, and are understood to have a duty to report violators of the ban on FGM/C. Thus, with the exception of leaders who are close kin, they have become excluded from excision networks. Their presence, however, may be influential.

Diversity in the reference group is starkly different in our two study sites. In South Senegal, networks of care are homogeneous, composed largely of Pulaar who have long-practiced FGM/C. In Central Senegal, networks are quite diverse, in terms of ethnicity and FGM/C traditions. This diversity appears to open "exit options" as people opt to abandon FGM/C.

At the same time, structural inequalities are mapped onto this constellation of local axes influencing FGM/C. The members of our study live in rural, poor communities that have limited educational and economic opportunities and low educational attainment. The law banning FGM/C has made women disproportionately vulnerable to prosecution, and imposed a deterrent to seeking health care, as the evidence of the crime is inscribed on their bodies. Leaders are understood to be mandated to report violators of the criminal ban on $\mathrm{FGM} / \mathrm{C}$, driving the practice underground and eroding trust and social cohesion. Moreover, people feel marginalised from the political processes that are driving legislative reform strategies, and view this as a mechanism for "forced assimilation."

How might programming aimed at ending FGM/C also address these broader structural factors? Is further research needed to understand barriers to education for girls and boys alike? Is research needed to identify possible income-generating activities that might supplement agricultural production? Do programmes that promote birth registration and voting increase a sense of political power in rural minority communities? Is it clear how to improve access to health care for girls and women living with $\mathrm{FGM} / \mathrm{C}$ ? Are there successful programmes that already aim to reduce these structural inequalities? Collaboration with development experts may answer many of these questions, and point to ways of using the evidence generated in this study to optimise programmes aimed at ending $\mathrm{FGM} / \mathrm{C}$. 


\section{Figure 14: Intersecting axes of power and influence over FGM/C in two rural Senegalese communities}

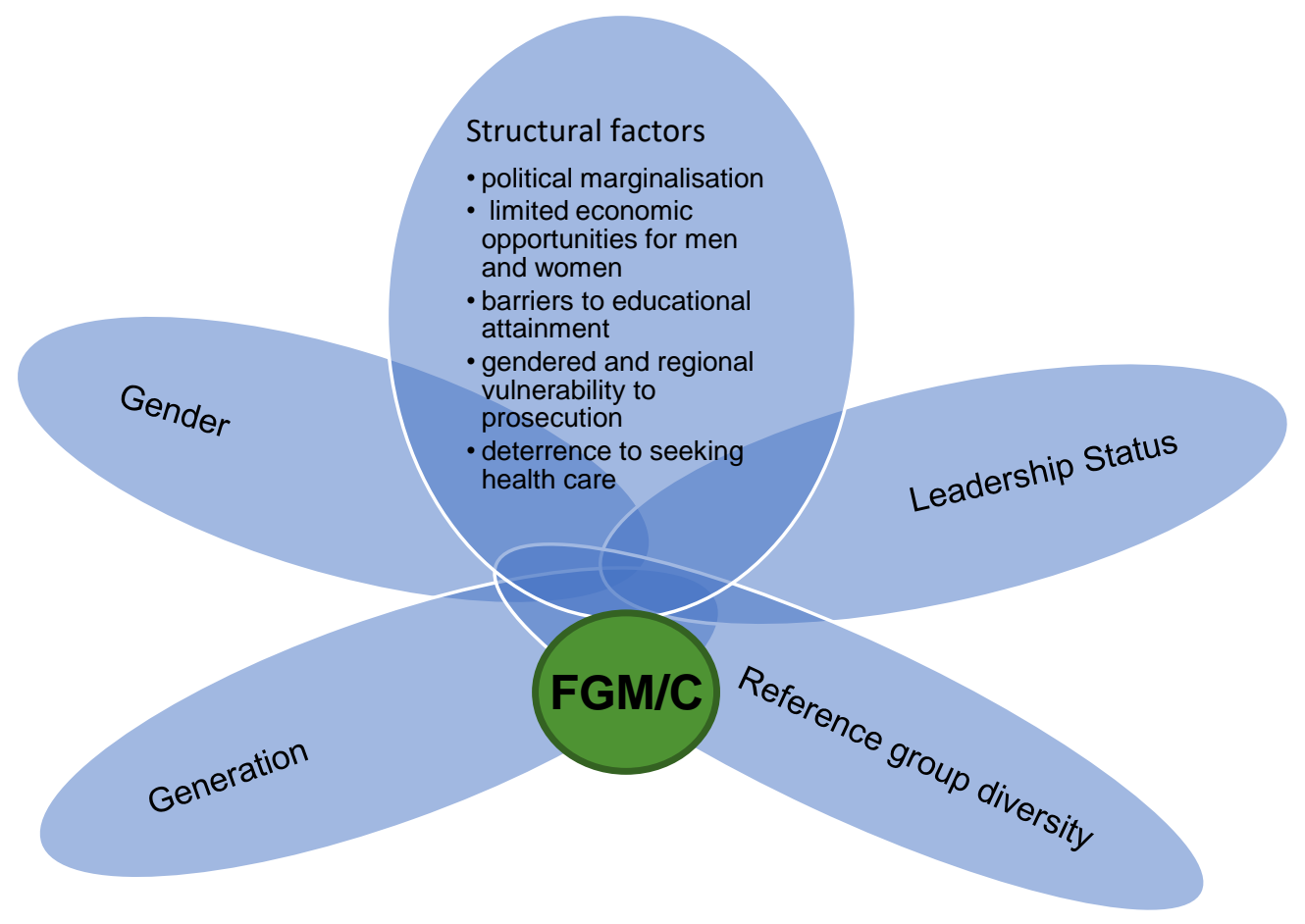

\section{Limitations}

This study applied a parallel mixed-methods approach to the study of social networks that involved first conducting in-depth social network interviews aided by the co-production of a sociogram. This rich qualitative data allowed us to then quantify selected metrics and provide statistical results. While this study represents one of the first large-scale efforts to apply social network methods to the study of $\mathrm{FGM} / \mathrm{C}$, this design falls short of the two common quantitative network study approaches: 1) egocentric studies, that involve survey data collection of network data from a large, randomly selected portion of a study population (Marin and Hampton 2007); and 2) sociocentric network studies, which obtain quantitative network data from an entire study population (Valente 2010; Shakya et al. 2017). The latter provide information on the architecture of social networks and allow for the identification of people in key positions, such as central opinion leaders or people who bridge subgroups in a community. Nonetheless, the approach adopted in this study generated rich qualitative and quantitative information on the social interactions salient to the formation of social norms surrounding $\mathrm{FGM} / \mathrm{C}$, as well as patterns of power and influence. We have documented lessons learned in the process of implementing this innovative methodology in detail (see Shell-Duncan et al. 2019b).

One important limitation of our study (one that would make quantitative egocentric or sociocentric studies difficult) is that participants were often reluctant to disclose their personal opinion on FGM/C or their perception of the opinion of their network partners. This was because of people's awareness that $\mathrm{FGM} / \mathrm{C}$ has been subject to censure and criminalised. This reluctance was, however, in and of itself important information. By triangulating our first-degree interview with second-degree interviews of influential network members, and also collecting focus group data 
and key informant interviews, we were able to obtain a rich picture of the social norms, network dynamics, and structural factors influencing FGM/C.

\section{Discussion and Summary}

The goal of this study is to integrate the analysis of the social norms and meanings associated with the practice of $\mathrm{FGM} / \mathrm{C}$, the ways in which these norms are being upheld or contested, and the social interactions that shape the formation and possible weakening of the norms. We find an intersectional analytic approach to be useful for understanding the gender dimensions influencing $\mathrm{FGM} / \mathrm{C}$ in the context of other dimensions of inequality in power that run along the lines of age, gender, ethnicity, locality, and broader structural divisions in Senegalese society. Importantly, intersectionality draws attention to the fact that local divisions that shape and constrain power must be understood in a broader social context (Collins and Bilge 2016). It is from this perspective that we examine power and influence on decisions to perform $\mathrm{FGM} / \mathrm{C}$, attempting not to single out gender inequality, but rather highlighting the intersecting axes of influence on decision-making.

We find that FGM/C is indeed "women's business" to the extent that it is arranged and carried out by older women on young girls. There is a generational component, wherein FGM/C confers access to the resources and support offered by older women; this system is however, in flux, and changing rapidly, particularly in Central Senegal. Men, however, are far from uninvolved in FGM/C, with fathers and their brothers commonly included in core networks of care and having high influence over FGM/C decision-making. Moreover, men have the ability to negotiate with older women who also have great influence over $\mathrm{FGM} / \mathrm{C}$ decision-making; indeed, when men are directly involved in decision-making, they commonly are advocating for abandonment of FGM/C. When they are not directly involved, their opinion about whether FGM/C should continue is often well known and influences decision-making. At the same time, broader structural factors are altering the role of men in excision networks. In South Senegal in particular, men are increasingly excluded from excision networks in order to minimise detection of criminal activity and protect men from prosecution. Formal leaders, including the Alkalo, health professionals, and teachers, are also commonly excluded from core networks of care because of their perceived duty to report violators of the ban on FGM/C. Additionally, structural factors are exacerbating disparities in health and wellbeing.

Residents of our rural study sites in Central and South Senegal worry about the viability of agriculture as an exclusive livelihood strategy and share concerns about the future welfare of their daughters in this setting filled with uncertainty. A pervasive sentiment among community members is that life is precarious because of economic instability, climatic instability, and political powerlessness. In turn, residents rely heavily upon their social networks for protection of and access to resources-possibly now more than ever. Lineage and marriage systems provide the foundation for these network ties. Thus, the importance of marriage in forging connections to enhance social support is of paramount importance, as is abiding by social norms that confer acceptance and access to social inclusion. It is within this context that FGM/C must be understood. We suggest that a fruitful alternative may involve exploring opportunities for opening alternative routes to achieving the goal of securing the future well-being of their daughters and families. How else might community members adapt to precarity in their lives? Solutions may involve strategies other than educating residents on the legal and health risks of FGM/C. Ignoring the disjuncture between social norms and meanings at the local level and legal norms introduced and enforced by the state seems to amplify resistance and further alienate a poor, rural, and minority population that already feels powerless and marginalised. This supports the assertion made by WHO (2012: 6): "FGM has rarely been abandoned when programmes against the practice have been perceived by the community as attacking and criticising local culture and values, and/or as driven by 
outsiders." Women are acutely aware that they are under surveillance and at risk of being reported as suspected violators of the ban on FGM/C. Additionally, the very population who has the greatest need for specialised reproductive health care-girls and women living with FGM/C-have increasingly limited access to professional medical treatment. Thus current strategies aimed at curbing FGM/C may be serving instead to increase marginality and exacerbate health disparities among rural girls and women.

Empirical studies of FGM/C often aim to identify girls who are "at risk" of being cut, along with the factors associated with variation in the level of risk. Programmes and policies aimed at ending FGM/C often focus on improving knowledge of the health effects and legal ramifications, facilitating a re-assessment of social norms through dialogue on values, and providing an "enabling environment" for abandonment of FGM/C by criminalising the practice and signing on to human rights treaties (Shell-Duncan 2008; UNICEF 2013). These change strategies rest on internalised norm change among decision-makers and coordinating change with members of their social networks. We argue that along with focusing on "risk," it is important to also invoke the concept of vulnerability, the differential ability to cope with social stressors or challenges (Chambers 1989). While "risk factors" are most often understood to be traits of an individual (e.g. ethnicity, age), family (e.g. economic status) or community (e.g. harmful social norms), vulnerability is not simply an attribute of the individual or the community, but the consequences of systems of power and access to resources in which they are situated. As we note above, it has two sides: 1) the challenges that an individual, family, or community are exposed to, and 2) factors that influence their ability to cope with these challenges (Chambers 1989).

Applied to the issue of FGM/C, it is important to recognise that the practice is not, for the most part, perpetuated out of ignorance of the health risks or criminal ban, nor out of a blind adherence to "tradition." Instead, it represents a strategy to cope with the challenges faced by families who seek to assure the future welfare of their daughters. In addition to focusing on "risk," it may be useful to ask, what are the intersecting factors that produce vulnerability to FGM/C? What is needed to diminish vulnerability, and allow individual, families, and communities to be resilient to the challenges they face. How can resilience be strengthened in a fashion that reduces the coping benefits of $F G M / C$ ? Vulnerability is, after all, not static; it can accumulate, shift over time and space, and be reduced when resilience is strengthened. Hence, the question we pose is, how can resilience be strengthened in a fashion that reduces the benefits of performing $\mathrm{FGM} / \mathrm{C}$ ? Intersectional analyses, we suggest, may offer insights on how to proceed.

\section{Implications for Policy/Programmes/Research}

This study has generated numerous new insights on the norms and meanings associated with $\mathrm{FGM} / \mathrm{C}$, the ways in which they are changing, and the social interactions and structural factors that are influencing the perpetuation, alteration, or abandonment of the practice. Our findings point to the importance of engaging older women and men, particularly fathers of young girls and their brothers, as well as addressing structural barriers to abandonment of FGM/C. We recommend that next steps involve working with experts in development to explore ways in which these findings can inform policies and programmes aimed at ending FGM/C. We propose the following next steps: First, organise a facilitated consultation in Senegal with development experts to share the evidence emerging from this study. These development partners would include people from established NGOs such as Tostan, The Girls' Holistic Development Project, World Vision, and Global Research and Advocacy Group. It would also include officials from the UNFPA-UNICEF Joint Programme on FGM/C and relevant government ministries. A goal of this consultation would be to begin the process of exploring the ways in which research findings from this study may inform and be incorporated into programmes and policies aimed at accelerating abandonment of $\mathrm{FGM} / \mathrm{C}$. 
Second, we would like to collaborate with and support development partners in the creation of concrete plans for conducting a trial of innovative approaches, and if welcomed, we would like to conduct implementation science studies on the systematic uptake of results, and document whether there are detectable anticipated improvements in programming results, or possibly unanticipated outcomes pointing to needs for reconsideration and modification within specific contexts. Such a collaboration is intended to document what works, where, and with whom, and can lend insights on means for strengthening monitoring and evaluation. And finally, we recommend the sharing of implementation science study findings with programme implementers, donors, and policymakers alike, reflecting on lessons learned, and planning next steps for strengthening programmes aimed at accelerating the abandonment of FGM/C. 


\section{References}

\section{Journal article}

Abusharaf, R.M. 1996. Revisiting feminist discourses on female infibulation: Responses from Sudanese indigenous feminists. Paper presented at annual meeting of the American Anthropological Association, San Francisco, November.

Armstrong, E.A., L. Hamilton, E.M. Armstrong, and J.L. Seeley. 2014. "'Good grls': Gender, social class, and slut discourse on campus," Social Psychology Quarterly 77(2): 100-122.

Aubel, J. 2011. "The role and influence of grandmothers on child nutrition: Culturally designated advisors and caregivers," Maternal and Child Nutrition 8(1): 19-35.

Aubel, J., I. Toure, and M. Diagne. 2004. "Senegalese grandmothers promote improved maternal and child nutrition practices: The guardians of tradition are not averse to change," Social Science and Medicine 59: 945-959.

Bandura, A. 1982. "Self-efficacy mechanism in human agency," American Psychologist 37(2): $122-147$.

Boddy, J. 1982. "Womb as oasis: The symbolic content of pharaonic circumcision in rural northern Sudan," American Ethnologist 9(4): 682-698.

Boddy, J. 2016. "The normal and the aberrant in female genital cutting: Shifting paradigms," HAU: Journal of Ethnographic Theory 6(2): 41-69.

Camilotti, G. 2016. "Interventions to stop female genital cutting and the evolution of the custom: Evidence on age at cutting in Senegal," Journal of African Economies 25(1): 133-159.

Carney, J. and M. Watts. 1991. "Disciplining women? Rice mechanization, and the evolution of Mandinka gender relations in Senegambia," Signs: Journal of Women in Culture and Society 4: 651-681.

Chambers, R. 1989. "Editorial introduction: Vulnerability, coping and policy," IDS Bulletin (Institute of Development Studies) 20(2): 1-7.

Cislaghi, B. and L. Heise. 2018a. "Four avenues of normative influence: A research agenda for health promotion in low and middle-income countries," Health Psychology 37(6): 562-573. http://dx.doi.org/10.1037/hea0000618.

Cislaghi, B., and Heise, L.2019. Using social norms theory for health promotion in low-income countries. Health Promotion International, 34(3), 616-623.

Cislaghi, B., and Heise, L. (2019. Gender norms and social norms: differences, similarities and why they matter in prevention science. Sociology of Health \& IIIness.

Cobbah, J. 1987. "African values and the human rights debate: An African perspective," Human Rights Quarterly 9: 309-331.

Crenshaw, K. 1991. "Mapping the margins: Intersectionality, identity politics and violence against women of color," Stanford Law Review 43(6): 1241-1299.

Desantis, J. 2008. "Exploring the concepts of vulnerability and resilience in the context of HIV infection," Research and Theory for Nursing Practice 22(4): 273-287.

Gillespie, D. and M. Melching. 2010. "The transformative power of democracy and human rights in nonformal education: The case of Tostan," Adult Education Quarterly 60(5): 477-498.

Gosselin, C. 2000. "Feminism, anthropology and the politics of excision in Mali: Global and local debates in a post-colonial world," Anthropologica XLII(1): 43-60.

Gruenbaum, E. 2005. "Sociocultural dynamics of female genital cutting: Research findings, gaps and directions," Culture, Health and Sexuality 7(5): 429-441.

Hankivsky, O. 2012. "Women's health, men's health, and gender and health: Implications of intersectionality," Social Science and Medicine 74: 1712-1720.

Heise, L., M.E. Greene, N. Opper, M. Stravopoulou, C. Harper, M. Nascimento, and D. Zewie. 2019. "Gender inequality and restrictive gender norms: framing the challenges to health. The Lancet (Special Series on Gender Equality, Norms and Health), 393(10189): 22402454. https://doi.org/10.1016/S0140-6736(19)30652-X

Hernlund, Y., and B. Shell-Duncan. 2007. "Contingency, context and change: Negotiating female genital cutting in The Gambia and Senegal," Africa Today 54(4): 43-57.

lyer, A., G. Sen, and P. Osterlin. 2008. "The intersections of gender and class in health status and health care," Global Public Health 3: 13-24. 
Kandala, N.-B., and P. Komba. 2015. "Geographic variation of female genital mutilation and legal enforcement in sub-Saharan Africa: A case study of Senegal," The American Journal of Tropical Medicine and Hygiene 92(4): 838-847.

Kandala, N.-B., and B. Shell-Duncan. 2019. "Trends in female genital mutilation/cutting in Senegal: What can we learn from successive household surveys in sub-Saharan African countries? International Journal for Equity in Health 18: 25. https://doi.org/10.1186/s12939-018-09079

Kingston, C., G. Irikana, V. Dienye, and K.G. Kingston. 2011. "The impact of the World Bank and IMF Structural Adjustment Programmes on Africa: The case study of Cote d'Ivoire, Senegal, Uganda, and Zimbabwe," Sacha Journal of Policy and Strategic Studies 1(2): $110-130$.

Mackie, G. 1996. "Ending footbinding and infibulation: A convention account," American Sociological Review 61: 999-1017.

Marin, A., and K.N. Hampton. 2007. "Simplifying the personal network name generator," Field Methods 19: 163.

McLaughlin, F. 1999. "Haalpulaar idenity as a response to Wolofization," African Languages and Culture 82(2): 153-168.

Patil, V. 2013. "From patriarchy to intersectionality: A transnational feminist assessment of how far we've really come," Signs: Journal of Women in Culture and Society 38(4): 847-867.

Ribera, J. M. and S. Hausmann-Muela. 2011. "The straw that breaks the camel's back: Redirecting health-seeking behavior studies on malaria," Medical Anthropology Quarterly 25(1): 103121.

Schwalbe, M., D. Holden, D. Schrock, A. Goodwin, and S. Thompson. 2000. "Generic processes in the reproduction of inequality: An interaction analysis," Social Forces 79(2): 419-452.

Shakya, H.B., C.J. Farris, C. Ojeda, A. Raj, and E. Reed. 2017. "Sexual network clustering of sexual violence experienced by adolescent girls," American Journal of Epidemiology 186(7): 796-804. https://doi.org/10.1093/aje/kwx154.

Shell-Duncan, B. 2008. "From health to human rights: Female genital cutting and the politics of intervention," American Anthropologist 110(2): 225-236.

Shell-Duncan, B., A. Moreau, K. Wander, and S. Smith. 2018. "The role of older women in contesting norms associated with female genital mutilation/cutting: A factorial focus group analysis," PLoS ONE 13(7): e0199217. https://doi.org/10.1371/journal.pone.0199217.

Shell-Duncan, B., K. Wander, Y. Hernlund, and A. Moreau. 2011. "Dynamics of change in the practicepractise of female genital cutting in Senegambia: Testing predictions of social convention theory," Social Science and Medicine 73: 1275-1283.

Shell-Duncan, B., Wander, K., Hernlund, Y., and Moreau, A. 2013. Legislating change? Responses to criminalizing female genital cutting in Senegal. Law \& society review, 47(4), 803-835.

Vogt, S., N.A.M. Zaid, H.E.F. Ahmed, E. Fehr, and C. Efferson. 2016. "Changing cultural attitudes towards female genital cutting," Nature 538: 506-509. doi:10.1038/nature20100

Wade, L. 2011. 'Learning from 'female genital mutilation': Lessons from 30 years of academic discourse," Ethnicities 12(11): 26-49.

Walley, C.J. 1997. "Searching for 'voices': Feminism, anthropology, and the global debate over female genital operations," Cultural Anthropology 12(3): 405-438.

West, C. and D. Zimmerman. 1987. "Doing gender," Gender and Society 1(2): 125-151.

\section{Book}

Bernard, H.R. 2011. Research Methods in Anthropology: Qualitative and Quantitative Approaches. 5th Ed. Lanham, MD: AltaMira Press.

Bledsoe, C.H. 2002. Contingent Lives: Fertility, Time and Aging in West Africa. Chicago: University of Chicago Press.

Collins, P.H., and S. Bilge. 2016. Intersectionality. Cambridge: Polity Press.

Creswell, J.W. 2007. Qualitative Inquiry and Research Design: Choosing among Five Approaches, 2nd Ed. Thousand Oaks, CA: Sage Publications, Inc.

Ellickson, R.C. 1991. Order without Law: How Neighbors Settle Disputes. Cambridge, MA: Harvard University Press. 
Engels, F. 1884. The Origin of the Family, Private Property and the State. New York: International Publishers.

Goffman, E. 1963. Stigma: Notes on the Management of Spoiled Identity. Englewood Cliffs: Prentice-Hall.

Knodel, J. 1993. "The design and analysis of focus group studies: A practical approach," in D.L. Morgan (ed.), Focus Groups: Advancing the State of the Art, 35-50. Newbury Park, CA: Sage Publications.

Kratz, C. 1994. Affecting Performance: Meaning, Movement, and Experience in Okiek Women's Initiation. Washington DC: Smithsonian Institution Press.

Lerner, G. 1986. The Creation of Patriarchy. Oxford: Oxford University Press.

Middelburg, A. 2016. Empty Promises? Compliance with the Human Rights Framework in Relation to Female Genital Mutilation/Cutting in Senegal. Rillburg, the Netherlands: PrismaPrint.

Posner, E.A. 2000. Law and Social Norms. Cambridge, MA: Harvard University Press.

Schroeder, R. 1999. Shady Practices: Agroforestry and Gender Politics in The Gambia. Berkeley: University of California Press.

Strauss, C. and N. Quinn. 1997. A Cognitive Theory of Cultural Meaning. Cambridge: Cambridge University Press.

Sylla, M.H.S. 1990. Excision au Sénégal (Série Études et Recherches \#137). Dakar: ENDA.

Valente, T.W. 2010. Social Networks and Health: Models, Methods, and Applications. New York: Oxford University Press.

Yoder, P.S., P.O. Camara, and B. Soumaoro. 1999. Female Genital Cutting and Coming of Age in Guinea. Calverton, MD: Macro International Inc.

Wilkins, A.C. 2008. Wannabes, Goths, and Christians: The Boundaries of Sex, Style, and Status. Chicago: University of Chicago Press.

\section{Article or chapter in an edited book}

Abusharaf, R.M. 2000. "Revisiting feminist discourses on infibulation: Responses from Sudanese feminists," in B. Shell-Duncan and Y. Hernlund (eds.), Female "Circumcision" in Africa: Culture, Controversy, and Change, 151-166. Boulder, CO: Lynne Rienner.

Ahmadu, F. 2000. "Rites and wrongs: An insider/outsider reflects on power and excision," in B. Shell-Duncan and Y. Hernlund (eds.), Female "Circumcision" in Africa: Culture, Controversy, and Change, 283-312. Boulder, CO: Lynne Rienner.

Botte, R. 1999. "Un Peul peut chacher un autre," in R. Botte, J. Boutrais, and J. Schmitz (eds.), Figures Peules, 7-18. Paris: Karthala.

Falcáo, R. 2018. "Resistance to change: FGM/C and gendered inequality in Senegal," in M. Fusaschi and G. Cavortorta (eds.), FGM/C: From Medicine to Critical Anthropology, 181194. Turin: Meti Edizioni.

Gilliam, A. 1991. "Women's equality and national liberation," in C.T. Mohanty, A. Russo, and L. Torres (eds.), Third World Women and the Politics of Feminism, 215-236). Bloomington, IN: University of Indiana Press.

Harrell, S. and G. Santos. 2017. "Introduction," in G. Santos and S. Harrell (eds.), Transforming Patriarchy, 3-36. Seattle and London: University of Washington Press.

Hernlund, Y. 2000. "Cutting without ritual and ritual without cutting: Female 'circumcision' and the re-ritualization of initiation in the Gambia," in B. Shell-Duncan and Y. Hernlund (eds.), Female "Circumcision" in Africa: Culture, Controversy, and Change, 235-252. Boulder, CO: Lynne Rienner.

Mackie, G. 2000. "Female genital cutting: The beginning of the end," in B. Shell-Duncan and Y. Hernlund (eds.), Female "Circumcision" in Africa: Culture, Controversy, and Change, 253283. Boulder, CO: Lynne Rienner.

Thomas, L. 2000. "'Ngaitana (I will circumcise myself)': Lessons from colonial campaigns to ban excision in Meru, Kenya," in B. Shell-Duncan and Y. Hernlund (eds.), Female "Circumcision" in Africa: Culture, Controversy, and Change, 129-150. Boulder, CO: Lynne Rienner.

Zaoual, H. 1997. "The economy and symbolic sites of Africa," in M. Rahnema and V. Bawtree (eds.), The Post-Development Reader, 30-39. London. Zed Books. 


\section{Non-periodical web document or report}

28TooMany. (2018). Senegal: The Law and FGM. Available at: https://www.28toomany.org/static/media/uploads/Law\%20Reports/senegal law report v 1 (August 2018).pdf [accessed 10 January 2019].

Ahmadu, F. 2005. "Cutting the Anthill: The Symbolic Foundations of Female and Male Circumcision Rituals among the Mandinka of Brikama, The Gambia." PhD Dissertation, London School of Economics, London.

CIA Central Intelligence Agency (CIA). 2019. The World Factbook. Available at: https://www.cia.gov/library/publications/the-world-factbook/ [accessed 15 January 2019].

Constant, T. 2016. "Social Support Networks and Self-Efficacy of Peruvian Women Diagnoses with Cancer: A Biocultural Analysis of Health Behavior Constructs." PhD Dissertation, Department of Anthropology, University of Washington, Seattle.

Dawit, S. and Mekuria, S. 1993. "The west just doesn't get it," New York Times, 7 December, A27.

The Economist. 1999. "Female genital cutting: Is it a crime or culture?" The Economist 45, 11 February.

Hernlund, Y. 2003. "Winnowing Culture: Negotiating Female 'Circumcision' in The Gambia." PhD Dissertation, University of Washington, Seattle.

Mackie, G., and J. LeJeune. 2009. "Social Dynamics of Abandonment of Harmful Practices: A New Look at the Theory." Special Series on Social Norms and Harmful Practices. Innocenti Working Paper No. 2009-06. Florence: UNICEF Innocenti Research Centre.

Mackie, G., F. Moneti, H. Shakya, and E. Denny. 2015. What Are Social Norms? How Are they Measured?

Available

at:

http://www/academia.edu/2007416/What are social norms How are they measured [accessed on 1 September 2014].

Matanda, D., G. Atilola, Z. Moore, P. Komba, L. Mavatikua, C.C Nnanatu, and N.-B. Kandala. 2019. Female Genital Mutilation/Cutting in Senegal: Is the Practice Declining? A Descriptive Analysis of Demographic and Health Surveys, 2005-2017. Evidence to End Female Genital Mutilation/Cutting: Research to Help Girls and Women Thrive. New York: Population Council.

Morgan, L.H. 1877. Ancient Society: Marxist Internet Archive. Available at: www.marxists.org/reference/archive/morgan-lewis/ancient-society/ch24.htm.

Musoko, A.S., C. Scoppa, and E. Manoncourt. 2012. Girls and Grandmothers Hand-in-Hand: Dialogue between generations for community change. Rome: The Grandmother Project. Available at: https://www.28toomany.org/static/media/uploads/Thematic\%20Research\%20and\%20Re sources/Social\%20Norms/gmp._Ildoc_dhf.eng.pdf.

Ndiaye, B. 2010. "L'État d'application de la loi sur excision au Sénégal (State of Application of the Law on Excision in Senegal)." New York: UNICEF and UNFPA.

O'Neill, S. 2013. "Defying the Law, Negotiating Change: The Futanke's Opposition to the National Ban on FGM in Senegal." PhD Dissertation. Goldmiths, University of London.

Shell-Duncan, B., Y. Hernlund, K. Wander, and A. Moreau. 2010. Contingency and Change in the Practice of Female Genital Cutting: Dynamics of Decision Making in Senegambia. Summary Report. Seattle: University of Washington.

Shell-Duncan, B., A. Moreau, S. Smith, and H. Shakya. 2019. Reference Guide for Data Collection: Qualitative Social Network Interviews. Evidence to End Female Genital Mutilation/Cutting: Research to Help Girls and Women Thrive. New York: Population Council. Available at: https://www.popcouncil.org/uploads/pdfs/2019RH FGMC-DataCollection.pdf

Shell-Duncan, B., A. Moreau, K. Wander, and S. Smith. 2019. A Reference Guide. Factorial Focus Group Analysis Methods for Studying Norm Change. Evidence to End Female Genital Mutilation/Cutting: Research to Help Girls and Women Thrive. New York: Population Council. Available at: https://www.popcouncil.org/uploads/pdfs/2019RH FGMCFactorialAnalysis.pdf

Shell-Duncan, B., R. Naik, and C. Feldman-Jacobs. 2016. A State-of-the-Art Synthesis on Female Genital Mutilation/Cutting: What Do We Know Now? October. New York: Population Council. Available at: http://www.popcouncil.org/EvidencetoEndFGM-C.

Simpson, C. 2002. "Peanut blues in Senegal." BBC News World Edition, 24 May. Available at: http://news.bbc.co.uk/2/hi/africa/1964795.stm [accessed 11 July 2019]. 
United Nations (UN). 1959. "Declaration of the Rights of the Child." New York: UN. Available at: https://www.humanium.org/en/declaration-rights-child-2/.

UNDP. 2019. Human Development Reports 2019. Statistical Update. New York: UNDP. Available at: http://hdr.undp.org/en/2019-update [accessed 3 July 2019].

UNICEF. 2007. Coordinated Strategy to End Female Genital Mutilation/Cutting in One Generation: A Human Rights-Based Approach to Programming. (Advance Copy). New York: UNICEF.

UNICEF. 2010. Dynamics of Social Change: Toward the Abandonment of Female Genital Mutilation/Cutting in Five African Countries. Florence: UNICEF, Innocenti Research Center. Available at: https://www.unicef-irc.org/publications/pdf/fgm_insight_eng.pdf

UNICEF. 2013. Female Genital Mutilation/Cutting: A Statistical Overview and Exploration of the Dynamics of Change. New York: UNICEF.

UNICEF. 2016. Female Genital Mutilation/Cutting: A Global Concern. New York: UNICEF. Available https://www.unicef.org/media/files/FGMC 2016 brochure final UNICEF SPREAD.pdf [accessed 8 January 2019].

US Department of State. 2015. Senegal 2015 Human Rights Report. Available at: https://20092017.state.gov/j/drl/rls/hrrpt/humanrightsreport/index.htm?year=2015\&dlid=252721 [accessed 10 January 2019].

World Health Organization. 2012. Understanding and Addressing Violence Against Women. Geneva: WHO. 


\section{Appendix A: Interview Guidelines for Key Informant Interviews and Focus Group Discussions}

\section{A1.1: Guidelines for Key Informant Interviews}

\section{Community leaders}

1. We would like to understand more about how people in your community are discussing the practice of female circumcision.

2. In the past, what were some of the benefits of practising female circumcision?

3. What changes have you seen in the practice over the years?

4. What is causing these changes?

5. What is the role of tradition in the practice?

6. What is the role of religion in the practice?

7. Who makes the decision that a girl is going to be circumcised?

8. Are there some people who have stopped practising excision?

9. What are some problems they might face?

10. Are circumcised and uncircumcised women equal in your community?

11. To whom do you think the practice is the most important in your community?

12. Have there ever been open discussions about circumcision in your community?

13. We understand that some people are campaigning against the practice and we are wondering if you have had any experience in this community with such campaigns. Please explain. If so, what were the reactions of community members?

14. Is there a law banning $F G M / C$ ? If yes, what does it ban specifically?

15. What is your opinion about the law banning FGM?

\section{Healthcare professionals: doctors, nurses, traditional birth attendants}

1. We would like to understand more about the health problems that women in your community face. Please tell us about the health problems specific to women that you commonly find in this community.

2. Please tell us about the health problems related to pregnancy and delivery that you find in this community.

3. Please explain the services that you offer to women who seek your help.

4. How long have you been practicing?

5. Some people argue that there are specific health consequences associated with the practice of female circumcision. Do you have experience with such complications? If yes:

6. At the immediate time of the circumcision, what are some of the problems that you find?

7. How do you treat these problems?

8. Do you find similar problems when boys go through circumcision?

9. What types of female circumcision do you most commonly see in this community?

10. Is there a difference in types of female circumcision related to ethnic background?

11. Do you find that women have long-term health problems from circumcision? Explain.

12. How do you treat these problems?

13. Do you find that women experience more difficult births because of the genital cutting that they have undergone? If so, what are the problems?

14. We understand that boys are sometimes circumcised in clinics. Does this seem to have an effect on the health effects they experience related to circumcision?

15. How do you feel about the fact that medicalisation of circumcision is available for boys but not for girls?

16. Do you think that discussing possible health effects is an effective way to campaign against excision?

\section{FGM/C specialists: Circumcisers}

We would like to understand more about how people in your community are discussing the practice of taking girls to be circumcised.

1. Please explain the services that you provide in this community.

2. How long have you been practicing your profession? 
3. How did you learn your profession?

4. What type of female circumcision do parents usually request?

5. Is there a difference in what kind of circumcision parents from different ethnic groups request?

6. Is there a difference in the kind of circumcision parents request now from past years?

7. What age do you think it is preferable for the girl to be at the time of circumcision?

8. What ages are the girls that you actually circumcise?

9. Has the age changed compared to past years?

10. How does a family prepare for the occasion?

11. Is there a special time of year when it is better to perform it?

12. How many girls usually go at one time?

13. Do they usually go to the bush or stay in a compound in town?

14. What are the steps that a girl goes through in her initiation?

15. Has this changed over the years?

16. What kind of things do the initiates learn?

17. Explain the difference in the characters of girls who have gone to circumcision and those who have not.

18. What kinds of medicines do you use?

19. Would you like to have access to other medical supplies?

20. We understand that some boys have their circumcisions in the clinic. Would that ever happen with girls also? Should it?

21. We understand that some people believe that this practice should be stopped.

22. How do you see this campaign? 


\section{A 1.2: Guidelines for Focus Group Discussions}

TOPIC 1. Roles and responsibilities of community members in raising and caring for young children

[Ask about different roles: mothers, elder women, other young women, fathers, other men, healthcare worker, religious leader]

1.1 How are involved in raising and assuring the well-being of young children?

[Probe: what responsibilities do they have regarding young children day-to day?

When ill

Training/behaviour

Making decisions such as if they will go to school

Paying for food, clothes, school]

1.2 If someone has difficulty meeting these responsibilities, what should they do? What should happen?

1.3 If you see that someone is not meeting their responsibilities, what should you do?

TOPIC 2. Advantages of performing FGM/C

2.1 What are the advantages of FGM/C for women?

[Probe: younger versus older women]

2.2 What are the advantages of $\mathrm{FGM} / \mathrm{C}$ for men?

[Probe: regarding wife versus regarding daughters]

TOPIC 3. Disadvantages of performing FGM/C

3.1 What are the disadvantages of FGM/C for women?

[Probe: younger versus older women]

3.2 What are the disadvantages of $\mathrm{FGM} / \mathrm{C}$ for men?

[Probe: regarding wife versus regarding daughters]

TOPIC 4. Solutions

4.1 (Regarding each disadvantage for women) What are the solutions?

[Probe: What are barriers to implementing solutions?]

4.2 (Regarding disadvantages for men) What are the solutions?

[Probe: What are the barriers to implementing solutions?]

TOPIC 5 Public discussions

5.1 Do you ever hear people discussing excision in public, such as at the market or at ceremonies? If yes, what do you hear people say?

[Do they say positive things or negative things?]

TOPIC 6. Acceptability of change

6.1 Would it be acceptable to abandon FGM/C in your community?

[Probe: Why?]

6.2 Would it be acceptable to encourage milder forms of cutting?

[Probe: Why? What type?]

6.3 Would it be acceptable to encourage circumcisers to use (list one at a time:

anesthesia, antibiotic powder, anti-tetanus injection)?

[Probe: Why? What are barriers?]

6.4 How is FGM/C changing in your community? 